MARIA PAULA PARADA PINILLA

\title{
CARACTERIZAÇÃO DE BACTÉRIAS HALOTOLERANTES ISOLADAS DO BIOMA CAATINGA E AVALIAÇÃO DA PRODUÇÃO DE BIOPOLÍMEROS
}

Dissertação apresentada ao Programa de PósGraduação em Microbiologia do Instituto de Ciências Biomédicas da Universidade de São Paulo, para a obtenção do título de Mestre em Ciências.

São Paulo 2016 
MARIA PAULA PARADA PINILLA

\section{CARACTERIZAÇÃO DE BACTÉRIAS HALOTOLERANTES ISOLADAS DO BIOMA CAATINGA E AVALIAÇÃO DA PRODUÇÃO DE BIOPOLÍMEROS}

Dissertação apresentada ao Programa de PósGraduação em Microbiologia do Instituto de Ciências Biomédicas da Universidade de São Paulo, para a obtenção do título de Mestre em Ciências.

Área de concentração: Microbiologia

Orientador: Prof. Dr. Gabriel Padilla Maldonado

Versão corrigida. A verção original eletrônica, encontra-se disponível tanto na Bilioteca do ICB quanto na Biblioteca Digital de Teses e Dissertações da USP (BDTD)

São Paulo

2016 


\section{CATALOGAÇÃO NA PUBLICAÇÃO (CIP) Serviço de Biblioteca e informação Biomédica do Instituto de Ciências Biomédicas da Universidade de São Paulo}

Ficha Catalográfica elaborada pelo(a) autor(a)

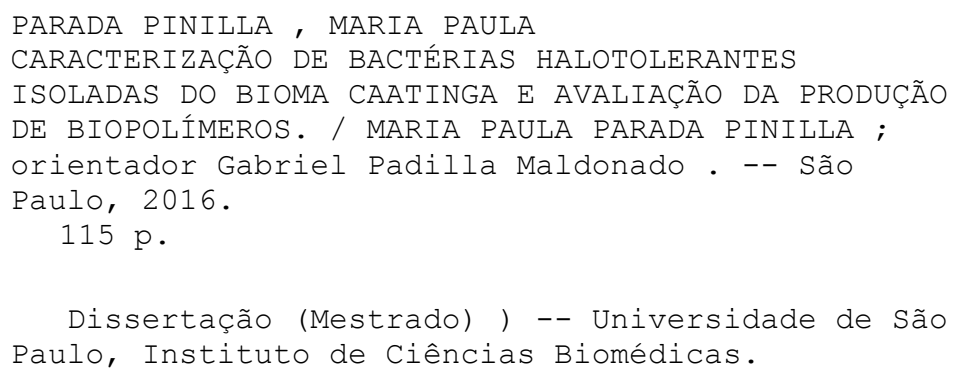

1. Microrganismos halotolerantes. 2 . Biopolímeros. 3. Exopolissacarídeos. 4. Ácido hialurônico. 5. Polihidroxialcanoatos. I. Padilla Maldonado, Gabriel, orientador. II. Título. 


\section{UNIVERSIDADE DE SÃO PAULO INSTITUTO DE CIÊNCIAS BIOMÉDICAS}

Candidato(a):

Maria Paula Parada Pinilla

Titulo da Dissertação/Tese: $\quad$ Caracterização de bactérias halotolerantes isolados do bioma caatinga e avaliação da produção de biopolímeros.

Orientador:

Prof. Dr. Gabriel Padilla Maldonado

A Comissão Julgadora dos trabalhos de Defesa da Dissertação de Mestrado/Tese de Doutorado, em sessão publica realizada a ............................, considerou o(a) candidato(a):

\section{( ) Aprovado(a) ( ) Reprovado(a)}

Examinador(a):

Examinador(a):

Presidente:
Assinatura:

Nome:

Instituição:

Assinatura:

Nome:

Instituição:

Assinatura:

Nome:

Instituição: 
Dedicado a mis abuelos, padres y hermanos. Mis primeros maestros en la fe, la esperanza y el amor. 


\section{AGRADECIMENTOS}

Agradeço, em primeiro lugar, a Deus, verdadeira fonte de felicidade, paz e amor. Obrigada por minha família e amigos. Obrigada por acompanhar meus passos, por ensinar-me a amar e perdoar, por permitir e fazer-me capaz de servir aos outros.

Agradeço a minha amada família pelo apoio incondicional, por ser sempre minha força. Obrigada pelo esforço material e emocional que fizeram para que eu estivesse o melhor possível em outro país. Por crer e confiar em mim. Por ensinar-me os valores que realmente são essenciais na vida. Amo vocês!

Agradeço ao Prof. Dr. Gabriel Padilla Maldonado por ter-me orientado e acolhido no seu laboratório, não só como meu chefe, mas também como um pai. Pela confiança depositada, pelos ensinamentos e discussões, pela sua qualidade humana e por respeitar minhas decisões professionais.

Agradeço ao Dr. Leandro Maza Garrido pela ajuda, orientação, exigência e conselhos, que fizeram possível o projeto. Obrigada especialmente pela sua amizade.

Agradeço ao Prof. Dr. Itamar Soares de Melo por permitir e disponibilizar o material biológico que fez possível o presente trabalho.

Agradeço à Dra. Suikinai Nobre Santos pela gentil colaboração no presente trabalho.

Agradeço ao Prof. Dr. Welington Luiz de Araújo pela sua gentileza e colaboração. Pela acolhida alegre aos estudantes estrangeiros, e por fazer-nos sentir em casa.

Agradeço à Dra. Renata Furlan, minha primeira chefe no Brasil, pelos ensinamentos e pela confiança. Obrigada por abrir as portas de sua casa para mim.

Agradeço ao Prof. Dr. José Gregório Cabrera Gómez pela ajuda e orientação nos experimentos de acúmulo de PHB. Obrigada por disponibilizar o seu laboratório para a realização dos experimentos.

Agradeço à Profa. Dra. Luiziana Ferreira da Silva pela amável colaboração e por ter-me permitido trabalhar no seu laboratório.

Agradeço ao Prof. Dr. Diego Veras Wilke pela ajuda nos ensaios de ativação de macrófagos, realizados no seu laboratório, os quais contribuíram enormemente no presente estudo.

Agradeço ao Prof. Dr. Enrique Mario Boccardo Pierulivo pela colaboração oferecida em alguns dos experimentos planejados.

Agradeço a Zita Maria de Oliveira Gregório por toda a ajuda e amizade oferecida.

Agradeço as secretárias do departamento de Microbiologia, especialmente a Gisele da Graça Santana pela ajuda constante e paciente durante os dois anos de mestrado. 
Agradeço a minha primeira amiga brasileira Simone Ichiwaki. Sua amizade é um tesouro para mim. Você é o anjo que Deus colocou no caminho dos estudantes colombianos do ICB. Não alcançam as palavras para expressar minha gratidão, carinho e admiração.

Agradeço aos meus colegas e amigos do laboratório 164: Alejandra F, Ruth, Roger, Fernanda, Aline, Mariana, Luana, Alejandra M, Mauricio, Vinicius, Vinicius Novi e Víctor. Obrigada por todos os momentos que passamos juntos, alguns de alegria, trabalho, decepções, de sucessos e de celebração.

Agradeço aos meus amigos do ICB, especialmente a Mireia, Henrique, Juliana, Alexandre e Nadia pela amizade sincera, o apoio e ajuda incondicional.

Agradeço a cada um dos meus amigos brasileiros, pela acolhida, simplicidade e amor que me ofereceram, e pelos quais vou sentir "saudades" sempre.

Agradeço especialmente a minha família colombiana em Brasil: Aleja, León, Ruthi, Inésita e Roger. Sem vocês não teria sido possível esta aventura. Guardo especialmente cada momento compartilhado com vocês.

Agradeço com todo o meu coração a Liz, Mairita e Juan. Nunca imaginamos a agradável surpresa que nos tinha preparado Deus em Brasil. Muito obrigada pela paciência, a amizade incondicional, os fins de semana cozinhando, o bate papo no sofá, as inúmeras tentativas de fazer esporte, as danças improvisadas, as aventuras na Polícia Federal, o consolo nas dificuldades, os sorrisos e piadas o tempo tudo, e os momentos de oração juntos. Vocês me fizeram uma melhor pessoa e uma mulher mais feliz.

Finalmente, agradeço à Coordenação de Aperfeiçoamento de Pessoal de Nível Superior (Capes) pelo suporte financeiro. 
"Creo para comprender, y comprendo para creer mejor"

San Agustín. 


\section{RESUMO}

PARADA M. P. P. Caracterização de bactérias halotolerantes isoladas do bioma caatinga e avaliação da produção de biopolímeros. 2016. 115 f. Dissertação (Mestrado em Microbiologia) - Instituto de Ciências Biomédicas, Universidade de São Paulo, São Paulo, 2016.

Os organismos extremófilos são considerados atualmente reservatórios de novas biomoléculas de interesse biotecnológico. Dentro deste grupo encontram-se os microrganismos que requerem altas concentrações de sal para crescer, denominados halófilos. Também existem os halotolerantes que são aqueles microrganismos que não precisam de sal para proliferar, mas toleram altas concentrações de $\mathrm{NaCl}$. Os ambientes salinos provaram ser uma fonte rica de microrganismos halotolerantes produtores de novos compostos naturais e, portanto, a pesquisa nestes ambientes torna-se de grande importância. No Brasil, na região salina de Areia Branca no bioma caatinga, foram isoladas bactérias halotolerantes que foram estudadas com o objetivo de avaliar a produção de novos biopolímeros de interesse biotecnológico. Acredita-se que os polímeros naturais desses microrganismos extremos podem ter aplicações inovadoras ou características diferentes às tradicionais. Neste estudo, os isolados foram identificados em nível de gênero com base na análise da sequência do gene 16s rRNA. Os isolados foram principalmente bactérias Gram-positivas atribuídas às famílias Bacillaceae, Staphylococcaceae, Microbacteriaceae e uma bactéria Incertae Sedis do filo firmicutes, afiliadas aos gêneros Bacillus, Staphylococcus, Curtobacterium e Exiguobacterium, respectivamente. Apenas um isolado Gram-negativo foi identificado e atribuído como membro da família Pseudomonadaceae, incluso no gênero Pseudomonas. Avaliou-se a tolerância ao sal dos isolados em meio TSB suplementado com 5, 35, 60 e $120 \mathrm{~g} / \mathrm{L}$ de $\mathrm{NaCl}$. Todos os isolados apresentaram a capacidade de crescer nas quatro concentrações de $\mathrm{NaCl}$ avaliadas, com exceção do isolado Exiguobacterium sp. sac36 que não cresceu na concentração de $120 \mathrm{~g} / \mathrm{L}$ de $\mathrm{NaCl}$ no meio. Realizaram-se ensaios de acúmulo de polihidroxialcanoatos (PHA) e evidenciou-se que quatro isolados do gênero Bacillus são capazes de acumular 3-hidroxibutirato (3HB) a partir de glicose, xilose, e alguns destes em glicerol. Adicionalmente, confirmou-se que quando há altas concentrações de $\mathrm{NaCl}$ no meio, o acúmulo de $3 \mathrm{HB}$ dos isolados produtores diminui. Observou-se também que doze isolados halotolerantes são produtores de exopolissacarídeos (EPS). Testes realizados indicaram que os mesmos podem ter efeitos imunoestimulantes em macrófagos. Finalmente, avaliou-se a produção de ácido hialurônico $(\mathrm{AH})$ pelos isolados halotolerantes. Segundo sugere o método de Alcian blue, todos os isolados foram capazes de produzir $\mathrm{AH}$, mostrando que a maior parte deles acumulou o biopolímero em concentrações maiores ou semelhantes ao controle. Os resultados obtidos evidenciam que os isolados halotolerantes avaliados são uma fonte rica em compostos com atividades promissoras para as diferentes indústrias. O presente trabalho contribui no estudo do potencial biotecnológico de microrganismos isolados no bioma caatinga, destacando sua biodiversidade, versatilidade e a necessidade de continuar explorando esses ambientes extremos pouco estudados. 
Palavras-chave: Microrganismos halotolerantes. Biopolímeros. Polihidroxialcanoatos. Exopolissacarídeos. Atividade imunoestimulatória. Ácido hialurônico. Ambientes extremos. 


\begin{abstract}
PARADA M. P. P. Characterization of halotolerant bacteria isolated from Caatinga and evaluation of biopolymers production. 2016. 115 p. Dissertation (Master thesis in Microbiology) - Instituto de Ciências Biomédicas, Universidade de São Paulo, São Paulo, 2016.
\end{abstract}

Extremophile organisms are considered reservoirs of new biomolecules of biotechnological interest. In this group there are microorganisms that require high salt concentration to grow, called halophiles, and halotolerant microorganisms, that do not need salt to proliferate but can tolerate high concentrations of $\mathrm{NaCl}$. Saline environments proved to be a rich source of new natural compounds by halotolerant producers and therefore, research in these environments becomes of great importance. In Brazil, in the saline region of Areia Branca in the caatinga biome, halotolerant bacteria were isolated and studied in order to evaluate the production of new biopolymers of biotechnological interest. It is believed that the natural polymers of those extreme microorganisms could have innovative applications or different characteristics from the traditional biopolymers. In this study, the isolates were identified at the genus level based on 16S rRNA gene sequence analysis. Isolates were mainly Gram-positive bacteria from Bacillaceae, Staphylococcaceae and Microbacteriaceae families, and Bacillus, Exiguobacterium, Staphylococcus and Curtobacterium genera. One of the Gram-negative isolate was identified as member of the Pseudomonadaceae family, genus Pseudomonas. The evaluation of salt tolerance of the bacterial isolates on TSB medium supplemented with 5 , 35,60 and $120 \mathrm{~g} / \mathrm{L} \mathrm{NaCl}$ was performed. All the isolates showed the ability to grow in the four concentrations evaluated, except for Exiguobacterium sp. sac36, that did not grow at $120 \mathrm{~g} / \mathrm{L} \mathrm{NaCl}$. Polyhydroxyalkanoate (PHA) accumulation assays were performed using glucose, xylose and glycerol as carbon source. The results showed that four strains of the genus Bacillus were able to accumulate 3-hydroxybutyrate (3HB) in all conditions. Additionally, it was confirmed that the presence of high concentrations of $\mathrm{NaCl}$ in the medium causes a decrease in $3 \mathrm{HB}$ accumulation in the cells. It was observed that twelve halotolerant bacteria produced exopolysaccharides (EPS). Tests performed indicated that those EPS could have immunostimulatory effects on macrophages. Finally, hyaluronic acid $(\mathrm{HA})$ production was evaluated. According to Alcian blue method, all strains were able to produce $\mathrm{HA}$, showing that most of the isolates accumulated the biopolymer in higher or similar concentrations to the control. The results showed that the halotolerant isolates are a rich source of compounds with promising activities for different industries. This study contributes to the knowledge of microorganisms from the caatinga biome and their biotechnological potential, highlighting their biodiversity, versatility and the need to continue exploring these poorly studied extreme environments.

Keywords: Halotolerant microorganisms. Biopolymers. Polyhydroxyalkanoate. Exopolysaccharides. Immunostimulating activity. Hyaluronic acid. Extreme environment. 


\section{LISTA DE FIGURAS}

Figura 1 - Visão geral dos extremófilos de diferentes condições extremas

Figura 2 - Aplicação de microrganismos extremófilos em biotecnologia, medicina e indústria .25

Figura 3 - Estruturas químicas de alguns polímeros bacterianos.............................30

Figura 4 - Estrutura química do poliéster polihidroxialcanoato .....................................31

Figura 5 - Estrutura química dos poliésteres polihidroxibutirato (PHB) e poli-3hidroxibutirato-co-hidroxivalerato (3HB-co-3HV) ..................................32

Figura 6 - Estrutura da unidade do dissacarídeo de ácido hialurônico ...........................36

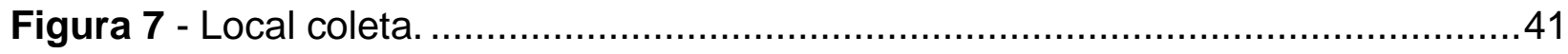

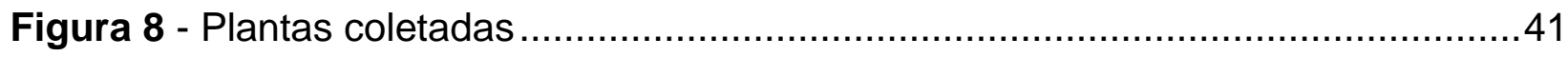

Figura 9 - Esquema dos procedimentos realizados para seleção, produção e determinação de PHA a partir dos isolados halotolerantes ......................45

Figura 10 - Esquema dos procedimentos realizados para seleção de isolados produtores de EPS

Figura 11 - Fluxograma esquemático dos procedimentos realizados para produção e extração de EPS

Figura 12 - Abundância de gêneros bacterianos a partir de amostras de solo rizosférico da caatinga. .55

Figura 13 - Árvore filogenética do gênero Bacillus .....................................................56

Figura 14 - Árvore filogenética do gênero Curtobacterium .........................................57

Figura 15 - Árvore filogenética do gênero Exiguobacterium .......................................58

Figura 16 - Árvore filogenética do gênero Staphylococcus. .........................................59

Figura 17- Árvore filogenética do gênero Pseudomonas..........................................61

Figura 18 - Crescimento dos isolados em diferentes concentrações de $\mathrm{NaCl}$...............62

Figura 19 - Curvas de crescimento de isolados halotolerantes da caatinga..................64

Figura 20 - Triagem qualitativa de produção de PHA com Sudan Black B.....................68

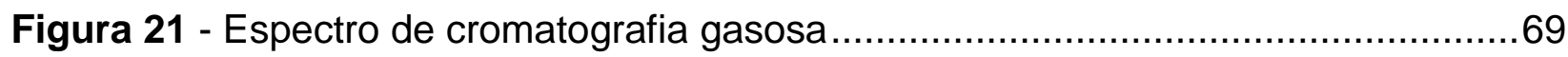

Figura 22 - Árvore filogenética dos isolados do gênero Bacillus produtores de PHA ....70

Figura 23 - Gráficos do perfil de acúmulo do monômero 3HB .....................................77 
Figura 24 - Teste qualitativo de produção de EPS por isolados halotolerantes .81

Figura 25 - Árvore filogenética do isolado do gênero Pseudomonas produtor de EPS.81 Figura 26 - Árvore filogenética do isolado do gênero Curtobacterium produtor de EPS

Figura 27 - Árvore filogenética dos isolados do gênero Bacillus produtores de EPS ....84

Figura 28 - Detecção de nitrito no sobrenadante de macrófagos murinos ....................86

Figura 29 - Morte celular quantificada pela redução do MTT ......................................88

Figura 30 - Gráfico da concentração relativa de $\mathrm{AH}$.................................................91 


\section{LISTA DE TABELAS}

Tabela 1 - Extremófilos e algumas aplicações em biotecnologia e indústrias ...............25

Tabela 2 - Aplicações industriais atuais e potenciais dos microrganismos halófilos......27

Tabela 3 - Biopolímeros microbianos de importância comercial ...................................29

Tabela 4 - EPS produzidos por microrganismos isolados de ambientes hipersalinos ...35

Tabela 5 - Condições da reação de PCR para a amplificação do gene RNAr 16S........43

Tabela 6 - Sequência dos iniciadores utilizados para amplificação e sequenciamento dos genes RNAr 16S

Tabela 7 - Isolados bacterianos obtidos na região de Areia Branca, distrito de de Mossoró,

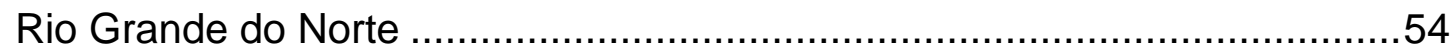

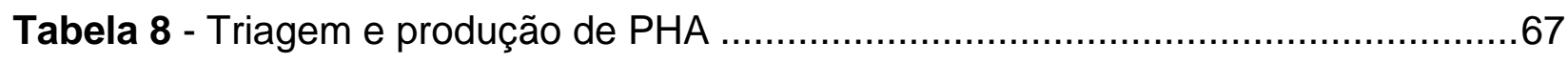

Tabela 9 - Produção de PHB por isolados halotolerantes do gênero Bacillus ................72

Tabela 10 - Produção de PHB por dois isolados halotolerantes do gênero Bacillus......76

Tabela 11 - Produção de PHA por bactérias do gênero Bacillus ...................................78

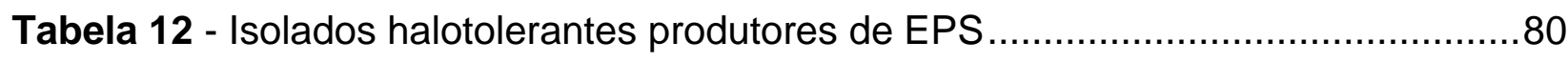

Tabela 13 -Screening de produção e quantificação de $\mathrm{AH}$.........................................90 


\section{LISTA DE ABREVIATURAS E SIGLAS}

$3 \mathrm{HB}$

3HB-co-3HV

$3 \mathrm{HD}$

3HDD

$3 \mathrm{HHp}$

$3 \mathrm{HHx}$

$3 \mathrm{HO}$

$3 \mathrm{HN}$

3HV

$\mu \mathrm{l}$

$\mu \mathrm{m}$

$\mathrm{AH}$

ATCC

ATP

BLAST

DNA

DO

EDTA

EPS

FDA

FID

Fru

Gal

GaIN

Glc

GlcN

HSV-2

IBAMA

IL 3-hidroxibutirato

3-hidroxibutirato-co-3-hidroxivalerato

3-Hidroxidecanoato

3-Hidroxidodecanoato

3-Hidroxiheptanoato

3-Hidroxihexanoato

3-Hidroxioctanoato

3-Hidroxinonanoato

3-Hidroxivalerato

Microlitro

Micrômetro

Ácido hialurônico

American Type Cell Culture

Adenosina 5'-trifosfato

Basic Local Alignment Search Tool

Ácido desoxirribonucleico

Densidade óptica

Ácido etilendiamino tetracético

Exopolissacarídeos

Food and Drug Administration

Flame ionization detector

D-Frutose

D-Glactose

D-Galactosamina

D-Glicose

D- Glicosamina

Herpes simples tipo 2

Instituto Brasileiro do Meio Ambiente e dos Recursos Renováveis Interleucina 


\begin{tabular}{|c|c|}
\hline $\mathrm{Kb}$ & Quilobases \\
\hline $\mathrm{kDa}$ & Kilodaltons \\
\hline LPS & Lipopolissacáridos \\
\hline M & Molar \\
\hline MLSA & Multi-Locus Sequence Analysis \\
\hline MM & Meio mineral \\
\hline $\mathrm{mM}$ & Milimolar \\
\hline MMG & Meio Mineral Glicose \\
\hline MMX & Meio Mineral Xilose \\
\hline MPa & Megapascal \\
\hline MSC & Massa Seca Celular \\
\hline NASA & National Aeronautics and Space Administration \\
\hline $\mathrm{NCBI}$ & National Center for Biotechnology Information \\
\hline $\mathrm{nm}$ & Nanômetros \\
\hline PBMC & Peripheral Blood Mononuclear Cell \\
\hline \multirow[t]{2}{*}{$P C R$} & Reação em Cadeia da polimerase, do inglês Polymerase Chain \\
\hline & Reaction \\
\hline $\mathrm{pH}$ & Potencial Hidrogeniônico \\
\hline PHA & Polihidroxialcanoato \\
\hline phaA & Gene codificador da enzima $\beta$-cetotiolase \\
\hline phaB & Gene codificador da enzima acetoacetil-CoA reductase \\
\hline phac & Gene codificador da enzima PHA sintase \\
\hline PHAMCL & $\begin{array}{l}\text { Polihidroxialcanoato com monômeros de cadeia média (6-14 } \\
\text { carbonos) (do inglês medium chain length) }\end{array}$ \\
\hline PHAscL & $\begin{array}{l}\text { Polihidroxialcanoato com monômeros de cadeia média (3-5 } \\
\text { carbonos) (do inglês short chain length) }\end{array}$ \\
\hline PHB & Polihidroxibutirato \\
\hline PHBV & Polihidroxibutirato-co-hidroxivalerato \\
\hline $\mathrm{pb}$ & Pares de base \\
\hline rpm & Revoluções por minuto \\
\hline sac & Salinas caatinga \\
\hline
\end{tabular}


TAE

TBT

TNF

TSA

TSB

ÚNICA
Tris-acetato-EDTA

Tributilestanho

Fator de necrose tumoral

Ágar Triptona Soja

Caldo Soja Tripticaseína

União da Industria de Cana-De-Açúcar 


\section{LISTA DE SÍMBOLOS}

>: maior que

$<$ : menor que

$\geq$ : maior ou igual a

${ }^{\circ} \mathrm{C}$ : graus Célsius

${ }^{\circ} \mathrm{C} / \mathrm{min}$ : graus Célsius por minuto

C-: Controle negativo

$\mathrm{C}+$ : Controle positivo

g/L: gramas por litro

$\mathrm{ml} / \mathrm{L}$ : mililitros por litro

$\mathrm{ml} / \mathrm{min}$ : mililitros por minuto

$\mathrm{m} / \mathrm{v}$ : massa por volume

$\mathrm{ng} / \mu \mathrm{l}$ : nanograma por microlitro

S: Sul/South

v/v: volume por volume

W: Oeste/West 


\section{SUMÁRIO}

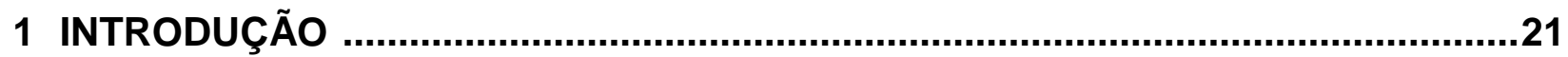

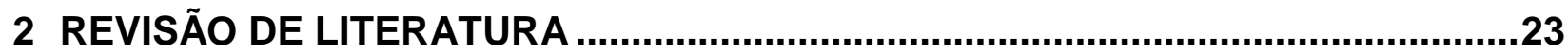

2.1 Ambientes extremos e microrganismos extremófilos......................................23

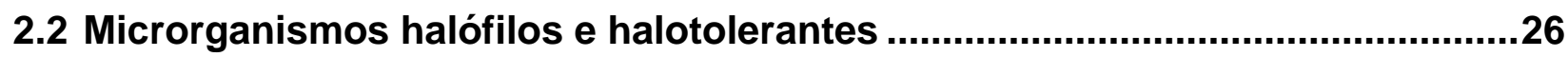

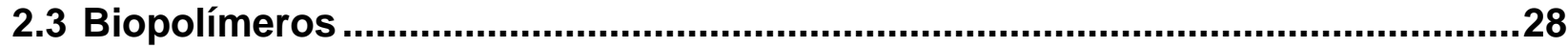

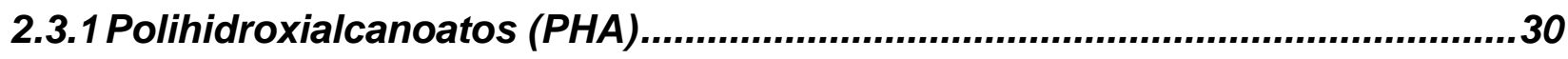

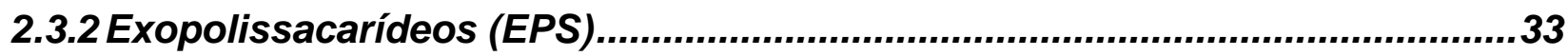

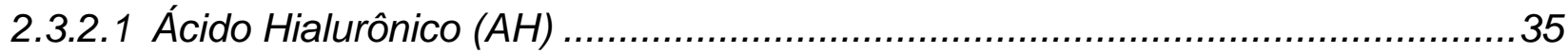

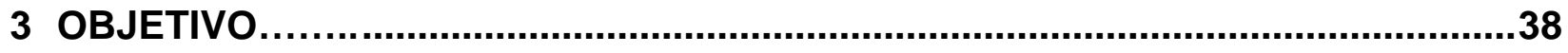

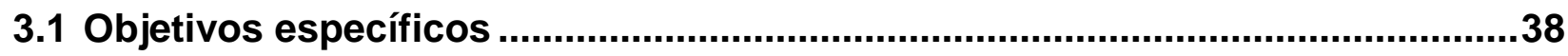

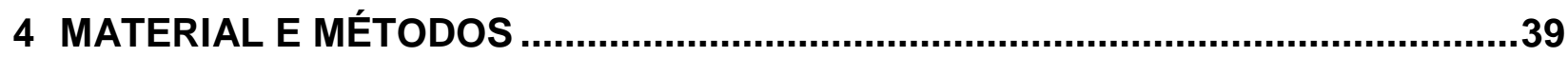

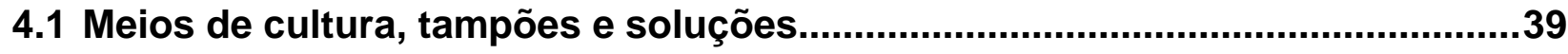

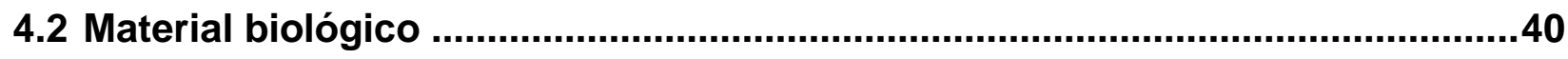

4.3 Extração de DNA genômico dos isolados bacterianos ........................................42

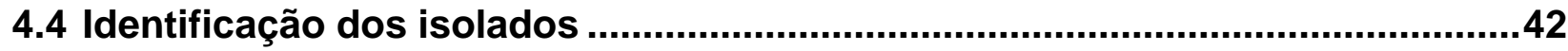

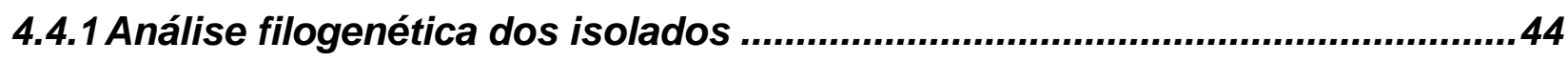

4.5 Crescimento em diferentes concentrações de $\mathrm{NaCl}$.........................................44

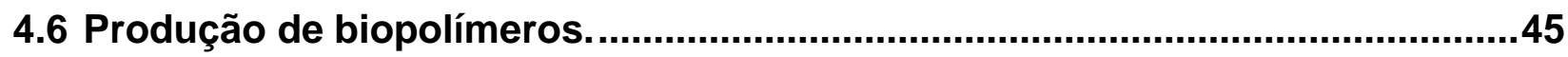

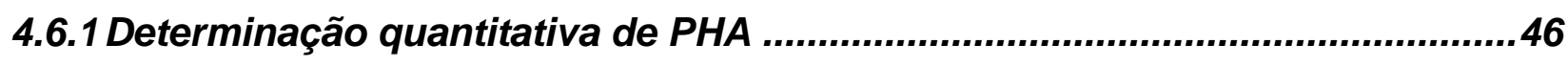

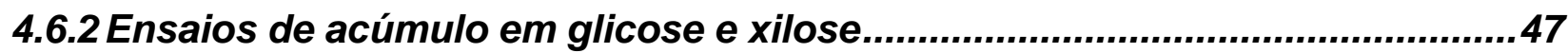

4.6.3 Acúmulo de PHA em três fontes de carbono e em diferentes concentrações de

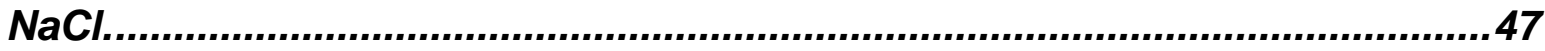

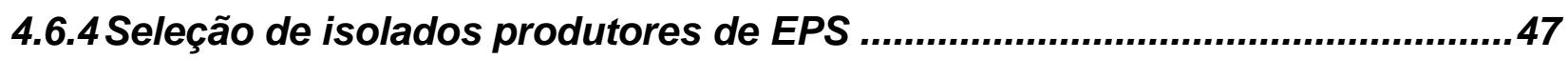

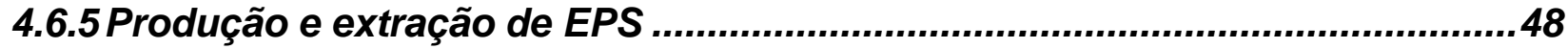

4.6.6 Estudo da atividade imunoestimulatória dos EPS........................................50

4.6.6.1 Avaliação da ativação de macrófagos e Teste do Griess ................................50

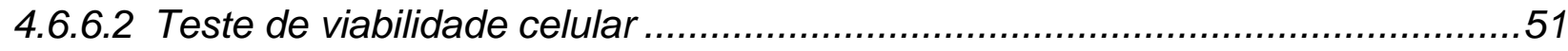

4.6.7 Curva padrão de ácido hialurônico .............................................................51 
4.6.7.1 Tabela Ensaio de produção e quantificação de $A H$.

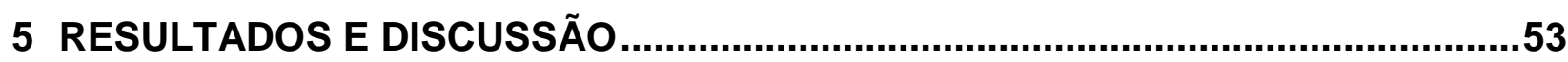

5.1 Crescimento em diferentes concentrações de $\mathrm{NaCl}$.....................................62

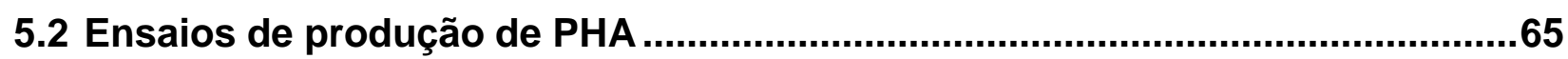

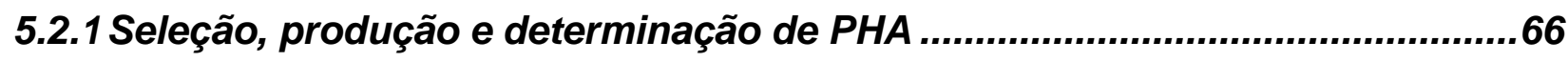

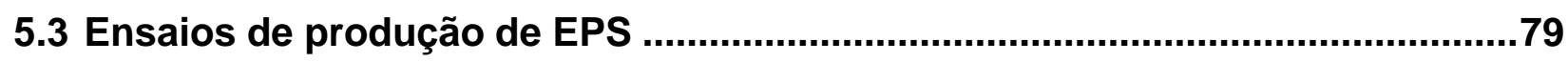

5.3.1 Seleção de isolados produtores de EPS ...................................................79

5.3.2 Produção, extração de EPS e ensaios de ativação de macrófagos .................84

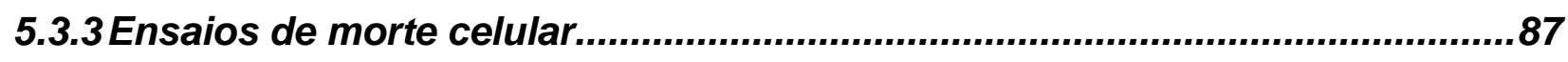

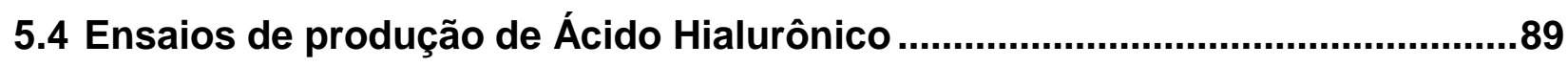

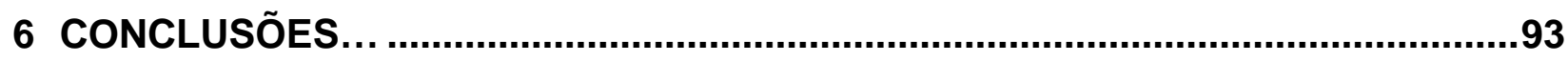

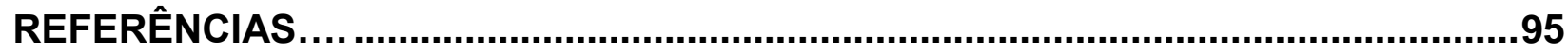

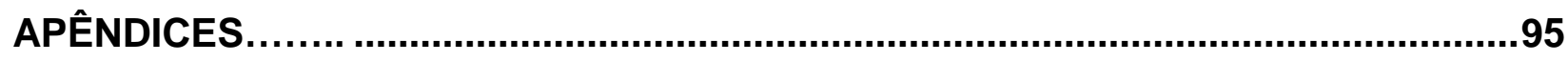

APÊNDICE A - Curvas de crescimento dos isolados da caatinga em meio TSB suplementado com quatro diferentes concentrações de $\mathrm{NaCl}$.........110

APÊNDICE B - Curva padrão de ácido hialurônico..............................................115 


\section{INTRODUÇÃO}

Os organismos que vivem nos extremos de $\mathrm{pH}(>\mathrm{pH} 8.5,<\mathrm{pH} 5.0)$, temperatura $\left(>45^{\circ} \mathrm{C},<15^{\circ} \mathrm{C}\right.$ ), pressão (>500 atmosferas), salinidade $(>58,4 \mathrm{~g} / \mathrm{L}$ de $\mathrm{NaCl}$ ) e em concentrações elevadas de compostos recalcitrantes ou metais pesados são conhecidos como extremófilos (PODAR; REYSENBACH, 2006). Graças às diferentes estratégias de adaptação que estes organismos desenvolveram para proliferar em ambientes extremos e também a capacidade de biossíntese de diferentes metabólitos, atualmente são considerados reservatórios de novas biomoléculas com potencial biotecnológico ( $D E$ CARVALHO; FERNANDES, 2010).

Dentro deste grupo, estão os microrganismos halófilos, que são aqueles que requerem altas concentrações de sal para crescer e podem ser classificados como: halófilos moderados, halófilos extremos limítrofes e halófilos extremos. No entanto, existe outra classificação para aqueles microrganismos que, embora não precisem de sal, toleram altas concentrações ( $\geq 58,4 \mathrm{~g} / \mathrm{L}$ ) de $\mathrm{NaCl}$, sendo então chamados de halotolerantes (HAMEDI; MOHAMMADIPANAH; VENTOSA, 2013; JAIN; NAGAL; JAIN, 2012; OREN, 2010; VENTOSA; ARAHAL, 2011).

Estes microrganismos podem ser encontrados nos três domínios da vida; Archaea, Bacteria e Eukarya, e têm sido isolados de ambientes hipersalinos das diversas áreas geográficas da Terra, tais como lagos salinos, pântanos de água salgada, desertos e mares (DALY, 2010; JAIN; NAGAL; JAIN, 2012; VENTOSA et al., 2008, 2015). Por outro lado, destacam-se também por serem possíveis produtores de diversos compostos de importância médica, alimentar, ambiental e cosmética (YIN et al., 2014).

Em particular, os biopolímeros destes organismos são macromoléculas interessantes que têm sido utilizadas recentemente em aplicações biomédicas e agroindustriais devido às suas propriedades terapêuticas e biodegradáveis, como, por exemplo, a capacidade imunoestimuladora em células humanas de sangue e atividade antioxidante para terapia contra o câncer (GUGLIANDOLO et al., 2014; RAVEENDRAN et al., 2015; YE et al., 2016).

Do mesmo modo, muitos desses microrganismos são capazes de acumular biopolímeros, como os polihidroxialcanoatos (PHA), uma família de plásticos 
biodegradáveis que representam uma alternativa promissora para substituir os plásticos derivados do petróleo, usando diferentes substratos de baixo custo (HUANG et al., 2016; MOORKOTH; NAMPOOTHIRI, 2016).

Igualmente, existe um grande interesse nos exopolissacarídeos (EPS), polímeros de elevado peso molecular sintetizados e acumulados na superfície das células de bactérias halotolerantes, devido às suas atividades biológicas inovadoras tais como: antioxidantes, imunoestimulantes, antitumorais e antivirais (GUGLIANDOLO et al., 2014; SPANÒ; ARENA, 2016; YE et al., 2012). Além disso, produzem solutos compatíveis, como a ectoína e a hidroxiectoína, comercialmente utilizados como agentes de proteção para células de mamíferos e peles (YIN et al., 2014).

Como se pode constatar, os ambientes salinos são uma fonte rica de microrganismos produtores de novos compostos naturais de interesse biotecnológico e a pesquisa nestes ambientes tornou-se de grande importância nos últimos anos (ZHANG et al., 2005). No caso particular do Brasil, encontram-se regiões salinas no bioma caatinga que representam uma fonte única de recursos naturais pouco estudados.

A caatinga é um bioma único que cobre uma vasta área no nordeste do Brasil, que corresponde a quase $10 \%$ do território brasileiro (DE ALBUQUERQUE et al., 2007). Este bioma, segundo a United Nations Environmental Programme (2007), tem um clima semiárido, ou seja, possui um índice de aridez de 0,2-0,5 (valores descritos para regiões desérticas), o qual considera tanto as precipitações em $\mathrm{mm}$ e temperaturas medias anuais, e apresenta duas estações bem definidas: chuvosa e seca, com predominância de um clima seco e quente.

Por outro lado, existem poucos estudos sobre o potencial biotecnológico de microrganismos nesta região (FERREIRA, 2014). Por esta razão, foram isoladas bactérias halotolerantes na região salina de Areia Branca no bioma caatinga, com o intuito de avaliar a produção de PHA e EPS de interesse biotecnológico. Acredita-se que os polímeros naturais desses microrganismos extremos podem ter aplicações inovadoras ou características diferentes às tradicionais. 


\section{REVISÃO DE LITERATURA}

A importância ecológica e biotecnológica dos microrganismos extremófilos explica-se pela capacidade para sintetizar diferentes metabólitos com atividade biológica, enzimas, biopolímeros, entre outros compostos. À continuação, descreve-se algumas generalidades dos ambientes extremos, em particular dos habitats salinos, assim como algumas características dos microrganismos halófilos e alguns dos produtos que podem sintetizar.

\subsection{Ambientes extremos e microrganismos extremófilos}

Um ambiente extremo é aquele em que algum fator físico, químico ou biológico cai fora do limite de um intervalo normal, tornando-se inabitável para os seres humanos e outros organismos (ALBARRACín; GÄRTNER; FARIAS, 2016; LINDGREN et al., 2016). Alguns exemplos dos ambientes mais " extremos" na Terra incluem fontes termais, o fundo do mar, regiões glaciais, lagoas do deserto e águas com pouco ou nenhum oxigênio (LINDGREN et al., 2016). Esses ambientes de condições adversas são definidos não só pelos extremos nas características abióticas, incluindo temperatura, pressão, pH, saturação de oxigênio e salinidade, mas também podem ser influenciados por características biológicas tais como pouco ou baixa disponibilidade de nutrientes, alta densidade populacional ou baixa disponibilidade de presas.

Nas duas últimas décadas têm aumentado o interesse pelo mundo dos microrganismos que vivem em condições extremas (JOGHEE; JAYARAMAN, 2014). Sabe-se que alguns microrganismos adaptaram-se às condições extremas, ocupando nichos considerados incomuns para a vida normal de animais, plantas e outros organismos (DHAKAR; PANDEY, 2016). Assim, extremos de temperatura, pH, potencial de oxido-redução, salinidade, umidade e diferentes combinações destes, que caracterizam a maioria dos diversos habitats terrestres e aquáticos, são colonizados por estes microrganismos (DHAKAR; PANDEY, 2016; LINDGREN et al., 2016; STOTT; TAYLOR, 2016; VARSHNEY et al., 2015). O termo "extremófilos" foi cunhado por Macelroy em 1974 e os primeiros extremófilos reconhecidos foram os microrganismos 
que vivem em altas temperaturas (termófilos) e em concentrações elevadas de sal (halófilos) (DHAKAR; PANDEY, 2016; LINDGREN et al., 2016).

Os extremófilos se encontram nos três domínios da vida, porém, principalmente pertencem aos domínios Archaea e Bacteria (NEIFAR et al., 2015; SARMIENTO; PERALTA; BLAMEY, 2015). É um grupo de microrganismos funcionalmente diverso e inclui termófilos, psicrófilos, acidófilos, alcalófilos, halófilos, barófilos / piezófilos, metalófilos e radiófilos (Figura 1) (RADDADI et al., 2015). No seu habitat natural, os extremófilos desenvolveram estratégias e mecanismos exclusivos para manter seus componentes celulares estáveis e ativos, o que permite-lhes tolerar e sobreviver aos fatores extremos de tais ambientes (ALBARRACÍN; GÄRTNER; FARIAS, 2016; ELLEUCHE et al., 2015; SARMIENTO; PERALTA; BLAMEY, 2015).

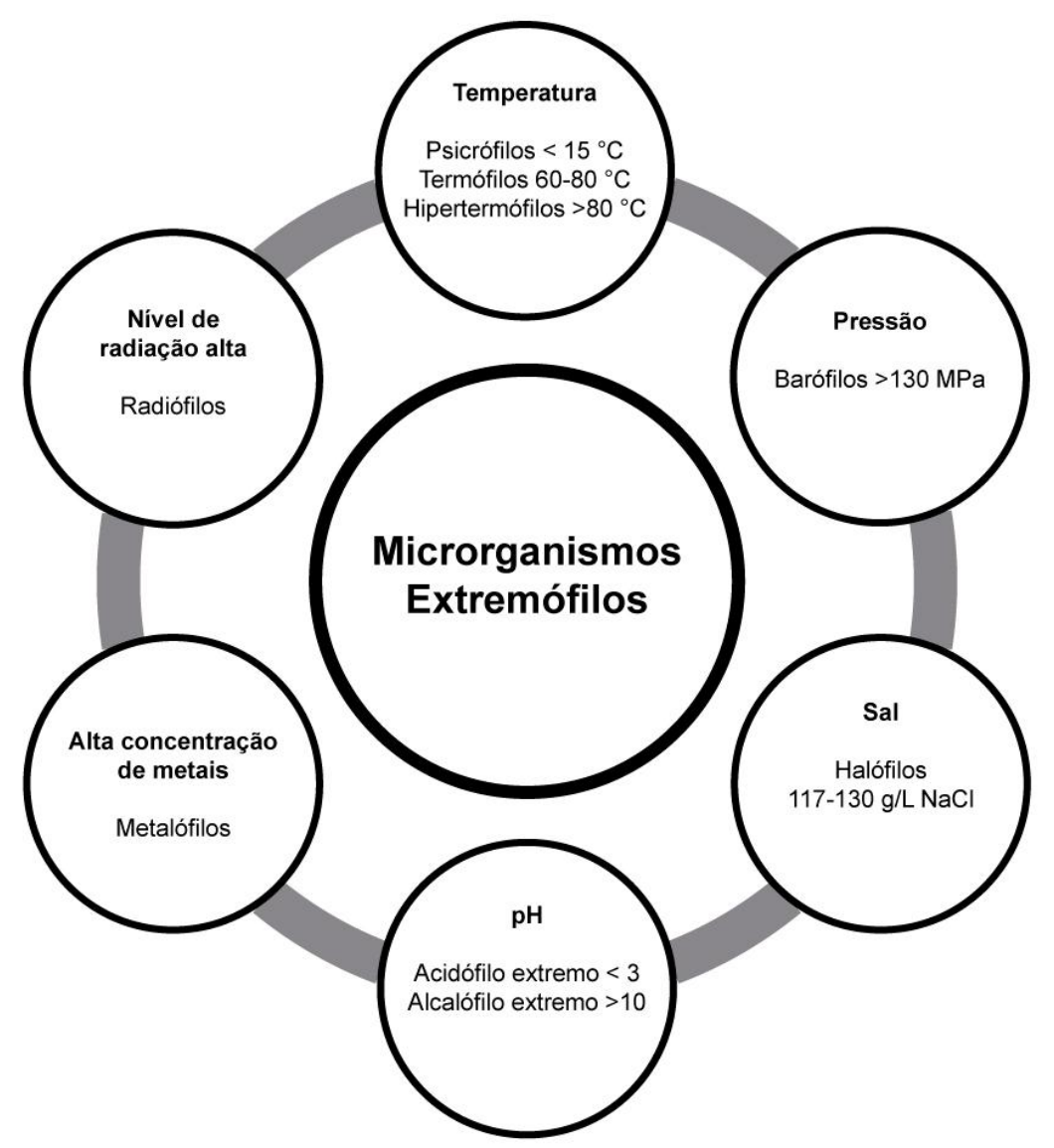

Figura 1 - Visão geral dos extremófilos de diferentes condições extremas. Fonte: Adaptada (DHAKAR e PANDEY, 2016) 
Como resultado à adaptação ao seu ambiente, muitos microrganismos extremófilos têm desenvolvido propriedades únicas e de considerável importância biotecnológica e comercial, sendo fonte de enzimas, metabólitos, biopolímeros e outros materiais biológicos (Figura 2) (Tabela 1) (ALBARRACíN; GÄRTNER; FARIAS, 2016; NEIFAR et al., 2015).

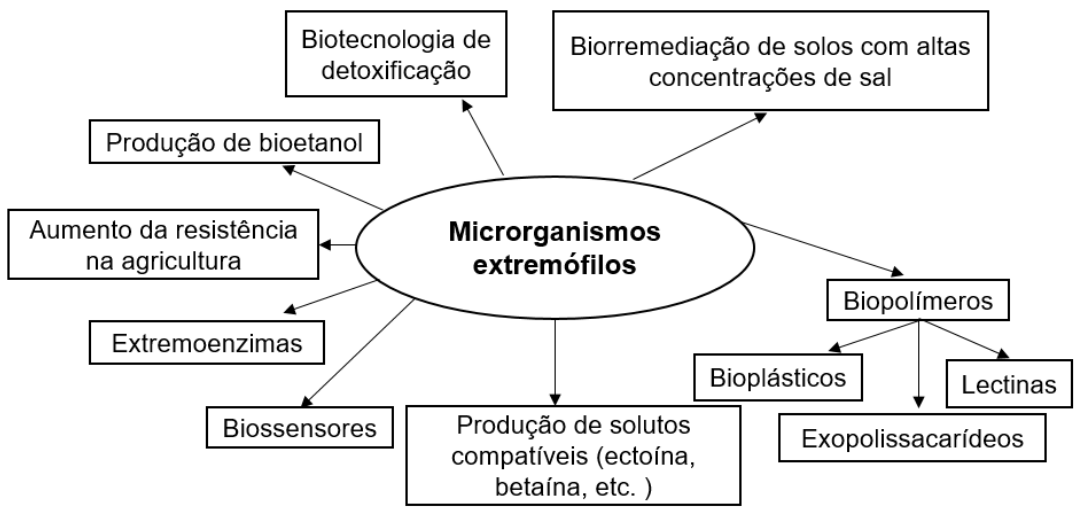

Figura 2 - Aplicação de microrganismos extremófilos em biotecnologia, medicina e indústria. Fonte: Adaptada (MOROZKINA et al., 2010)

Tabela 1 - Extremófilos e algumas aplicações em biotecnologia e indústrias

\begin{tabular}{|c|c|c|c|c|}
\hline Extremófilos & Gênero & Uso-produto & Aplicações & Referência \\
\hline Termófilos & $\begin{array}{l}\text { Ureibacillus } \\
\text { thermosphaericus }\end{array}$ & $\begin{array}{l}\text { Biossíntese } \\
\text { extracelular de } \\
\text { nanopartículas de ouro }\end{array}$ & Biocatálise & $\begin{array}{l}\text { (JUIBARI et al., } \\
\text { 2015) }\end{array}$ \\
\hline Psicrófilos & $\begin{array}{l}\text { Purpureocillium } \\
\text { lilacinum }\end{array}$ & $\begin{array}{l}\text { Atividade tripanocida, } \\
\text { antifúngica e } \\
\text { antibacteriana. }\end{array}$ & $\begin{array}{l}\text { Desenvolvimento de } \\
\text { novas drogas }\end{array}$ & $\begin{array}{l}\text { (GONÇALVES } \\
\text { et al., 2015) }\end{array}$ \\
\hline Halófilos & Halomonas maura & $\begin{array}{l}\text { Mauran } \\
\text { (polissacarídeo) }\end{array}$ & $\begin{array}{l}\text { Mecanismo } \\
\text { antioxidante- } \\
\text { Terapia do câncer }\end{array}$ & $\begin{array}{l}\text { (RAVEENDRAN } \\
\text { et al., 2015) }\end{array}$ \\
\hline Barófilos & $\begin{array}{l}\text { Photobacterium } \\
\text { profundum SS9 }\end{array}$ & Acumulação de solutos & $\begin{array}{l}\text { Processamento de } \\
\text { alimentos e } \\
\text { produção de } \\
\text { antibióticos }\end{array}$ & $\begin{array}{l}\text { (MOTA et al., } \\
\text { 2013; NEIFAR } \\
\text { et al., 2015) }\end{array}$ \\
\hline Metalófilos & $\begin{array}{l}\text { Moraxella } \\
\text { osloensis }\end{array}$ & $\begin{array}{l}\text { Biodegradação de } \\
\text { tributilestanho (TBT) }\end{array}$ & Biorremediação & $\begin{array}{l}\text { (YÁÑ̃̃EZ et al., } \\
2015)\end{array}$ \\
\hline Acidófilos & Trametes hirsuta & $\begin{array}{l}\text { Amilases e } \\
\text { glucoamilases } \\
\text { (enzimas) }\end{array}$ & $\begin{array}{l}\text { Biodegradação, } \\
\text { promoção de } \\
\text { crescimento vegetal } \\
\text { e controle biológico. }\end{array}$ & $\begin{array}{l}\text { (DHAKAR; } \\
\text { PANDEY, 2016) }\end{array}$ \\
\hline Alcalófilo & $\begin{array}{l}\text { Anditalea andensis } \\
\text { ANESC-S }^{\top}\end{array}$ & $\begin{array}{l}\text { Geração de energia } \\
\text { elétrica em condições } \\
\text { alcalinas }\end{array}$ & $\begin{array}{l}\text { Tratamento de água } \\
\text { poluída- } \\
\text { Biorremediação }\end{array}$ & $\begin{array}{l}\text { (SHI et al., } \\
2015)\end{array}$ \\
\hline Radiófilos & $\begin{array}{l}\text { Rubrobacter } \\
\text { radiotolerans }\end{array}$ & $\begin{array}{l}\text { Bacterioruberin } \\
\text { (carotenoide) }\end{array}$ & $\begin{array}{l}\text { Reparo de DNA } \\
\text { danificado- } \\
\text { prevenção câncer } \\
\text { de pele }\end{array}$ & $\begin{array}{l}\text { (VATSA et al., } \\
\text { 2014) }\end{array}$ \\
\hline
\end{tabular}




\subsection{Microrganismos halófilos e halotolerantes}

Os ambientes salinos são habitats extremos com diversidade microbiana limitada devido aos efeitos combinados de diversos fatores ambientais, incluindo altas concentrações de sal, temperatura, $\mathrm{pH}$ e baixa disponibilidade de nutrientes e de oxigênio (VENTOSA et al., 2015). Os microrganismos halófilos podem crescer nesses ambientes já que requerem altas concentrações de sal para proliferar e são classificados segundo seu crescimento ótimo em diferentes concentrações do mesmo (HAMEDI; MOHAMMADIPANAH; VENTOSA, 2013; JAIN; NAGAL; JAIN, 2012).

Os dois grupos principais são os halófilos extremos (crescimento ótimo acima de $150 \mathrm{~g} / \mathrm{L} \mathrm{NaCl}$ ) e halófilos moderados (crescimento ótimo entre $30-150 \mathrm{~g} / \mathrm{L} \mathrm{NaCl}$ ). Em contraste, os halófilos leves apresentam um crescimento ótimo num meio com 10-30 g/L $\mathrm{NaCl}$ (VENTOSA et al., 2015). No entanto, existe outra classificação para aqueles microrganismos que não precisam de sal para se desenvolver, mas toleram altas concentrações de $\mathrm{NaCl}$ ( $\geq 58,4 \mathrm{~g} / \mathrm{L}$ ) chamados de halotolerantes (HAMEDI; MOHAMMADIPANAH; VENTOSA, 2013; JAIN; NAGAL; JAIN, 2012).

Estes microrganismos têm sido isolado de lugares como lagos hipersalinos, solos salinos, fontes hidrotermais, produtos alimentares salgados, e também em alguns lugares inesperados, bem como salmouras no fundo do mar, sobre as plantas que excretam sais de suas folhas e até nas pinturas antigas das paredes (DALY, 2010).

Para que os microrganismos halófilos e halotolerantes possam viver e tolerar essas condições extremas desenvolveram diferentes mecanismos especiais de adaptação e resistência, tais como High-salt-in-strategy e Low-salt-in-strategy que evitam - $\mathrm{NaCl}$ difundir-se para dentro das células (OREN, 2008). Os microrganismos que seguem a estratégia High-salt-in, principalmente arqueias aeróbias e bactérias anaeróbias (halófilos extremos), acumulam concentrações molares de potássio $\left(\mathrm{K}^{+}\right)$e cloreto $\left(\mathrm{Cl}^{-}\right)$no citoplasma, além de adaptar a maquinaria enzimática intracelular na presença de concentrações elevadas de sais. Por outro lado, a estratégia Low-salt-in é usada principalmente no domínio Bacteria (halófilos moderados e halotolerantes) e consiste na biossíntese e/ou acumulação de solutos orgânicos, também chamados solutos compatíveis, de baixo peso molecular e solúveis em água (JAIN; NAGAL; JAIN, 
2012; JOGHEE; JAYARAMAN, 2014; OREN, 2008). Esses solutos podem agir como estabilizadores de estruturas biológicas e também permitem que as células se adaptem ao calor, dessecação, frio e até condições de congelamento (JAIN; NAGAL; JAIN, 2012; OREN, 2008; YIN et al., 2014).

Quando comparados com outros grupos de microrganismos extremófilos como os termófilos, os halófilos têm sido relativamente pouco explorados em processos biotecnológicos, com algumas exceções. No entanto, devido às suas habilidades de osmoadaptação e capacidades metabólicas para a produção de solutos compatíveis, produtos nutricionais, biopolímeros e enzimas halofílicas, representam um potencial promissor em diversas indústrias, incluindo produtos químicos, ambientais, biocombustíveis, médicos, farmacêuticos e de cuidado da saúde (Tabela 2) (DIKEN et al., 2015).

Tabela 2 - Aplicações industriais atuais e potenciais dos microrganismos halófilos (YIN et al., 2014)

\begin{tabular}{|c|c|c|}
\hline Produto & Aplicação & Produtor representativo \\
\hline Polihidroxibutirato (PHB) & Biomateriais, plástico & $\begin{array}{l}\text { Halomonas boliviensis } \\
\text { Halomonas sp. TD01 }\end{array}$ \\
\hline $\begin{array}{l}\text { Poli (hidroxibutirato-co-hidroxivalerato) } \\
\text { (PHBV) }\end{array}$ & Plástico, materiais médicos & Haloferax mediterranei \\
\hline & $\begin{array}{l}\text { Protetor de proteínas e células, } \\
\text { proteção da membrana celular }\end{array}$ & Halomonas elongata \\
\hline Ectoina & $\begin{array}{l}\text { Proteção antienvelhecimento da } \\
\text { pele }\end{array}$ & Halomonas salina \\
\hline Hidroxiectoína & $\begin{array}{l}\text { Proteção das proteínas contra } \\
\text { mal dobramento, degradação e } \\
\text { congelamento }\end{array}$ & Marinococcus M52 \\
\hline Amilases & Indústria alimentícia & $\begin{array}{l}\text { Halomonas sp. } \\
\text { Halobacillus sp. } \\
\text { Streptomyces sp. }\end{array}$ \\
\hline Proteases & $\begin{array}{l}\text { Aditivos em produtos } \\
\text { farmacêuticos, detergentes para } \\
\text { a roupa }\end{array}$ & $\begin{array}{l}\text { Bacillus sp. } \\
\text { Halobacillus sp. } \\
\text { Chromohalobacter sp. }\end{array}$ \\
\hline Xilanases e celulases & $\begin{array}{l}\text { Biolixiviação, hidrólise da } \\
\text { celulose, biocombustíveis }\end{array}$ & $\begin{array}{l}\text { Streptomonospora sp. } \\
\text { Halomonas sp. }\end{array}$ \\
\hline Biossurfactantes e bioemulsionantes & $\begin{array}{l}\text { Solubilização de substratos } \\
\text { hidrofóbicos }\end{array}$ & $\begin{array}{l}\text { Halomonas spp. } \\
\text { Natrialba sp. linhagem E21 }\end{array}$ \\
\hline$\beta$ - caroteno & Aditivo alimentar & Dunaliella spp. \\
\hline Glicerol & Indústrias de cosméticos & Dunaliella spp. \\
\hline
\end{tabular}




\subsection{Biopolímeros}

Os biopolímeros de origem microbiana são moléculas solúveis em água produzidos diretamente através de fermentação ou por polimerização química de monômeros (processo que acontece também na fermentação) (MOKHTARZADEH et al., 2016; SUKAN; ROY; KESHAVARZ, 2015). A maior parte desses polímeros industrial e clinicamente relevantes foi encontrada no início e meados do século $X X$, tais como o alginato, goma xantana, poli-y-glutamato e polifosfatos (REHM, 2010). Nos últimos anos, os biopolímeros mostraram-se promissores como nanomateriais não-tóxicos, biocompatíveis e biodegradáveis (MOKHTARZADEH et al., 2016).

De acordo com a estrutura e composição química, esses compostos podem ser categorizados em quatro classes principais: polissacarídeos, poliésteres, poliamidas e polianidridos (Tabela 3) (Figura 3) (KREYENSCHULTE; KRULL; MARGARITIS, 2014). Estes polímeros cumprem várias funções biológicas, por exemplo, como material de reserva ou como parte de uma estrutura de proteção, e podem proporcionar uma vantagem substancial para os microrganismos, sob certas condições ambientais (NICOLAUS et al., 2004; SUKAN; ROY; KESHAVARZ, 2015). 
Tabela 3 - Biopolímeros microbianos de importância comercial (KREYENSCHULTE; KRULL; MARGARITIS, 2014; REHM, 2010)

\begin{tabular}{lllll}
\hline $\begin{array}{l}\text { Classe de } \\
\text { polímero }\end{array}$ & Fonte & $\begin{array}{l}\text { Localização } \\
\text { do polímero }\end{array}$ & $\begin{array}{c}\text { Componentes } \\
\text { principais }\end{array}$ & $\begin{array}{l}\text { Aplicações } \\
\text { industriais }\end{array}$ \\
\hline
\end{tabular}

Polissacarídeos

Xantana

Xanthomonas campestres

Pseudomonas spp.

Azotobacter spp.

Dextrano

Leuconostoc spp.

Streptococcus spp.

Lactobacillus spp.

Gluconobacter sp.

Pediococcus pentosaceus

Ácido

Hialurônico

Streptococcus spp.

S. equi

Pasteurella

multocida

\section{Poliamidas}

$\begin{array}{ll}\text { Poli- }- \text { - } & \text { Bacillus spp. } \\ \text { glutamato } & \text { Staphylococcus } \\ & \text { epidermis } \\ & \text { Fusobacterium } \\ & \text { Nucleatum, } \\ & \text { Natronococcus occultus } \\ & \text { Natrialba aegyptiaca }\end{array}$

\section{Poliéster}

Polihidroxia Bacteria e Archaea

Icanoatos

\section{Polianidridos}

Polifosfatos Bacteria e Archaea
Extracelular

ou cápsula
Intracelular

Intracelular
Extracelular

Ácido manurónico

e ácido gulurónico

\section{Extracelular Glicose}

Extracelular

Glucuronato e

acetilglucosamina
Biomaterial, produtos agrícolas, cosméticos, recuperação de óleo, indústria do papel.

Expansor do plasma sanguíneo, remoção de metais pesados, cosméticos.

Cosméticos, reparação de tecidos e entrega de drogas
D-glutamato e/ou
L-glutamato
Substituição de poliacrilato, fertilizante, espessante, agente humectante, entrega de drogas e cosméticos

\author{
Bioplásticos e \\ biomateriais \\ (R) -3-Hidroxi \\ ácidos graxos
}

Fosfato
Agente antibacteriano, substituto de ATP na síntese enzimática e intensificador de sabor 
A

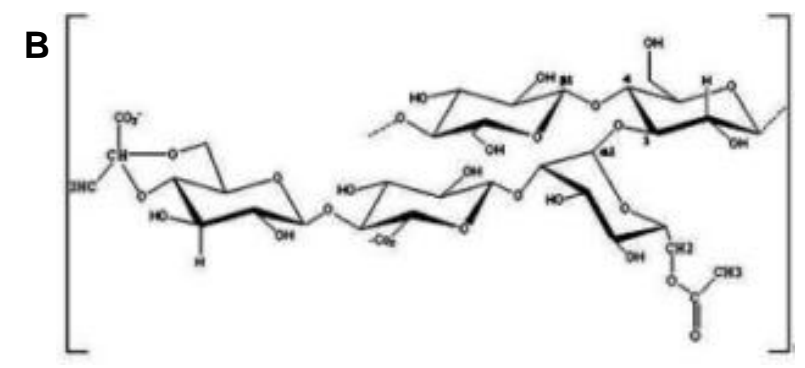

Poli-L-lisina

Xantana

C

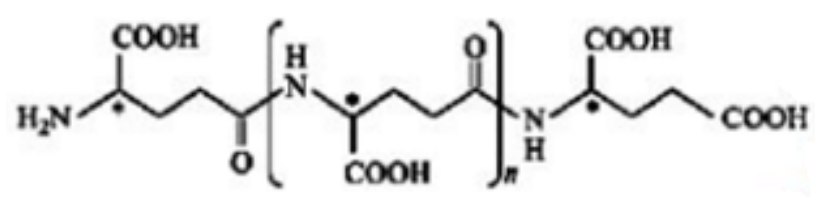

PGA

Figura 3 - Estruturas químicas de alguns polímeros bacterianos. A, Poli-L-lisina, B, Xantana, e C, PGA. Fonte: Adaptada (MOKHTARZADEH et al., 2016)

\subsubsection{Polihidroxialcanoatos (PHA)}

Os plásticos tornaram-se uma parte importante da vida moderna e são utilizados em diferentes setores, como embalagens, materiais de construção, produtos de consumo, entre outros. Estima-se que cada ano cerca de 100 milhões de toneladas de plástico são produzidos em todo o mundo, usando principalmente material petroquímico que não pode ser degradado facilmente. A utilização desses materiais plásticos não biodegradáveis tem causado a poluição ambiental e, portanto, os bioplásticos têm emergido como uma alternativa útil para evitar a poluição do meio ambiente. (KUMAR et al., 2013; SINGH et al., 2011).

Os polihidroxialcanoatos (PHA), conhecidos como bioplásticos bacterianos, representam uma grande família de poliésteres biodegradáveis (Figura 4), biocompatíveis e renováveis, acumulados na forma de grânulos intracelulares por uma ampla variedade de bactérias como compostos de armazenamento de carbono e energia (SILVA et al., 2014; YUE et al., 2014). As características mecânicas e físicas desses biopolímeros se assemelham às dos plásticos derivados do petróleo (LOPES et al., 2009; RIVERA-TERCEROS et al., 2015). 


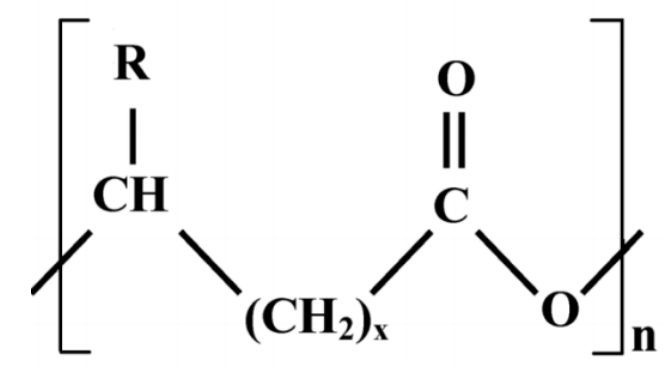

Figura 4 - Estrutura química do poliéster polihidroxialcanoato. $R=$ cadeia alquílica de 1-13 átomos de carbono. Fonte: Adaptada (PRADOS e MAICAS, 2016)

Os plásticos microbianos podem ser produzidos a partir de fontes renováveis, como resíduos agroindustriais, e através de um processo de fermentação sob condições de restrição de crescimento de nitrogênio, fósforo, enxofre e/ou oxigénio na presença de um excesso de fonte de carbono (NARANJO et al., 2013b).

Os PHA podem variar consideravelmente na composição do polímero. Existem mais de 150 componentes conhecidos, o que resulta numa enorme diversidade de propriedades do biopolímero. As propriedades termoplásticas que apresentam os PHA, como a cristalinidade compreendida entre $30-70 \%$ e temperaturas de fusão de 50-180 ${ }^{\circ} \mathrm{C}$, fazem que sejam comercialmente relevantes como alternativas de plásticos derivados de petróleo (REHM, 2010).

Estes poliésteres podem ser classificados em dois grandes grupos pelo comprimento da cadeia: PHA de cadeia média (PHAMCL do inglês medium chain length) que contêm monômeros com 6 a 14 átomos de carbono na cadeia principal, sendo produzidos principalmente por Pseudomonas, e PHA de cadeia curta (PHAscL, short chain length) constituídos por monômeros contendo de 3 a 5 átomos de carbono na cadeia principal, produzidos por uma ampla gama de bactérias e arqueias (SURIYAMONGKOL et al., 2007).

O polihidroxibutirato $(\mathrm{PHB})$, primeiro tipo de PHA descoberto, e o copolímero poli-3-hidroxibutirato-co-3-hidroxivalerato (3HB-co-3HV) são os PHAs mais estudados (Figura 5) (LOPES et al., 2009). O PHB tem propriedades mecânicas semelhantes aos plásticos convencionais como o polietileno e o polipropileno, mas os seus custos de produção são mais elevados do que os plásticos petroquímicos (SUKAN; ROY; 
KESHAVARZ, 2015). O custo total de produção de PHB depende do microrganismo (rendimento e produtividade), as fontes de carbono e de nitrogênio (substratos), as condições de fermentação (temperatura, aeração, $\mathrm{pH}$ ) e os processos de recuperação e purificação (NARANJO et al., 2013b; PRADOS; MAICAS, 2016).

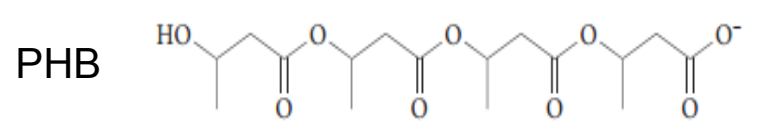

3HB-co-3HV

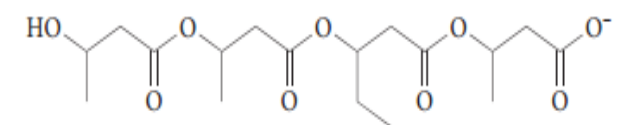

Figura 5 - Estrutura química dos poliésteres polihidroxibutirato (PHB) e poli-3-hidroxibutirato-cohidroxivalerato (3HB-co-3HV). Fonte: Adaptada e modificada (REHM, 2010)

A via metabólica para a produção de PHB envolve três enzimas distintas. $\mathrm{O}$ primeiro passo é catalisado pela enzima $\beta$-cetotiolase (codificada por phaA), pela qual duas moléculas de acetil-CoA reagem para formar acetoacetil-CoA. O acetoacetil-CoA é então reduzido pela enzima acetoacil-CoA redutase NADPH dependente (codificada por phaB). Finalmente, os monómeros [(R) -3-hidroxibutiril-CoA] são polimerizados em PHB pela PHB sintase (codificada por phaC) (KUMAR et al., 2013).

Na produção industrial de PHB, o custo da fonte de carbono tem-se considerado como um dos principais fatores limitantes para a produção de polímeros, pois representa mais de 50\% dos custos totais de produção (NARANJO et al., 2013a; SILVA et al., 2014). Portanto, a produção de PHB utilizando outras fontes baratas, tais como agroresíduos e o resíduos de várias indústrias podem contribuir significativamente para reduzir os custos de fabricação (SINDHU et al., 2013).

$\mathrm{Na}$ literatura tem-se descrito alguns microrganismos capazes de produzir PHB a partir de diversos resíduos agroindustriais, os quais pertencem aos gêneros Bacillus, Pseudomonas, Burkholderia, Escherichia, Alcaligenes, Halomonas, Ralstonia, Azotobacter, Cupriavidus, Methylobacterium (SANGKHARAK; PRASERTSAN, 2012; SILVA et al., 2014; SINGH et al., 2011). 
Finalmente, os polímeros de PHA podem ser sintetizados por algumas espécies halófilas dos géneros Haloferax, Halococcus, Natronobacterium, Natronococcus, Bacillus, Cupriavidus, Staphylococcus, Micrococcus, Methylobacterium, Paracoccus e Rhodococcus. Dependendo do género, alguns destes microrganismos são capazes de sintetizar, além de PHA, exopolissacarídeos (EPS) (DE JESUS ASSIS et al., 2016a).

\subsubsection{Exopolissacarídeos (EPS)}

O termo exopolissacarídeos foi usado pela primeira vez por Sutherland em 1972, para descrever polímeros de elevado peso molecular produzidos por bactérias marinhas (POLI; ANZELMO; NICOLAUS, 2010). Os exopolissacarídeos (EPS) podem ser polímeros naturais de elevado o baixo peso molecular, de resíduos de açúcar, biodegradáveis e não tóxicos, envolvidos em diversas funções, incluindo adesão, interações célula-célula, formação de biofilme, e proteção da célula em os ambientes extremos. Devido as suas propriedades físico-químicas, biológicas e reológicas, EPS como xantana, dextrano, pululano e gelano têm encontrado inúmeras aplicações em alimentação como agentes espessantes; na medicina como curativos de feridas, na indústria cosmética como protetor da pele e em setores ambientais como removedores de óleo e tratamento de águas poluídas (YILDIZ et al., 2015).

Os EPS podem ser obtidos a partir de fontes naturais como plantas, algas e microrganismos (WANG et al., 2016). EPS bacterianos são os componentes mais abundantes no ambiente, representando geralmente $40-95 \%$ dos polímeros extracelulares (SPANÒ et al., 2016). Porém, a produção de polímeros por microrganismos ainda é muito insignificante em comparação com a quantidade de polímeros derivados de plantas e animais (PAULO et al., 2012).

Contudo, nos últimos anos tem aumentado o interesse no isolamento e identificação de novos exopolissacarídeos microbianos, graças às evidências descritas por diferentes autores que sugerem que esses biopolímeros possuem efeitos imunomoduladores, antioxidantes, antitumorais, antivirais, antibacterianos e antidiabéticos (GUGLIANDOLO et al., 2014; HEYMANN et al., 2016; SHIN et al., 2016; SPANÒ et al., 2016; SPANÒ; ARENA, 2016; WANG et al., 2016; ZHENG et al., 2013). 
Estes compostos são produzidos por uma grande variedade de bactérias e algumas espécies de Archaea. Para alguns microrganismos os EPS são altamente importantes como um mecanismo de defesa e adaptação a condições ambientais estremas (KAVAMURA et al., 2013a; SIRAJUNNISA et al., 2016). A maioria dos EPS bacterianos têm estruturas complexas e diversas que conferem diversas propriedades funcionais, comercialmente relevantes e atraentes para diferentes sectores industriais, entre esses, o setor da saúde (SHIN et al., 2016).

São conhecidos, até o momento, quatro mecanismos gerais para a produção destes polímeros de hidratos de carbono em bactérias: (i) a chamada via Wzx/Wzydependente; (ii) transportadores dependentes de energia do tipo $A B C$; (iii) a via dependente de sintase e (iv) a síntese extracelular através da utilização de uma única proteína de sacarose (SCHMID; SIEBER; REHM, 2015).

A produção de EPS por muitas bactérias, apenas algumas gramas por litro, é bastante baixa para sua utilização prática. Em contraste, algumas espécies são conhecidas por seus altos níveis de produção. Entre elas, cepas de Xanthomonas campestris, Bacillus polymyxa, Klebsiella pneumoniae e Sphingomonas elodea são as mais estudadas e apenas alguns são utilizados em nível industrial (SILVI et al., 2013).

Por outro lado, os EPS microbianos são abundantes em ambientes marinhos, onde eles podem ajudar as comunidades microbianas a suportar grandes variações de temperatura, salinidade e limitação de nutrientes (POLI; ANZELMO; NICOLAUS, 2010). Assim, os microrganismos halófilos e halotolerantes têm a capacidade de produzir exopolissacarídeos como estratégia para o crescimento, a adesão a substratos sólidos e a sobrevivência em condições adversas (Tabela 4) (SPANÒ; ARENA, 2016; UPADHYAY et al., 2016). 
Tabela 4 - EPS produzidos por microrganismos isolados de ambientes hipersalinos (POLI; ANZELMO; NICOLAUS, 2010)

\begin{tabular}{|c|c|c|c|}
\hline Microrganismo & Ambiente de origem & $\begin{array}{l}\text { Descrição do EPS e } \\
\text { composição química }\end{array}$ & $\begin{array}{c}\text { Papel ecológico } \\
\text { sugerido e potencial } \\
\text { de aplicação } \\
\text { biotecnológica }\end{array}$ \\
\hline $\begin{array}{l}\text { Haloferax } \\
\text { mediterranei }\end{array}$ & Mar Mediterrâneo & $\begin{array}{l}\rightarrow 4)-\beta-D-G l c p N A c A- \\
(1 \rightarrow 6)-\alpha-D-M a n p- \\
(1 \rightarrow 4)-\beta-D-G l c p N A c A- \\
\text { 3-O-SO3-- }(1 \rightarrow\end{array}$ & $\begin{array}{l}\text { Candidato na } \\
\text { recuperação de óleo, } \\
\text { especialmente em } \\
\text { depósitos de petróleo } \\
\text { com alta concentração } \\
\text { de salinidade }\end{array}$ \\
\hline $\begin{array}{l}\text { Hahella } \\
\text { chejuensis }\end{array}$ & $\begin{array}{l}\text { Amostra de sedimento } \\
\text { marinho recolhido de } \\
\text { Marado, Ilha de Cheju, } \\
\text { República da Coreia }\end{array}$ & $\begin{array}{l}\text { EPS nomeado EPS-R } \\
\text { Glc:Gal }(0.68: 1.0)\end{array}$ & $\begin{array}{l}\text { Biossurfactante e } \\
\text { desintoxicação de áreas } \\
\text { poluídas a partir de } \\
\text { óleos petroquímicos }\end{array}$ \\
\hline $\begin{array}{l}\text { Halomonas } \\
\text { alkaliantarctica } \\
\text { CRSS }\end{array}$ & $\begin{array}{l}\text { Lago de sal em Cabo } \\
\text { Russell na Antártida }\end{array}$ & $\begin{array}{l}\text { Glc:Fru:GlcN:GalN } \\
\text { (1.0:0.7:0.3:trace) }\end{array}$ & Alta viscosidade \\
\hline
\end{tabular}

\subsubsection{1 Ácido Hialurônico (AH)}

Meyer e Palmer (1934) descreveram um novo polissacarídeo isolado do corpo vítreo bovino. Eles descobriram que a substância continha um ácido urónico e um açúcar aminado, e chamaram o polímero de "ácido hialurônico". O termo "hialuronan" foi introduzido em 1986 para estar em conformidade com a nomenclatura dos polissacáridos. Durante as décadas de 1930 e 1940, o AH foi isolado a partir de muitas fontes, tais como o corpo vítreo, cordão umbilical, crista galo, e de estreptococos (LIU et al., 2011).

O ácido hialurônico $(\mathrm{AH})$ é um biopolímero natural (Figura 6) com peso molecular variando dentro do intervalo de 50 a $8000 \mathrm{kDa}$ (KIM et al., 2008b), que desempenha 
funções estruturais, de reconhecimento e de sinalização nos tecidos do corpo de humanos e animais (SHENG; LING; WANG, 2014; WIDNER et al., 2005; YU et al., 2008).

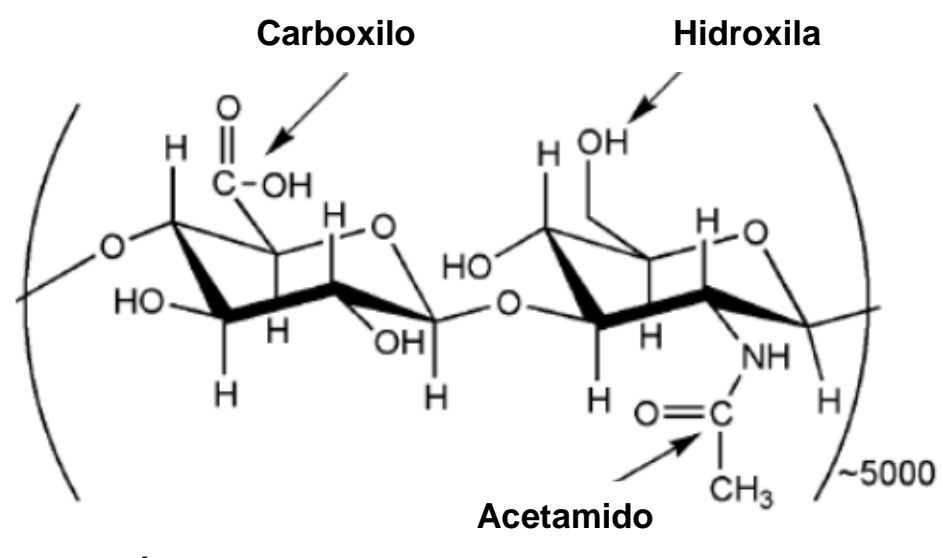

Ácido glucurónico

$\mathrm{N}$-acetilglucosamina

Figura 6 - Estrutura da unidade do dissacarídeo de ácido hialurônico. Fonte: Adaptada (LIU et al., 2011)

$\mathrm{O} A \mathrm{H}$ é um glicosaminoglicano, com um hialuronato não ramificado ou polissacarídeo hialuronan como suporte principal composto por sequências alternadas do $\beta$ - (1-4) de ácido glucurónico e porções de $\beta$ - (1-3) N-acetilglucosamina, geralmente presente na sua forma de sal de sódio (KIM et al., 2008b).

Algumas bactérias marinhas tem sido descritas como produtoras de $\mathrm{AH}$ e algumas delas são modificadas geneticamente para produzir maiores quantidades do biopolímero em processos fermentativos (KIM et al., 2008b). Na indústria, o AH é produzido utilizando a bactéria Gram-positiva Streptococcus zooepidemicus. No entanto, o gênero Streptococcus não é uma fonte ideal para obtenção desse EPS, devido ao seu potencial para produzir exotoxinas, a dificuldade no controle da fermentação e do elevado custo do meio de cultivo necessário para o crescimento. Portanto, outros microrganismos produtores, fontes alternativas de $\mathrm{AH}$, são desejáveis para a indústria (SHENG; LING; WANG, 2014).

Considerando a variedade de funções naturais, o AH tem aplicações na medicina sendo usado no tratamento da artrose do joelho por meio da viscossuplementação (infiltração de $\mathrm{AH}$ ) e em cosméticos como preenchedores dérmicos (LIU et al., 2011). Também tem sido usado topicamente para a cura de queimaduras e úlceras, e em 
procedimentos para extração de catarata, transplante de córnea, filtração de glaucoma, e em cirurgias de descolamento de retina (CHONG et al., 2005). 


\section{OBJETIVO}

O trabalho tem como objetivo geral caracterizar bactérias halotolerantes isoladas de um local salino do bioma caatinga e avaliar a produção de biopolímeros de interesse biotecnológico.

\subsection{Objetivos específicos}

- Identificar os isolados halotolerantes utilizando o gene RNAr 16S.

- Avaliar o crescimento das bactérias em diferentes concentrações de $\mathrm{NaCl}$.

- Avaliar a produção de polihidroxialcanoatos (PHA) em diferentes condições de cultura.

- Avaliar a produção de exopolissacarídeos (EPS) e detectar possível atividade imunoestimulatória.

- Avaliar a produção de ácido hialurônico (AH). 


\section{MATERIAL E MÉTODOS}

No estudo foram utilizados meios de cultura e métodos descritos a seguir.

\subsection{Meios de cultura, tampões e soluções}

Todos os meios de cultura, tampões e soluções foram feitos com água destilada, e autoclavados a $121^{\circ} \mathrm{C}$ durante 15 minutos.

Ágar Nutriente Modificado. Meio usado para o isolamento de microrganismos halotolerantes. Composição: Peptona ( $5 \mathrm{~g} / \mathrm{L})$, extrato de levedura ( $3 \mathrm{~g} / \mathrm{L})$, ágar (15 g/L), e $\mathrm{NaCl}(116,8 \mathrm{~g} / \mathrm{L})$.

Ágar TSA. Meio utilizado para cultivo e crescimento das bactérias e isolamento de colônias. Composição: caseína pancreática (15 g/L), farinha de soja ( $5 \mathrm{~g} / \mathrm{L}), \mathrm{NaCl}(5$ $\mathrm{g} / \mathrm{L})$, ágar (15 g/L), $\mathrm{pH}:$ 7,3 \pm 0.2 .

Meio de produção de EPS Modificado. Meio líquido ou sólido usado para produção de exopolissacarídeos (EPS). Composição: sacarose (100 g/L), extrato de levedura (20 g/L), $\mathrm{K}_{2} \mathrm{HPO}_{4}(15 \mathrm{~g} / \mathrm{L}), \mathrm{MgSO}_{4}$ (0,2 g/L), $\mathrm{MnSO}_{4}$ (0,015 g/L), $\mathrm{FeSO}_{4}$ (0,015 $\mathrm{g} / \mathrm{L}), \mathrm{CaCl}_{2}(0,03 \mathrm{~g} / \mathrm{L}), \mathrm{NaCl}(0,015 \mathrm{~g} / \mathrm{L})$, e ágar (15 g/L) quando necessário, $\mathrm{pH}:$ 7,5 (KAVAMURA et al., 2013b).

Meio Mineral. Meio liquido ou sólido usado para avaliar a produção de PHA. Composição: $\mathrm{Na}_{2} \mathrm{HPO}_{4}(3,5 \mathrm{~g} / \mathrm{L}), \mathrm{KH}_{2} \mathrm{PO}_{4}(1,5 \mathrm{~g} / \mathrm{L}),\left(\mathrm{NH}_{4}\right)_{2} \mathrm{SO}_{4}(1,0 \mathrm{~g} / \mathrm{L})$, citrato de amônio férrico $\left(\mathrm{C}_{6} \mathrm{H}_{5}+4 \mathrm{y} \mathrm{Fe}_{x} \mathrm{~N}_{\mathrm{y}} \mathrm{O}_{7}\right) 6 \%(1 \mathrm{ml} / \mathrm{L}), \mathrm{MgSO}_{4} .7 \mathrm{H}_{2} \mathrm{O} 20 \%(1 \mathrm{ml} / \mathrm{L}), \mathrm{CaCl}_{2} .2 \mathrm{H}_{2} \mathrm{O} 1 \%(1$ $\mathrm{ml} / \mathrm{L}), 1 \mathrm{ml} / \mathrm{L}$ de solução de elementos traços. Após autoclavar, adicionou-se ao meio sintético diferentes fontes de carbono; glicose, xilose ou glicerol (10 g/L) segundo o ensaio, para oferecer condições adequadas de acúmulo de PHA. Ágar (20 g/L) quando for meio sólido (RAMSAY et al., 1990).

Meio de produção de Ácido Hialurônico. Meio líquido para avaliar a produção de ácido Hialurônico. Composição: Extrato de levedura (20 g/L), $\mathrm{K}_{2} \mathrm{HPO}_{4}(15 \mathrm{~g} / \mathrm{L}), \mathrm{MgSO}_{4}$ (0,2 g/L), $\mathrm{MnSO}_{4}(0,015 \mathrm{~g} / \mathrm{L}), \mathrm{FeSO}_{4}(0,015 \mathrm{~g} / \mathrm{L}), \mathrm{CaCl}_{2}(0,03 \mathrm{~g} / \mathrm{L}), \mathrm{NaCl}(0,015 \mathrm{~g} / \mathrm{L})$, e sacarose (100 g/L) (YU et al., 2008). 
Meio TSB Modificado. Meio líquido para obter massa celular dos isolados. Composição: caseína pancreática (17 g/L), farinha de soja (3 g/L), $\mathrm{K}_{2} \mathrm{HPO}_{4}(2,5 \mathrm{~g} / \mathrm{L})$, dextrose (2,5 g/L), NaCl (5 g/L, $35 \mathrm{~g} / \mathrm{L}, 60 \mathrm{~g} / \mathrm{L}, 120 \mathrm{~g} / \mathrm{L}), \mathrm{pH}: 7,3 \pm 0.2$.

Tampão TAE. Tris (0,04 M), ácido acético glacial (0,12\%), Na2-EDTA (1 mM), $\mathrm{pH}: 8,0$.

Tampão salino. $\mathrm{NaCl}(0,8 \%), \mathrm{KCl}(0,02 \%), \mathrm{Na}_{2} \mathrm{HPO}_{4}(0,14 \%), \mathrm{KH}_{2} \mathrm{PO}_{4}(0,024 \%)$.

Solução de elementos traços. $\mathrm{H}_{3} \mathrm{BO}_{3}(0,3 \mathrm{~g} / \mathrm{L}), \mathrm{CoCl}_{2} \cdot 6 \mathrm{H}_{2} \mathrm{O}(0,2 \mathrm{~g} / \mathrm{L})$, $\mathrm{ZnSO}_{4} .7 \mathrm{H}_{2} \mathrm{O}(0,1 \mathrm{~g} / \mathrm{L}), \mathrm{MnCl}_{2} .4 \mathrm{H}_{2} \mathrm{O}(30,0 \mathrm{mg} / \mathrm{L}), \mathrm{NaMoO}_{4} .2 \mathrm{H}_{2} \mathrm{O}(30,0 \mathrm{mg} / \mathrm{L}), \mathrm{NiCl}_{2} .6 \mathrm{H}_{2} \mathrm{O}$ (20,0 mg/L), $\mathrm{CuSO}_{4} .5 \mathrm{H}_{2} \mathrm{O}(10,0 \mathrm{mg} / \mathrm{L})$.

Solução de Ácido Hialurônico. Solução usada para a curva padrão de ácido hialurônico. Dissolver 1 grama em 1 litro de água destilada.

Solução de Alcian Blue 8GX. Solução usada para quantificação do ácido hialurônico. Dissolveu-se 1 grama de Alcian Blue $8 \mathrm{GX}$ em $100 \mathrm{~mL}$ de ácido acético glacial $3 \%$. O pH foi ajustado com ácido acético para 2,5. Foram filtrados com membrana de $0,45 \mu \mathrm{m}$ e armazenados à temperatura ambiente (Estável até seis meses).

\subsection{Material biológico}

Os isolados bacterianos foram recuperados da Coleção de Microrganismos da Empresa Brasileira de Pesquisa Agropecuária (2014), Laboratório de Microbiologia Ambiental, localizado em Jaguariúna. Esses microrganismos foram previamente isolados de solo rizosférico de um local salino do bioma caatinga, distrito de Mossoró, Rio Grande do Norte, próximo da salina de Areia Branca. Coordenadas geográficas: S 457’22” W $37^{\circ} 08^{\prime} 13^{\prime \prime}$ (Figura 7 ). 

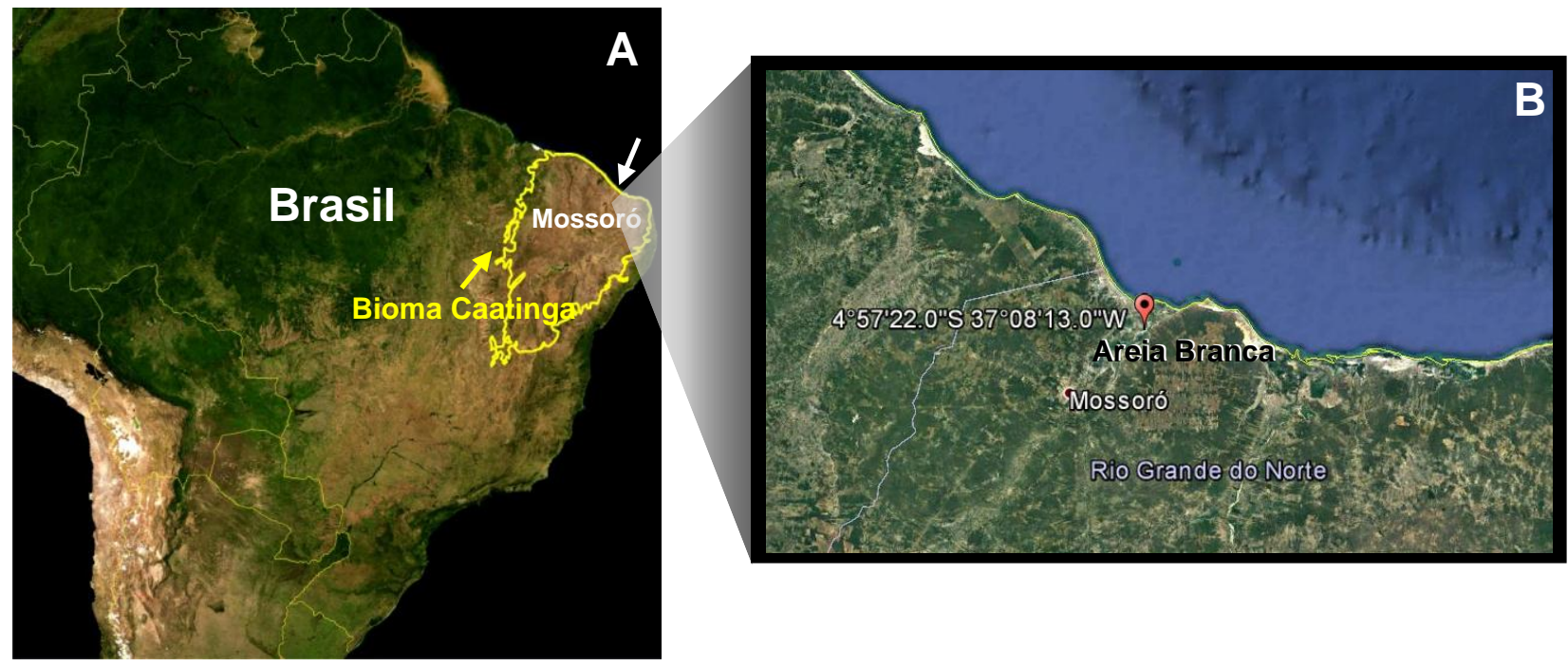

Figura 7 - Local coleta. A, mapa indicando a localização do bioma caatinga como definido pelo IBAMA Fonte: Modificado (Google, 2014) e B, posição do ponto de coleta, próximo da salina de Areia Branca, no distrito de Mossoró, Rio Grande do Norte Fonte: Modificado (Google Earth, 2016)

A coleta ocorreu em região de salina, onde foram coletadas partes de rizosfera de duas espécies de plantas: Blutaparon portulacoides e Spergularia sp. (Figura 8), que se encontravam nas margens das salinas. As amostras da coleta foram armazenadas em sacos estéreis e levadas ao Laboratório de Microbiologia Ambiental da Embrapa.
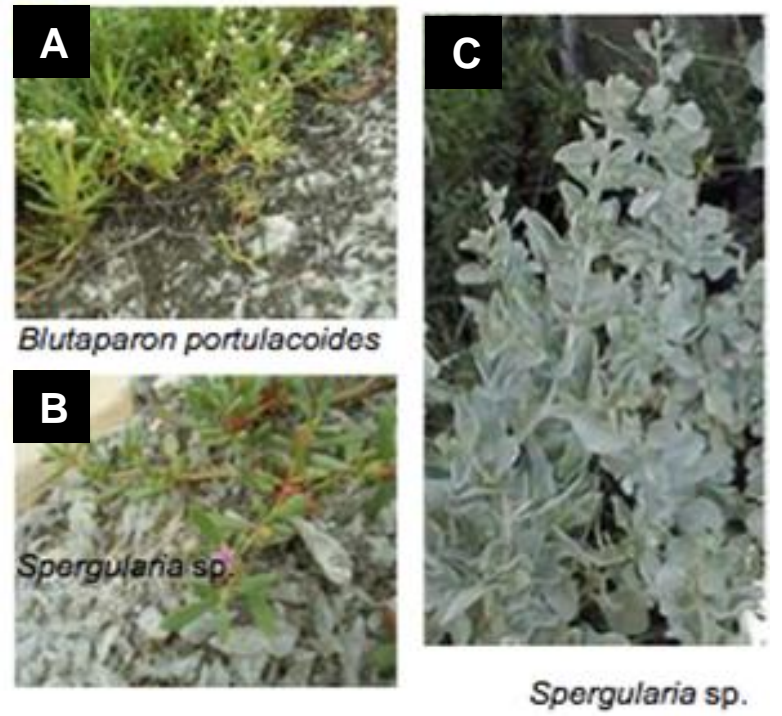

Figura 8 - Plantas coletadas. A, planta da espécie Blutaparon portulacoides, conhecida popularmente como Suculenta, e B - C, planta da espécie Spergularia sp., conhecida como Pirristio. Fonte: (Embrapa, 2014) 
As raízes e solos foram colocados em frascos de vidro embebidos com $90 \mathrm{ml}$ tampão salino por três horas, para dissolução dos solos. Seguidamente, $1 \mathrm{ml}$ de cada solução foi diluído em série até $10^{-6}$, e as diluições $10^{-4}, 10^{-5}$ e $10^{-6}$ foram semeadas no meio de cultura Ágar Nutriente, adicionado de $\mathrm{NaCl}$ a $2.0 \mathrm{M}$, para o isolamento de linhagens halofílicas e/ou halotolerantes. Finalmente, as placas foram incubadas a 28-30 ${ }^{\circ} \mathrm{C}$ por sete dias.

As bactérias isoladas foram crescidas e mantidas em placas contendo meio Ágar Triptona Soja (TSA) a $28^{\circ} \mathrm{C}$ por $24-48$ horas. Ao término deste, a biomassa foi recolhida com ajuda de uma alça estéril e transferida para meio líquido TSB com glicerol a uma concentração de $20 \%$. Foram feitos estoques em micro tubos de 1,5 contendo $1 \mathrm{~mL}$ da suspensão e armazenados a $-80^{\circ} \mathrm{C}$ e $-20^{\circ} \mathrm{C}$.

\subsection{Extração de DNA genômico dos isolados bacterianos}

A extração de DNA genômico dos isolados foi realizada a partir de culturas líquidas em meio TSB, centrifugadas após 12 horas de crescimento sob agitação a 28 ${ }^{\circ} \mathrm{C}$. O DNA foi extraído utilizando o kit comercial Wizard® Genomic DNA Purification Kit (Promega Corporation, Fitchburg, USA) seguindo as recomendações do fabricante para bactérias Gram positivas ou Gram negativas segundo o caso.

A concentração do DNA foi avaliada por espectrofotometria $(260 \mathrm{~nm} / 280 \mathrm{~nm})$ (Sambrook, Fritsch and Maniatis, 1989) no espectrofotômetro Nanodrop ND 2000 (Thermo Fisher Scientific, Waltham, USA).

A qualidade da extração foi verificada através de eletroforese em gel de agarose a uma concentração de $1 \%$ contendo SYBR® Safe (Thermo Fisher Scientific) em tampão TAE.

\subsection{Identificação dos isolados}

Para a amplificação dos genes RNAr 16 S foi utilizado o método de Reação em Cadeia da Polimerase (PCR). Na tabela 5 encontram-se as condições para as reações 
de PCR que foram padronizadas em um volume final de $50 \mu \mathrm{L}$ e o programa de amplificação que foi realizado no termociclador Veriti® (Thermo Fisher Scientific).

Tabela 5 - Condições da reação de PCR para a amplificação do gene RNAr 16S

\begin{tabular}{ccc}
\hline Condições da reação de PCR para a amplificação do gene RNAr 16S. \\
\hline Reativos & Concentração & Volume \\
DNA bacteriano & $25 \mathrm{ng} / \mu \mathrm{L}$ & $1 \mu \mathrm{L}$ \\
Iniciadores (cada um) & $10 \mathrm{mM}$ & $2,0 \mu \mathrm{L}$ \\
Master Mix® (Promega) & $5 \mathrm{x}$ & $25 \mu \mathrm{L}$ \\
Água deionizada & - & $20 \mu \mathrm{L}$ \\
\hline & \multicolumn{2}{c}{ Volume final } \\
\hline & Programa Termociclador & $50 \mu \mathrm{L}$ \\
\hline & $95^{\circ} \mathrm{C}$ por 2 min \\
\hline Desnaturação inicial & $95^{\circ} \mathrm{C}$ por 1 min \\
Desnaturação & $60^{\circ} \mathrm{C}$ por 30 segs. \\
Anelamento & $72^{\circ} \mathrm{C}$ por 1 min \\
Extensão & $72^{\circ} \mathrm{C}$ por 10 min \\
Extensão final & Ciclos & 40 \\
\hline
\end{tabular}

Os iniciadores forward e reverse utilizados nas reações de $P C R$ encontram-se na tabela 6.

Tabela 6 - Sequência dos iniciadores utilizados para amplificação e sequenciamento dos genes RNAr 16S

\begin{tabular}{|c|c|c|}
\hline Iniciador & Sequência (5'-3') & Referência \\
\hline $27 f$ & AGAGTTTGATCCTGGCTCAG & \\
\hline $1492 r$ & GGTTACCTTGTTACGACTT & (WEISBURG et al., 1991) \\
\hline $536 f$ & CAGCMGCCGCGGTAATWC & (HOLBEN et al., 2004) \\
\hline $782 r$ & ACCAGGGTATCTAATCCTGT & (CHIMETTO et al., 2008) \\
\hline
\end{tabular}

O tamanho dos amplicons foi determinado em gel de agarose $1 \%$ contendo SYBR ${ }^{\circledR}$ Safe (Thermo Fisher Scientific) em tampão TAE e comparado com um marcador de peso molecular $1 \mathrm{~kb}$ (Thermo Fisher Scientific). Os produtos amplificados foram purificados com o KIT comercial GFX MicroSpin Column (General Electric, Buckinghamshire, UK) seguindo as recomendações do fabricante.

O sequenciamento foi realizado com a metodologia de Sanger (SANGER; NICKLEN; COULSON, 1977), utilizando o equipamento ABI 3730 DNA Analyser (Thermo Fisher Scientific) no Instituto de Genoma Humano da Universidade de São Paulo e outra 
parte enviada a Genomic Engenharia Molecular@, onde usaram o sequenciador modelo $3130 x \mathrm{x}$ ou 3500 (Thermo Fisher Scientific).

\subsubsection{Análise filogenética dos isolados}

As sequências do gene 16S rDNA dos isolados foram editadas no programa ChromasPro (CHROMASPRO, 1998) e comparadas com a base de dados do GeneBank mediante o software Basic Local Alignment Search Tool (BLAST) (GENBANK, 2015). Em seguida, foram analisadas no Ribosomal Database Project II (RIBOSOMAL DATABASE PROJECT II, 2015) selecionando aquelas sequências que apresentaram maiores identidades.

$O$ alinhamento das sequências e a análise de filogenia foram realizados com o programa MEGA 6.0 utilizando o algoritmo do software MUSCLE (TAMURA et al., 2013). A árvore filogenética foi construída usando o método de Neighbor-joining com um bootstrap de 1000 réplicas e as distâncias evolutivas foram estimadas pelo modelo Kimura 2-parámetros (KIMURA, 1980).

\subsection{Crescimento em diferentes concentrações de $\mathrm{NaCl}$}

Para avaliar o limite de tolerância no ambiente halofílico, todos os isolados foram semeados em meio líquido TSB suplementado com quatro diferentes concentrações de $\mathrm{NaCl}: 5 \mathrm{~g} / \mathrm{L}, 35 \mathrm{~g} / \mathrm{L}, 60 \mathrm{~g} / \mathrm{L}$ e $120 \mathrm{~g} / \mathrm{L}$, em placas de 96 poços. As culturas foram incubadas a $30^{\circ} \mathrm{C}$ por 48 horas. $\mathrm{O}$ crescimento bacteriano foi acompanhado por meio da densidade ótica (DO) a $600 \mathrm{~nm}$, no leitor de placas Synergy H1 microplate reader (Biotek Instruments, Inc., Winooski, USA). Foram realizadas leituras pontuais e os experimentos foram realizados em triplicata. 


\subsection{Produção de biopolímeros}

Os procedimentos de seleção, produção e determinação de PHA a partir dos isolados halotolerantes da caatinga estão sintetizados na figura 9.

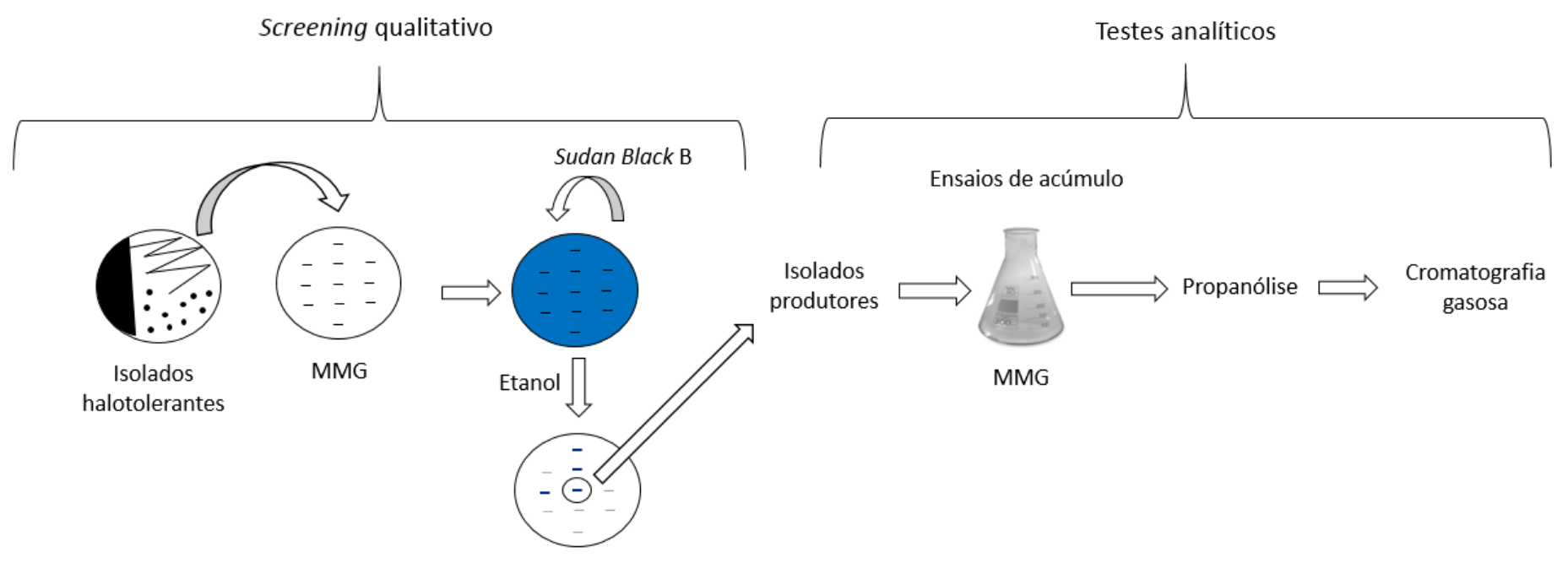

Figura 9 - Esquema dos procedimentos realizados para seleção, produção e determinação de PHA a partir dos isolados halotolerantes (RISS et al, 1988; SCHLEGEL; LAFFERTY; KRAUSS, 1970)

Para avaliar a produção de PHA, cada isolado foi semeado em meio mineral sólido contendo excesso de fonte de carbono, glicose (10 g/L), por 72 horas. Foram usados como controle positivo e negativo as linhagens Pseudomonas sp. LFM 046 e Pseudomonas sp. LFM 461 (mutante obtido por UV), respectivamente. Após este período, os microrganismos foram corados com Sudan Black $B(0,02 \% \mathrm{~m} / \mathrm{v}$ em etanol $96 \%$ ) por 20 minutos e descorados com etanol $96 \%$ por um minuto. Os isolados foram considerados produtores de PHA quando as colônias bacterianas adquiriram coloração azul, enquanto os isolados que não contêm este biopolímero ficaram levemente azulados ou não se coraram (SCHLEGEL; LAFFERTY; KRAUSS, 1970).

A partir dos isolados selecionados como produtores, foram realizados ensaios de acúmulo de PHA em pequeno volume $(50 \mathrm{~mL})$ em meio mineral líquido contendo glicose (10 g/L), a $30^{\circ} \mathrm{C}$ por 72 horas. Ao término deste, os meios foram centrifugados a 10.000 rpm por 10 minutos a $4{ }^{\circ} \mathrm{C}$, para recuperar as células do meio de cultura. Em seguida, estas células foram liofilizadas para realização do protocolo de propanólise. 


\subsubsection{Determinação quantitativa de PHA}

Para a caracterização dos PHA, foram submetidas à propanólise aproximadamente $10 \mathrm{mg}$ das células liofilizadas, segundo a metodologia descrita por Riis et al. (1988). Nos tubos foram adicionados $100 \mu \mathrm{L}$ de uma solução de ácido benzóico (3,9864 g/100 $\mu \mathrm{L}), 2 \mathrm{~mL}$ de solução HCl-propanol (1:4 v/v), $2 \mathrm{~mL}$ de 1,2-dicloroetano. Após agitação, incubou-se a mistura em banho a $100{ }^{\circ} \mathrm{C}$ por três horas, agitando-se mais duas vezes após os primeiros 15 e 30 minutos. Em seguida, os tubos foram resfriados e adicionou-se $4 \mathrm{~mL}$ de água destilada, foram submetidos à agitação e ficaram em repouso até haver uma separação das fases aquosa e orgânica, que contém os propil-ésteres. A fase aquosa foi retirada com ajuda de uma pipeta e vácuo e, na mistura restante, foi adicionado sulfato de sódio anidro para absorção de água remanescente na fase contendo os propil-ésteres. O restante foi transferido para frascos apropriados e analisado no cromatógrafo. Um volume de $1 \mu \mathrm{L}$ da fase orgânica foi analisado após fracionamento da amostra (split 1:20) em cromatógrafo gasoso HP6890 Series GC System equipado com uma coluna HP-5 (5 \% fenil-metil-siloxane, comprimento $30 \mathrm{~m}$, diâmetro $0,25 \mathrm{~mm}$, espessura do filme $0,25 \mu \mathrm{m}$ ). A análise foi conduzida nas seguintes condições: gás de arraste: Hélio $(0,8 \mathrm{~mL} / \mathrm{min})$; temperatura do injetor: $250{ }^{\circ} \mathrm{C}$; temperatura do detector: $300^{\circ} \mathrm{C}$; sistema de detecção: ionização de chama (FID).

Programa de temperaturas do forno: $100{ }^{\circ} \mathrm{C}$ por um minuto, elevação da temperatura até $185^{\circ} \mathrm{C}$ a $8{ }^{\circ} \mathrm{C} / \mathrm{min}$ e $185^{\circ} \mathrm{C}$ por 15 minutos.

Ácido benzoico foi utilizado como padrão interno. Polímeros produzidos por $P$. oleovorans ou P. putida, a partir de diferentes fontes de carbono, ou P3HB e P3HB-co3HV (Aldrich Chem. CO) foram utilizados como padrões para a geração das curvas de calibração. O PHA total foi calculado somando-se as quantidades dos constituintes $3 \mathrm{HB}$ (3-Hidroxibutirato), 3HV (3-Hidroxivalerato), 3HHx (3-Hidroxihexanoato), 3HHp (3Hidroxiheptanoato), 3HO (3-Hidroxioctanoato), 3HN (3-Hidroxinonanoato), 3HD (3Hidroxidecanoato) e 3HDD (3-Hidroxidodecanoato). 


\subsubsection{Ensaios de acúmulo em glicose e xilose}

Com o intuito de comparar o acúmulo dos isolados produtores em duas diferentes fontes de carbono, realizaram-se ensaios de acúmulo de PHA em pequeno volume (10 $\mathrm{ml})$, em meio mineral líquido contendo glicose $(10 \mathrm{~g} / \mathrm{L})$ e xilose $(10 \mathrm{~g} / \mathrm{L})$ a $30^{\circ} \mathrm{C}$ durante 72 horas. Após este período, os meios foram centrifugados a 10.000 rpm por 10 minutos a $4{ }^{\circ} \mathrm{C}$, para recuperar as células do meio de cultura. Em seguida, estas células foram liofilizadas para realização do protocolo de propanólise e análise em cromatógrafo gasoso descritos anteriormente (4.6.1).

\subsubsection{Acúmulo de PHA em três fontes de carbono e em diferentes concentrações de $\mathrm{NaCl}$}

A partir dos resultados obtidos nos ensaios de acúmulo em glicose e xilose (4.6.2), foram selecionados os isolados que apresentaram maiores porcentagens de acúmulo, para realizar ensaios de acúmulo de PHA em pequeno volume $(10 \mathrm{ml})$, em meio mineral líquido contendo três diferentes fontes de carbono: glicose, xilose e glicerol (10 $\mathrm{g} / \mathrm{L}$ ) e testando quatro diferentes concentrações de $\mathrm{NaCl}: 0 \mathrm{~g} / \mathrm{L}, 35 \mathrm{~g} / \mathrm{L}, 60 \mathrm{~g} / \mathrm{L}$ e $120 \mathrm{~g} / \mathrm{L}$. As culturas foram incubadas a $30^{\circ} \mathrm{C}$ por 72 horas. Após este período, os meios foram centrifugados a $10.000 \mathrm{rpm}$ por 10 minutos a $4{ }^{\circ} \mathrm{C}$, para recuperar as células do meio de cultura. Em seguida, estas células foram liofilizadas para realização do protocolo de propanólise e análise em cromatógrafo gasoso descritos anteriormente (4.6.1).

\subsubsection{Seleção de isolados produtores de EPS}

Os procedimentos de seleção de isolados produtores de EPS a partir de bactérias halotolerantes da caatinga estão sintetizados na figura 10 . 


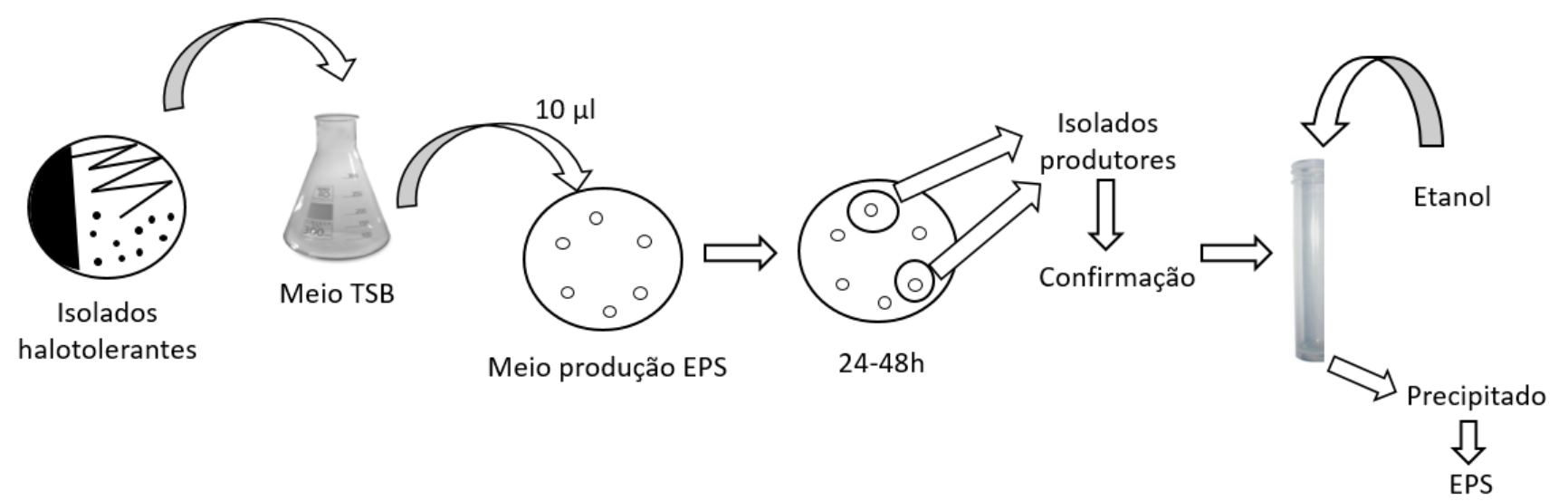

Figura 10 - Esquema dos procedimentos realizados para seleção de isolados produtores de EPS segundo o método de (PAULO et al., 2012) a partir de bactérias halotolerantes da caatinga

A determinação qualitativa da produção de exopolissacarídeos foi realizada segundo a metodologia descrita por (PAULO et al., 2012). Cada isolado bacteriano foi inoculado em discos de papel de $6 \mathrm{~mm}$ de diâmetro dispostos no meio sólido de produção de EPS (KAVAMURA et al., 2013b). A produção foi caracterizada pelo tamanho do halo produzido, pela aparente viscosidade e confirmada através da mistura de uma porção da substância mucóide em $2 \mathrm{~mL}$ de etanol absoluto. A formação de um precipitado indicou a presença de EPS (PAULO et al., 2012).

\subsubsection{Produção e extração de EPS}

Os procedimentos de produção e extração realizados para obtenção de exopolissacarídeos (EPS) estão sintetizados na figura 11. 


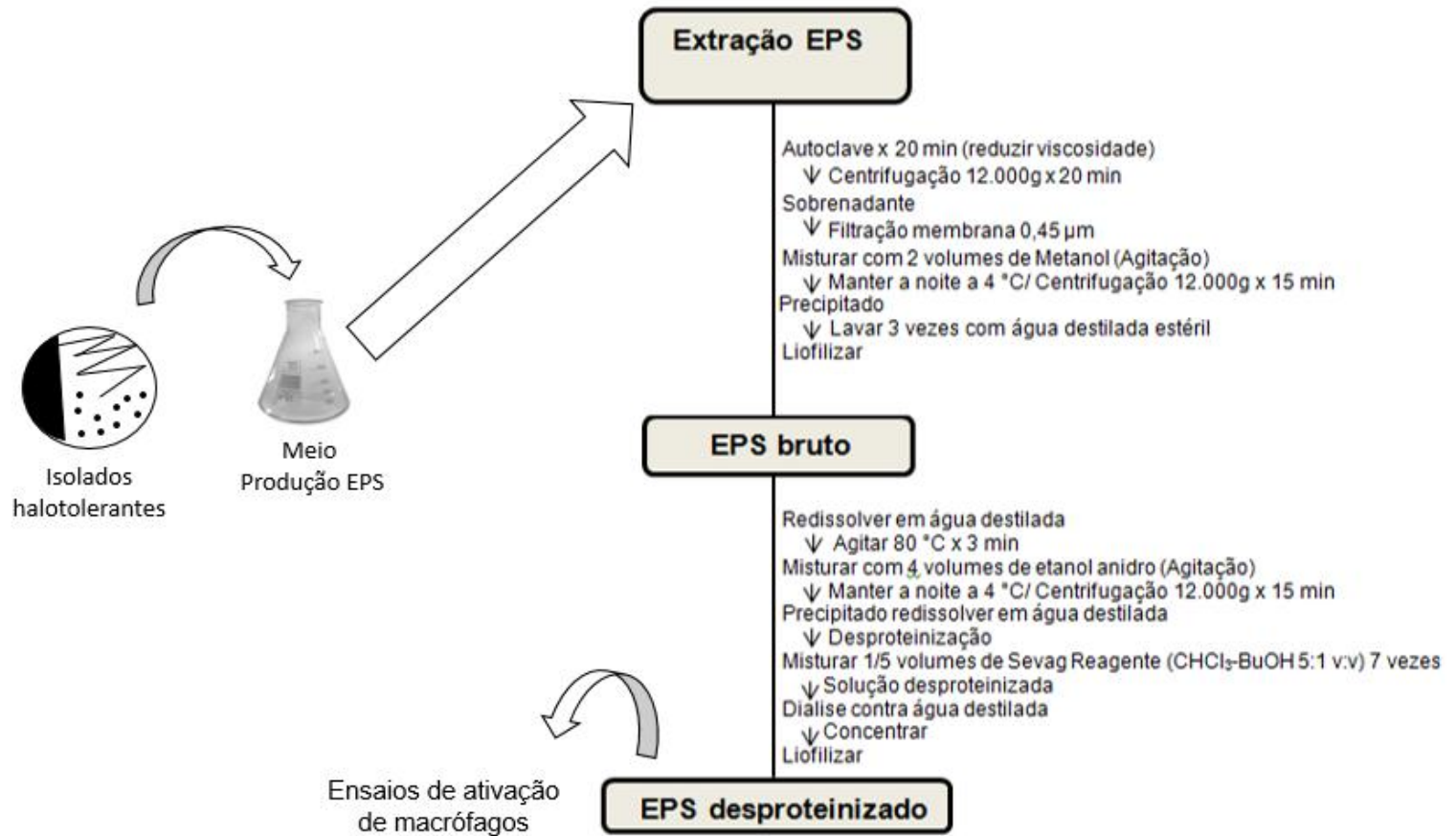

Figura 11 - Fluxograma esquemático dos procedimentos realizados para produção e extração de EPS segundo o método de LIANG et al. (2015) a partir dos isolados halotolerantes previamente selecionados

A partir dos isolados selecionados, realizaram-se culturas para produção de EPS em pequeno volume $(10 \mathrm{~mL})$ em meio líquido de produção de EPS (KAVAMURA et al., 2013b), por quatro dias, com agitação a $180 \mathrm{rpm}$ e a $30^{\circ} \mathrm{C}$.

Após este período, a extração dos EPS foi realizada segundo a metodologia descrita por (LIANG et al., 2015). Cada cultura foi autoclavada a $121{ }^{\circ} \mathrm{C}$ durante 20 minutos para reduzir a viscosidade, e centrifugadas a $10.000 \mathrm{rpm}$ por 20 minutos a $4{ }^{\circ} \mathrm{C}$ para remoção da biomassa. Em seguida, os sobrenadantes foram filtrados com ajuda de uma membrana de 1,2 $\mu \mathrm{m}$ e vácuo. Os filtrados foram misturados com dois volumes de metanol $(\mathrm{MeOH})$ e agitados vigorosamente para serem mantidos durante a noite a $4^{\circ} \mathrm{C}$. Após extração, os extratos em MeOH foram centrifugados a 10.000 rpm por 15 minutos para recuperação dos precipitados. Posteriormente, os precipitados foram lavados três vezes com água destilada estéril e liofilizados para obtenção do extrato denominado EPS bruto. 
Após obtenção do EPS bruto, o material foi dissolvido em água destilada e agitado por três minutos a $80^{\circ} \mathrm{C}$. Em seguida, o EPS bruto foi misturado em quatro volumes de etanol $(\mathrm{EtOH})$ e agitado vigorosamente para ser mantido durante a noite a 4 ${ }^{\circ} \mathrm{C}$. Após extração, os extratos em EtOH foram centrifugados a 10.000 rpm por 15 minutos para recuperação dos precipitados. Posteriormente, os precipitados foram dissolvidos em água destilada e desproteinizados em $1 / 5$ volumes de Sevag Reagent $\left(\mathrm{CHCl}_{3}-\mathrm{BuOH}, \mathrm{v} / \mathrm{v}\right.$ $=5 / 1$ ) sete vezes. Cada solução desproteinizada foi dialisada contra água destilada, concentrada em evaporador rotativo Concentrator plus (Eppendorf, Hamburg, Alemanha) a pressão reduzida $\left(45^{\circ} \mathrm{C}\right)$ para aproximadamente $5 \mathrm{ml}$ de uma suspensão aquosa e liofilizadas para obtenção do denominado EPS desproteinizado.

Finalmente, os EPS desproteinizados foram armazenados a $4{ }^{\circ} \mathrm{C}$ para serem avaliados em ensaios de atividade imunoestimulatória.

\subsubsection{Estudo da atividade imunoestimulatória dos EPS}

As análises da atividade imunoestimulatória foram realizadas pelo Laboratório de Bioprospecção e Biotecnologia Marinha, situado no Núcleo de Pesquisa e Desenvolvimento de Medicamentos da Universidade Federal do Ceará, utilizando a seguinte metodologia:

\subsubsection{Avaliação da ativação de macrófagos e Teste do Griess}

Para avaliar a ativação de macrófagos tratados com EPS de bactérias da caatinga, foram usados macrófagos murinos (RAW 264.7) e o teste da reação de Griess.

O reagente de Griess foi preparado imediatamente antes do uso pela mistura 1:1 das soluções preparadas em ácido acético $60 \%$ (v/v) contendo N-(1-Naftil)-etilenodiamina $0,1 \%(\mathrm{p} / \mathrm{v})$ e sulfonamida $1 \%(\mathrm{p} / \mathrm{v})$ em ácido acético $30 \%$, protocolo adaptado do estudo de Green et al. (1981). Em uma placa de 96 poços foram colocados $50 \mu \mathrm{L}$ do sobrenadante dos macrófagos incubados com EPS bacterianos (1, 10 e $100 \mu \mathrm{g} / \mathrm{ml}$ ), LPS (C+) ou sem tratamento (meio de cultura, C-) e em seguida adicionou-se em cada poço mais $50 \mu \mathrm{L}$ de reagente de Griess. Após 48 horas de incubação a temperatura ambiente 
no escuro, a absorbância foi medida em $560 \mathrm{~nm}$ e comparada com uma curva padrão de $\mathrm{NaNO}_{2}$.

\subsubsection{Teste de viabilidade celular}

Para avaliar a viabilidade celular de três linhagens celulares, HCT-116 (câncer de cólon), B16-F10 (melanoma murino) e RAW 264.7 (macrófagos murinos) tratadas com EPS bacterianos, foi utilizado o teste do MTT. As células foram tratadas após 24 horas de plaqueamento e a viabilidade mensurada após 48 horas de tratamento.

\subsubsection{Curva padrão de ácido hialurônico}

A curva padrão foi realizada segundo a metodologia descrita por Yu et al. (2008), com as seguintes modificações: a partir da solução padrão de ácido hialurônico ( $1 \mathrm{~g} / \mathrm{L})$, realizaram-se diluições para obter concentrações de 50, 100, 200, 300 e 500 mg/L de $\mathrm{AH}$. Seguidamente, em micro tubos de $1,5 \mathrm{~mL}$, contendo $550 \mu \mathrm{L}$ de solução de ácido acético $3 \%$, foram adicionados $400 \mu \mathrm{l}$ de solução de $\mathrm{AH}$ nas concentrações preparadas anteriormente. Foram adicionados $50 \mu \mathrm{L}$ da solução Alcian Blue 8GX, os tubos foram agitados em vortex e aquecidos por 30 segundos em micro-ondas. As amostras foram resfriadas em temperatura ambiente por 2,5 horas e então centrifugadas a $10.000 \mathrm{rpm}$ por dois minutos. Finalmente, mediou-se a absorbância das amostras à $540 \mathrm{~nm}$ no espectrofotômetro modelo Scanning Double Beam 1.8nm 115VAC (Cole-Parmer, Illinois, USA). O experimento foi realizado em triplicata.

\subsubsection{Ensaio de produção e quantificação de $A H$}

Para avaliar a produção de $\mathrm{AH}$, realizaram-se culturas dos 26 isolados em pequeno volume $(10 \mathrm{~mL})$ em meio liquido de produção descrito por $\mathrm{YU}$ et al (2008), por sete dias, a $180 \mathrm{rpm}$ e a $30^{\circ} \mathrm{C}$. Do mesmo modo, realizou-se a cultura da linhagem produtora de ácido hialurônico Streptococcus equi Farrow and Callins subsp. zooepidemicus ATCC 39920. 
Após este período, realizou-se a quantificação de ácido hialurônico segundo a metodologia descrita por Yu et al. (2008) com as seguintes modificações: em micro tubos de $1,5 \mathrm{~mL}$, contendo $550 \mu \mathrm{L}$ de solução de ácido acético $3 \%$, foram adicionados $400 \mu \mathrm{L}$ de cada cultura bacteriana. Em seguida, foram adicionados $50 \mu \mathrm{L}$ da solução Alcian Blue $8 \mathrm{GX}$, os tubos foram agitados em vortex e aquecidos por 30 segundos em micro-ondas. As amostras foram resfriadas em temperatura ambiente por 2,5 horas e então centrifugadas a $10.000 \mathrm{rpm}$ por dois minutos. Posteriormente, mediu-se a absorbância dos sobrenadantes a $540 \mathrm{~nm}$ no leitor de placas Synergy H1 microplate reader (Biotek Instruments, Inc., Winooski, USA). Finalmente, a partir da equação obtida na curva padrão (numeral 4.6.3.2) (apêndice B), encontraram-se as concentrações de ácido hialurônico produzidas pelos isolados. A quantifição foi realizada em triplicata. 


\section{RESULTADOS E DISCUSSÃO}

A partir dos isolados recuperados do biobanco do Laboratório de Microbiologia Ambiental da Embrapa, 26 bactérias halotolerantes foram identificadas em nível de gênero com base na análise da sequência do gene RNAr 16S (Tabela 7), revelando que os isolados pertencem aos filos Firmicutes, Actinobacteria e Proteobacteria.

A maior parte dos isolados foi bactérias Gram-positivas atribuídas às famílias Bacillaceae, Staphylococcaceae e Microbacteriaceae, e uma bactéria Incertae Sedis do filo firmicutes, afiliadas aos gêneros Bacillus (18 cepas), Staphylococcus (duas cepas), Curtobacterium (quatro cepas) e Exiguobacterium (uma cepa). Apenas um isolado Gramnegativo foi atribuído como membro da família Pseudomonadaceae, incluso no gênero Pseudomonas. 


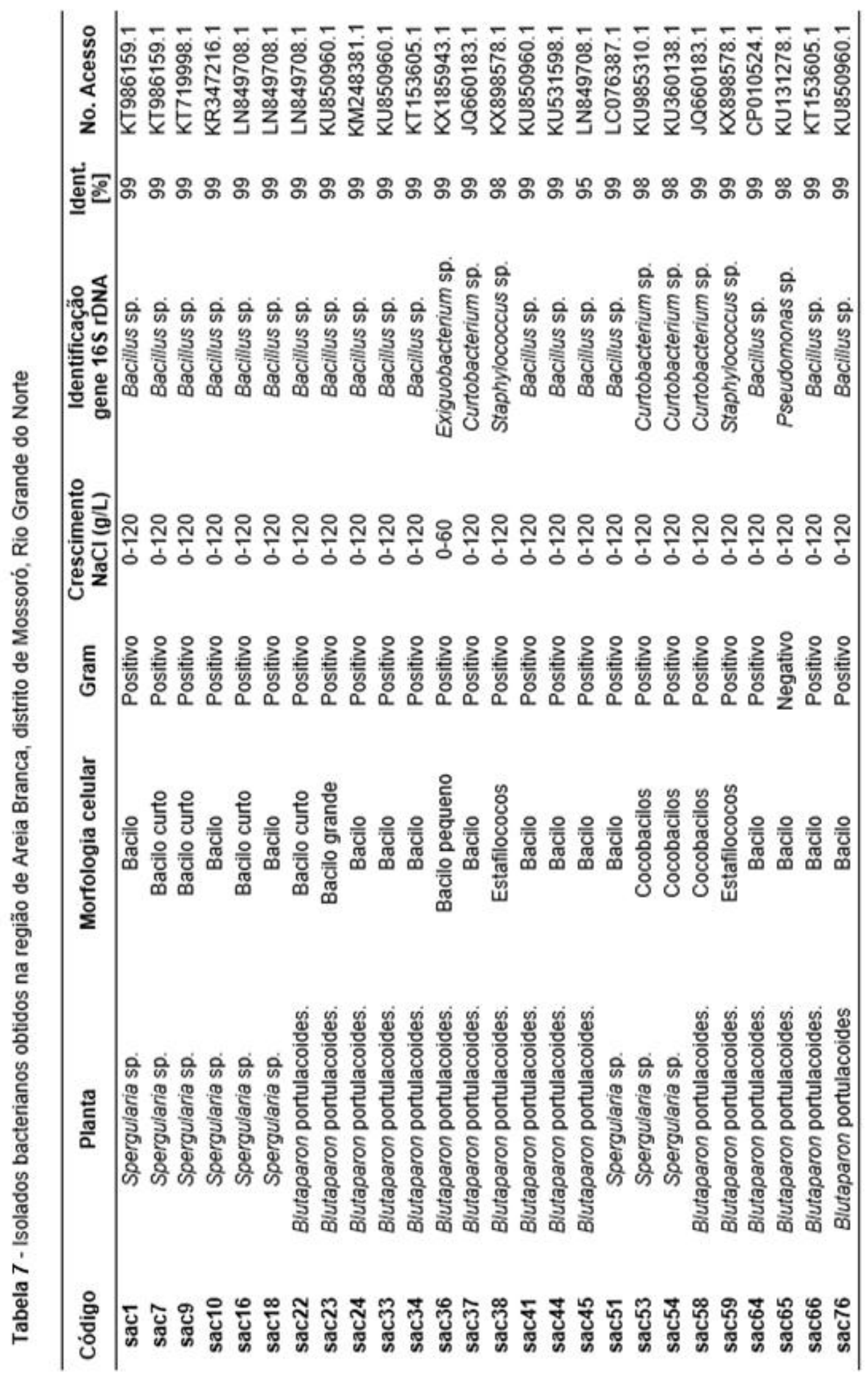


O gênero Bacillus foi o mais frequente no estudo, constituindo $69 \%$ dos isolados identificados (Figura 12), porém várias cepas são similares à mesma espécie (Figura 13). Segundo a análise filogenética os isolados sac1, sac7, sac9, sac16, sac18, sac22, sac44, sac45, sac51 e sac64 são próximos à espécie $B$. paralicheniformis, enquanto que os isolados sac23, sac33, sac34, sac41, sac66 e sac76 são próximos à espécie $B$. endophyticus. No caso dos isolados sac10 e sac24, eles são próximos às espécies $B$. seohaeanensis e $B$. thuringiensis, respectivamente. Observa-se também na árvore que alguns valores de Bootstrap foram baixos.

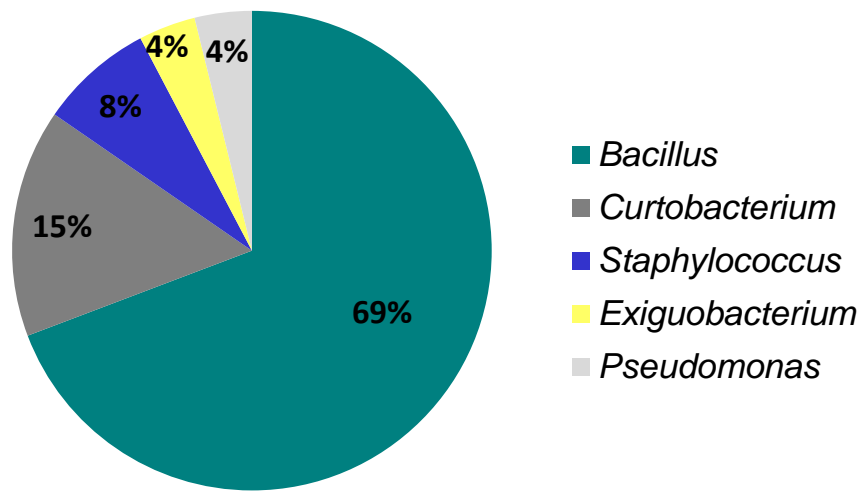

Figura 12 - O gráfico representa a abundância de gêneros bacterianos a partir de amostras de solo rizosférico da caatinga

Vale a pena mencionar que este gênero, que consiste em pelo menos 300 espécies (MANDIC-MULEC; STEFANIC; ELSAS, 2015; ZHU et al., 2016), é atualmente o maior dentro da família Bacillaceae que compreende pelo menos 62 gêneros bacterianos (GENBANK, 2015).

$\mathrm{Na}$ literatura, tem sido amplamente relatado que o gênero Bacillus é bastante frequente em ambientes hostis, como são os solos semiáridos da caatinga (DIAS et al., 2009; NESSNER KAVAMURA et al., 2013; POWELL et al., 2015; SOARES et al., 2012), pela capacidade que tem estes microrganismos de formar endósporos, característica que torna este tipo de bactérias resistentes a condições desfavoráveis como o calor, alta radiação, estresse hídrico, baixa disponibilidade de nutrientes, compostos químicos, 
entre outros, durante períodos prolongados de tempo. (KAVAMURA et al., 2013b; MARRONI, 2014; ZHAO et al., 2014).

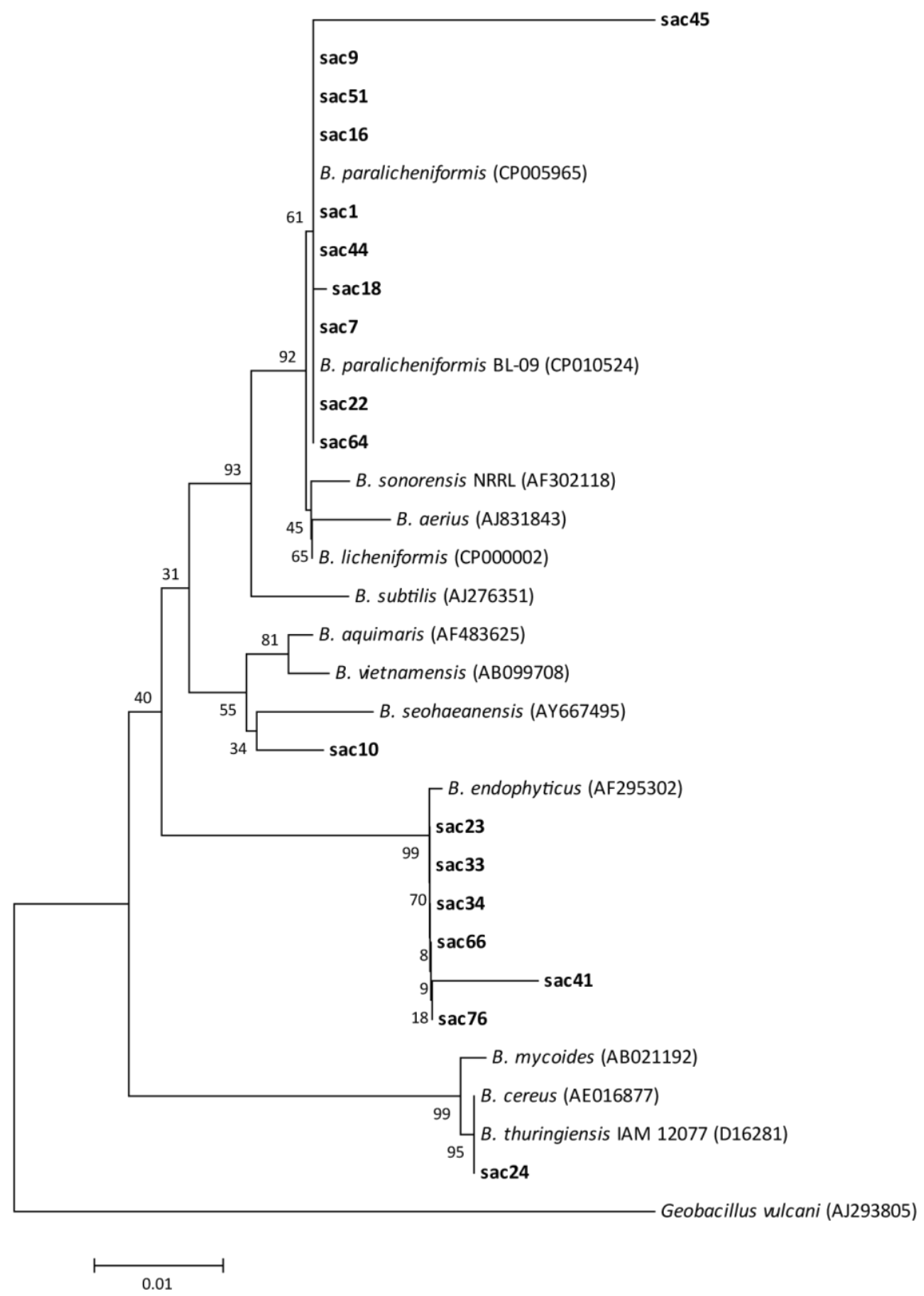

Figura 13 - Árvore filogenética baseada na sequência parcial do gene 16S rDNA, construída usando o método Neighbour-joining, indicando a posição dos isolados sac1, sac7, sac9, sac10, sac16, sac18, sac22, sac23, sac24, sac33, sac34, sac41, sac44, sac45, sac51, sac64, sac66 e sac76 entre os membros relatados do gênero Bacillus. Organismos de referência estão incluídos e os números de acesso das sequências Genbank são apresentados entre parênteses. Geobacillus vulcani foi usado como grupo externo na árvore. Valores de Bootstrap, expresso como percentagem de 1000 repetições, são dados nos nodos. Barra de escala, uma substituição por 100 nucleotídeos 
Por outro lado, os isolados sac37, sac53, sac54 e sac58 foram identificados como actinobactérias do gênero Curtobacterium. A análise filogenética mostrou que os quatro isolados da caatinga são próximos entre eles, porém são distantes das espécies usadas como referência apresentadas na figura 14.

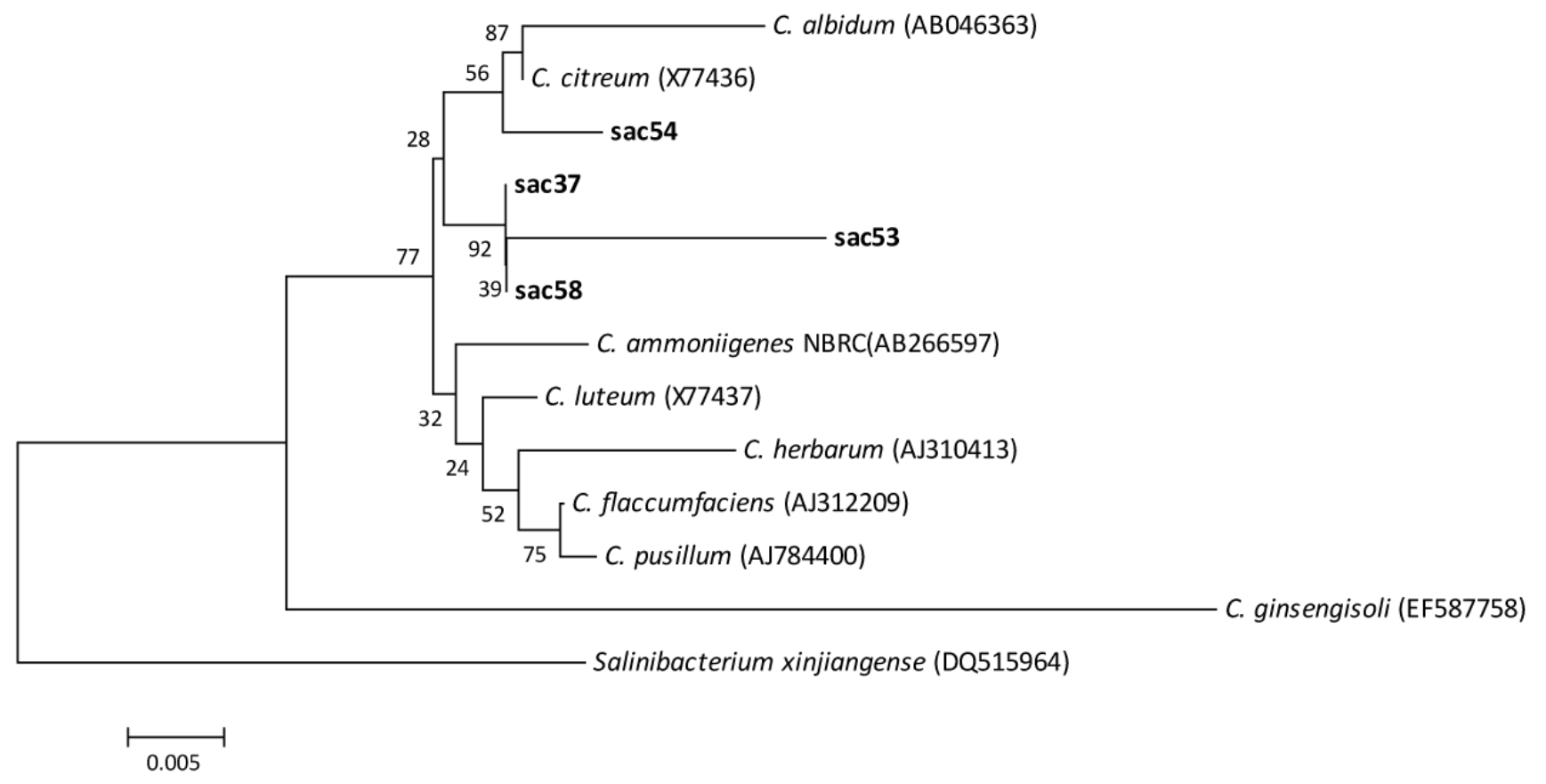

Figura 14 - Árvore filogenética baseada na sequência parcial do gene 16S rDNA, construída usando o método Neighbour-joining, indicando a posição dos isolados sac37, sac53, sac54 e sac58 entre os membros relatados do gênero Curtobacterium. Organismos de referência estão incluídos e os números de acesso das sequências Genbank são apresentados entre parênteses. Salinibacterium xinjiangense foi usado como grupo externo na árvore. Valores de Bootstrap, expresso como percentagem de 1000 repetições, são dados nos nodos. Barra de escala, uma substituição por 50 nucleotídeos

O gênero Curtobacterium foi definido por Yamada \& Komagata (1972) para classificar seis espécies; $C$. albidum, $C$. citreum, $C$. luteum, $C$. pusillum, $C$. saperdae e $C$. testaceum, e posteriormente outras quatro espécies foram adicionadas ao gênero: $C$. flaccumfaciens, C. plantarum, C. herbarum e C. ammoniigenes (KIM et al., 2008a). Algumas dessas actinobactérias têm sido isoladas de ecossistemas de deserto (BHATNAGAR; BHATNAGAR, 2005), de rochas de regiões áridas extremas (KUHLMAN et al., 2005) e de planícies de sal (CARDINALE et al., 2015), o que coincide com ás condições adversas dos locais escolhidos na caatinga para a coleta das amostras. Além 
disso, na literatura encontra-se este gênero associado a diversos cultivos agronômicos, sendo descritas como bactérias endófitas de trevo vermelho (Trifolium pratense), batata, morango (Fragaria spp.) e Eucalyptus spp. (DE LOS SANTOS et al., 2015), entretanto, são microrganismos pouco estudados.

Do mesmo modo, outra bactéria identificada em nível de gênero sendo representada por apenas um isolado pertence ao filo Firmicutes, gênero Exiguobacterium. $\mathrm{Na}$ árvore filogenética observa-se que o isolado sac36 é próximo da espécie E. aestuarii, dado que foram agrupadas no mesmo cluster (Figura 15).

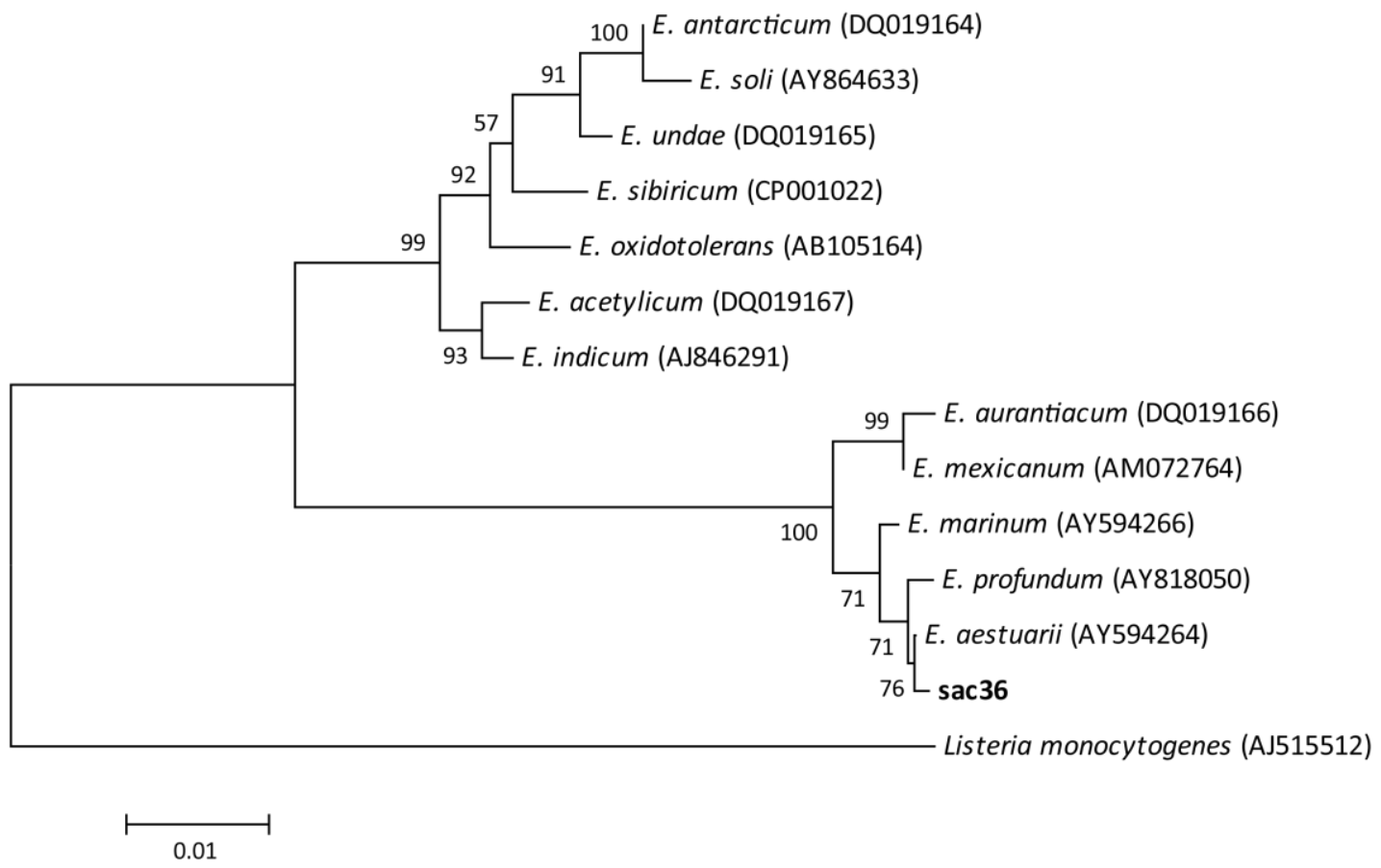

Figura 15 - Árvore filogenética baseada na sequência parcial do gene 16S rDNA, construída usando o método Neighbour-joining, indicando a posição do isolado sac36 entre os membros relatados do gênero Exiguobacterium. Organismos de referência estão incluídos e os números de acesso das sequências Genbank são apresentados entre parênteses. Listeria monocytogenes foi usado como grupo externo na árvore. Valores de Bootstrap, expresso como percentagem de 1000 repetições, são dados nos nodos. Barra de escala, uma substituição por 100 nucleotídeos

As bactérias do gênero Exiguobacterium têm baixo conteúdo de $\mathrm{G}+\mathrm{C} \%$, são gram-positivas, anaeróbias facultativas e caracterizam-se pela alta diversidade morfológica e geográfica (CHAUHAN et al., 2015). Em consequência, esses microrganismos têm sido isolados a partir de diversas fontes na natureza, mas nota-se 
que os relatos são principalmente de ambientes extremos que incluem o pergelissolo (em inglês, permafrost) siberiano, gelo da Groenlândia, ambientes frios dos Himalaias ocidentais, nascentes de água quente do Yellowstone National Park, fontes hidrotermais profundas, lagos andinos com condições físicas semelhantes às marcianas, ambientes hipersalinos em Kuwait (AL-MAILEM et al., 2014; CABRIA et al., 2014; CHAUHAN et al., 2015; ORDOÑEZ et al., 2009; VISHNIVETSKAYA; KATHARIOU; TIEDJE, 2009) e no caso do presente estudo, de locais semiáridos da caatinga.

Adicionalmente, foram identificadas duas bactérias do gênero Staphylococcus, isolados sac38 e sac59, e a partir da análise filogenética, observou-se que os isolados são próximos à espécie S.warneri (Figura 16).

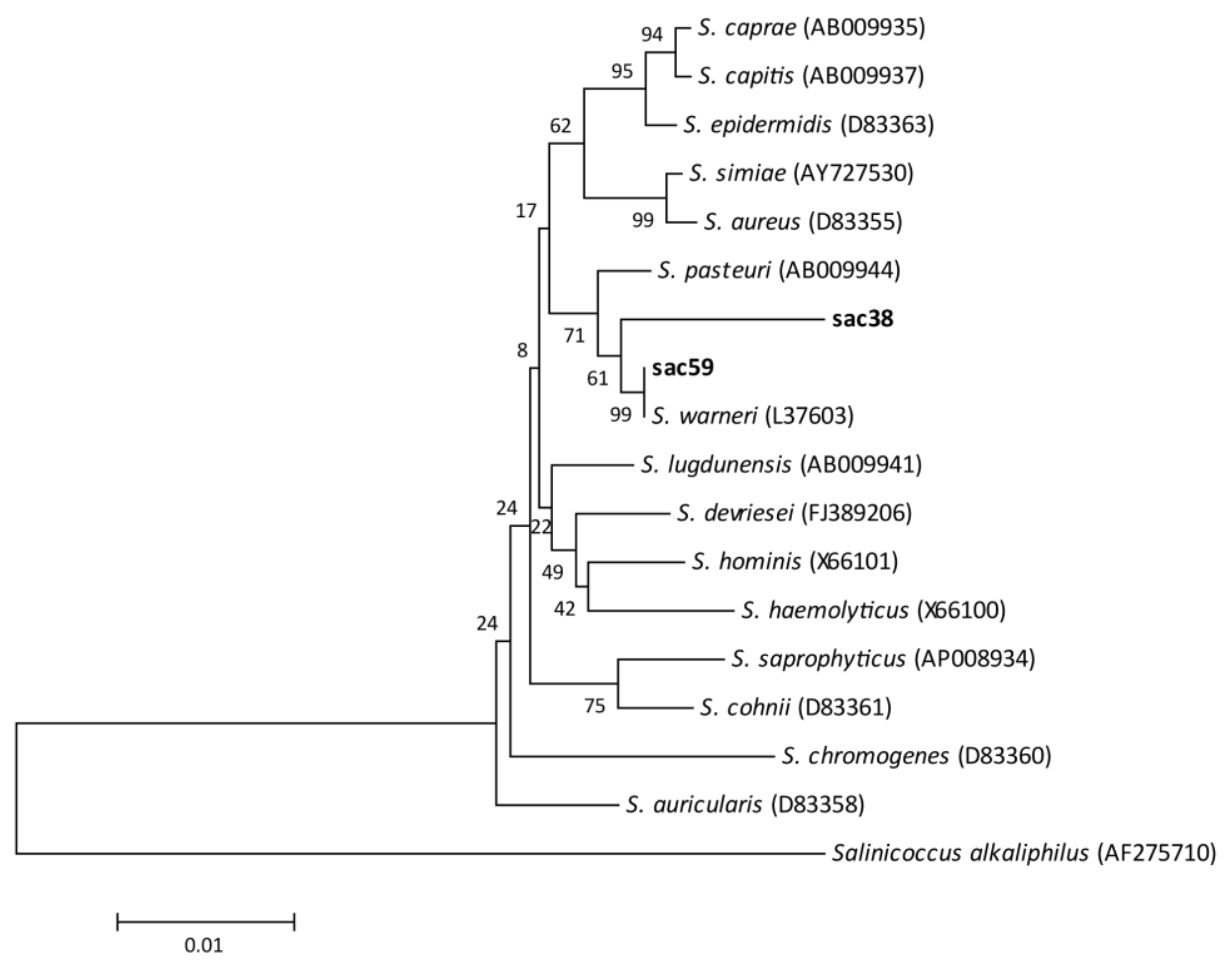

Figura 16 - Árvore filogenética baseada na sequência parcial do gene 16S rDNA, construída usando o método Neighbour-joining, indicando a posição dos isolados sac38 e sac59 entre os membros relatados do gênero Staphylococcus. Organismos de referência estão incluídos e os números de acesso das sequências Genbank são apresentados entre parênteses. Salinicoccus alkaliphilus foi usado como grupo externo na árvore. Valores de Bootstrap, expresso como percentagem de 1000 repetições, são dados nos nodos. Barra de escala, uma substituição por 100 nucleotídeos 
O gênero Staphylococcus também pertence ao filo Firmicutes e compreende 58 espécies descritas, incluindo 28 subespécies de acordo com a List of Prokaryotic Names with Standing in Nomenclature. São bactérias gram-positivas, catalase positivo e apenas algumas espécies de importância clínica são coagulase positiva, como é o caso das espécies $S$. aureus, S. intermedius, S. delphini, S. schleiferi subsp. coagulans, e algumas cepas de $S$. hyicus.

Além disso, os estafilococos são amplamente difundidos em vários nichos, tais como ambientes hospitalares, plantas alimentícias (DRANCOURT; RAOULT, 2002; GIAMMARINARO et al., 2005), e também têm sido isolados de ambientes hipersalinos como lagos de sal na Tunísia e Roménia (DAOUD et al., 2013; MÁTHÉ et al., 2014), de minas de sal como mostraram estudos feitos na região de Karak no Paquistão $(\mathrm{ROOHI}$ et al., 2014), e do mesmo modo, no nosso trabalho, de locais salinos da caatinga.

Por outro lado, embora o gênero seja conhecido pela associação a doenças em seres humanos ou animais, diferentes cepas isoladas de ambientes naturais podem ser usadas para estudos biotecnológicos e produção de substâncias de interesse industrial, por exemplo, como foi descrito no estudo realizado por Eddouaouda et al. (2012), a cepa Staphylococcus sp. 1E é capaz de excretar um biossurfactante com propriedades tensoativas interessantes. Finalmente, o último isolado identificado pertence ao gênero Pseudomonas. A análise filogenética mostrou que o isolado sac65 é próximo à espécie P. alcaliphila como observa-se na figura 17. 


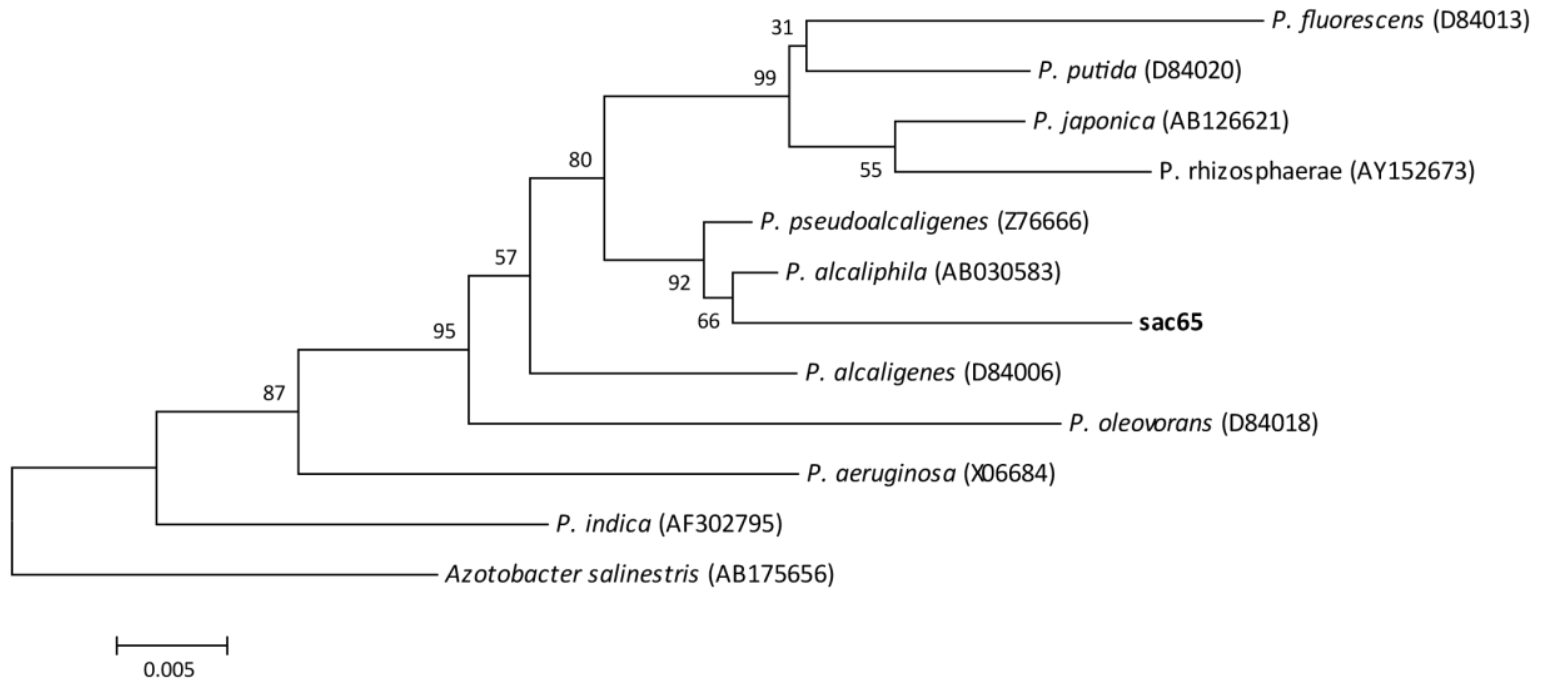

Figura 17 - Árvore filogenética baseada na sequência parcial do gene 16S rDNA, construída usando o método Neighbour-joining, indicando a posição do isolado sac65 entre os membros relatados do gênero Pseudomonas. Organismos de referência estão incluídos e os números de acesso das sequências Genbank são apresentados entre parênteses. Azotobacter salinestris foi usado como grupo externo na árvore. Valores de Bootstrap, expresso como percentagem de 1000 repetições, são dados nos nodos. Barra de escala, uma substituição por 50 nucleotídeos

Pseudomonas pertence ao filo Proteobacteria e é um gênero de bactérias gramnegativas, não fermentativas que foi descrito em 1894. Constate-se que é um dos microrganismos mais diversos e ubíquos em todo o mundo, cujas espécies foram isoladas de diferentes tipos de ambientes; na Antártida, nos trópicos, presente em sedimentos, amostras clínicas, plantas e rizosfera, água, solo, mar e desertos (ISNANSETYO; KAMEI, 2009; PEIX; RAMÍREZ-BAHENA; VELÁZQUEZ, 2009). Em particular, para o interesse deste estudo, encontra-se descrito em vários estudos realizados em ambientes semiáridos ou desérticos, que bactérias do gênero Pseudomonas são uma das mais frequentes ou dominantes nessas condições extremas (EL-DEEB; FAYEZ; GHERBAWY, 2012; GOUDARZI et al., 2014; KAPLAN et al., 2013; LIU et al., 2008; PEIX; RAMÍREZ-BAHENA; VELÁZQUEZ, 2009).

Como foi apresentado anteriormente, todos os isolados foram identificados em nível de gênero baseado apenas na sequência parcial do gene 16S rDNA. Uma análise mais detalhada, como por exemplo, a Multi-Locus Sequence Analysis (MLSA), é necessária para a atribuição da espécie de cada bactéria isolada no estudo. 


\subsection{Crescimento em diferentes concentrações de $\mathrm{NaCl}$}

Os 26 isolados foram cultivados em meio TSB suplementado com quatro concentrações diferentes de $\mathrm{NaCl}$ para avaliar a tolerância ao sal das bactérias. Assim, observou-se que todos os isolados são halotolerantes, já que apresentaram a capacidade de crescer em faixas de salinidade que vão desde 5 a $120 \mathrm{~g} / \mathrm{L}$ de $\mathrm{NaCl}$ (APÊNDICE A), contudo os isolados não precisam do sal para se desenvolver. Certamente, os microrganismos halotolerantes podem crescer em ausência como em presença do sal, enquanto os microrganismos halófilos requerem sal para serem viáveis (OREN, 2008). Especificamente, todos os isolados cresceram em 5, 35, e $60 \mathrm{~g} / \mathrm{L}$ de $\mathrm{NaCl}$ e apenas um isolado, pertencente ao gênero Exiguobacterium, não cresceu em 120 g/L (Figura 18).

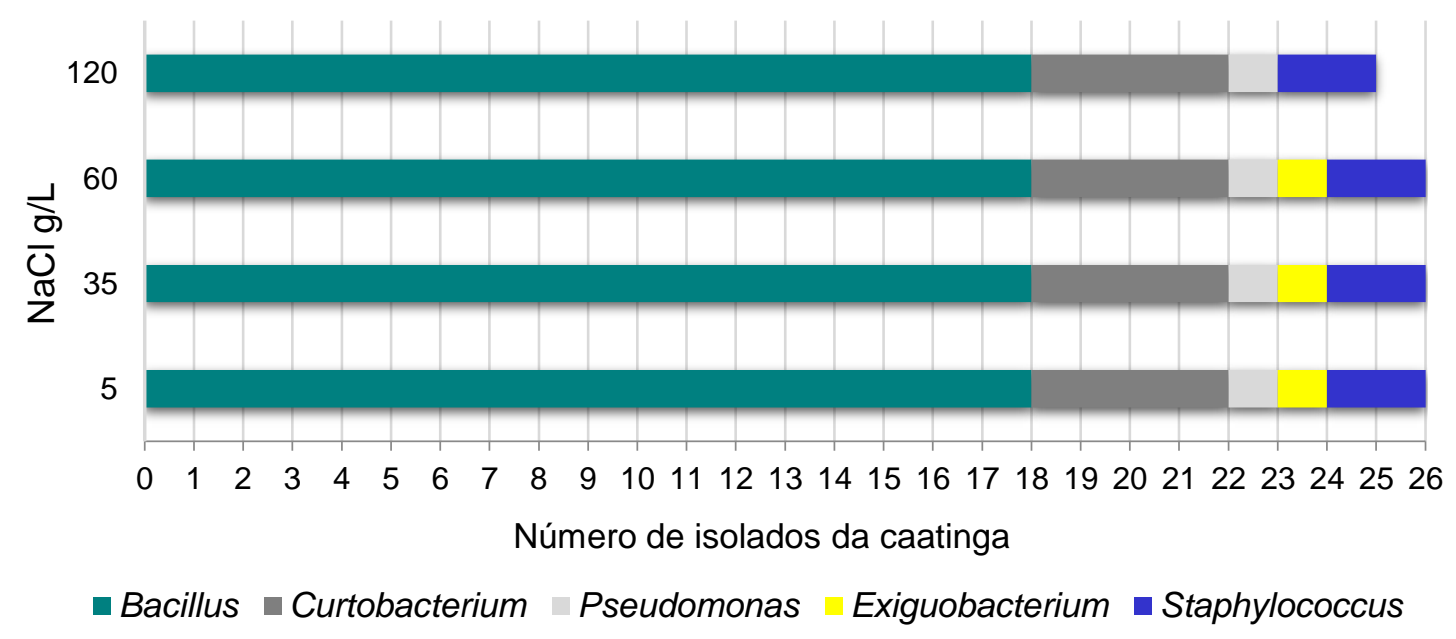

Figura 18 - Crescimento dos isolados em diferentes concentrações de $\mathrm{NaCl}$

Várias espécies do género Bacillus têm sido isoladas a partir de diversos tipos de ambientes salinos (ZHU et al., 2016). Em 2008 Ventosa e colaboradores compararam 18 espécies reconhecidas do gênero Bacillus que cabem nas categorias de halófilos moderados ou halotolerantes. Entre essas espécies encontram-se $B$. patagoniensis, $B$. oshimensis, B. taeanensis, B. isabeliae, B. aurantiacus, B. aidingensis, B. pumilus, $B$. subtilis, B. cereus e B. licheniformis (VENTOSA et al., 2008).

Geralmente, essas espécies são aeróbias ou anaeróbias facultativas, formadoras de endósporos e alcalófilas (ZHU et al., 2016). Do mesmo modo, vários autores 
mostraram que as diferentes cepas do gênero Bacillus crescem em faixas de 20-200 g/L de $\mathrm{NaCl}$ (VENTOSA et al., 2008), faixa de salinidade semelhante à que foi avaliada no presente estudo e que também permitiu evidenciar o crescimento de todos os isolados do gênero Bacillus nas concentrações de 5, 35, 60 e $120 \mathrm{~g} / \mathrm{L}$ de NaCl (Figura 18).

Os isolados do gênero Curtobacterium também cresceram nas quatro concentrações de sal. Ainda assim, não se encontram dados na literatura desse gênero classificando-o como microrganismo halotolerante ou halófilo. Entretanto Cardinale et al. (2015) descreve-ram uma cepa promotora do crescimento vegetal identificada como Curtobacterium que aumentou significativamente a resistência de plantas de cevada ao estresse salino. Contudo, neste trabalho descrevem-se quatro bactérias halotolerantes do gênero Curtobacterium que podem crescer em $120 \mathrm{~g} / \mathrm{L}$ de $\mathrm{NaCl}$.

Igualmente, os isolados do gênero Pseudomonas e Staphylococcus cresceram nas quatro concentrações de $\mathrm{NaCl}$ avaliadas, resultado esperado já que esse grupo de bactérias encontra-se amplamente relatado como microrganismos halotolerantes presentes em plantas, solos, lagos, desertos salinos, entre outros. Assim, na literatura descreve-se que essas bactérias crescem em concentrações de 20-300 g/L de NaCl (ALMAILEM et al., 2014; DAOUD et al., 2013; ISNANSETYO; KAMEI, 2009; MÁTHÉ et al., 2014; ORDOÑEZ et al., 2009; ROOHI et al., 2014), o que evidencia a grande capacidade de tolerância ao sal por parte desses microrganismos.

Contrariamente aos outros isolados, a bactéria pertencente ao gênero Exiguobacterium não cresceu em $120 \mathrm{~g} / \mathrm{L}$ de $\mathrm{NaCl}$, porém, cresceu em 35 e $60 \mathrm{~g} / \mathrm{L}$ de $\mathrm{NaCl}$, concentrações também consideradas altas. Exiguobacterium encontra-se extensamente descrita na literatura como bactéria halotolerante presente em solos, plantas, desertos salinos, fontes hidrotermais e lagos de sal (AL-MAILEM et al., 2014; CABRIA et al., 2014; ORDOÑEZ et al., 2009; VISHNIVETSKAYA; KATHARIOU; TIEDJE, 2009; YUMOTO et al., 2004), e note-se que vários estudos relatam que algumas espécies desse gênero são bactérias promotoras do crescimento vegetal em condições de estresse salino para as plantas (BHARTI et al., 2013; CHAUHAN et al., 2015). 
Além disso, cabe ressaltar que evidenciou-se um comportamento interessante nas curvas de crescimento de alguns isolados dos gêneros Bacillus e Curtobacterium nas diferentes concentrações avaliadas (Figura 19).
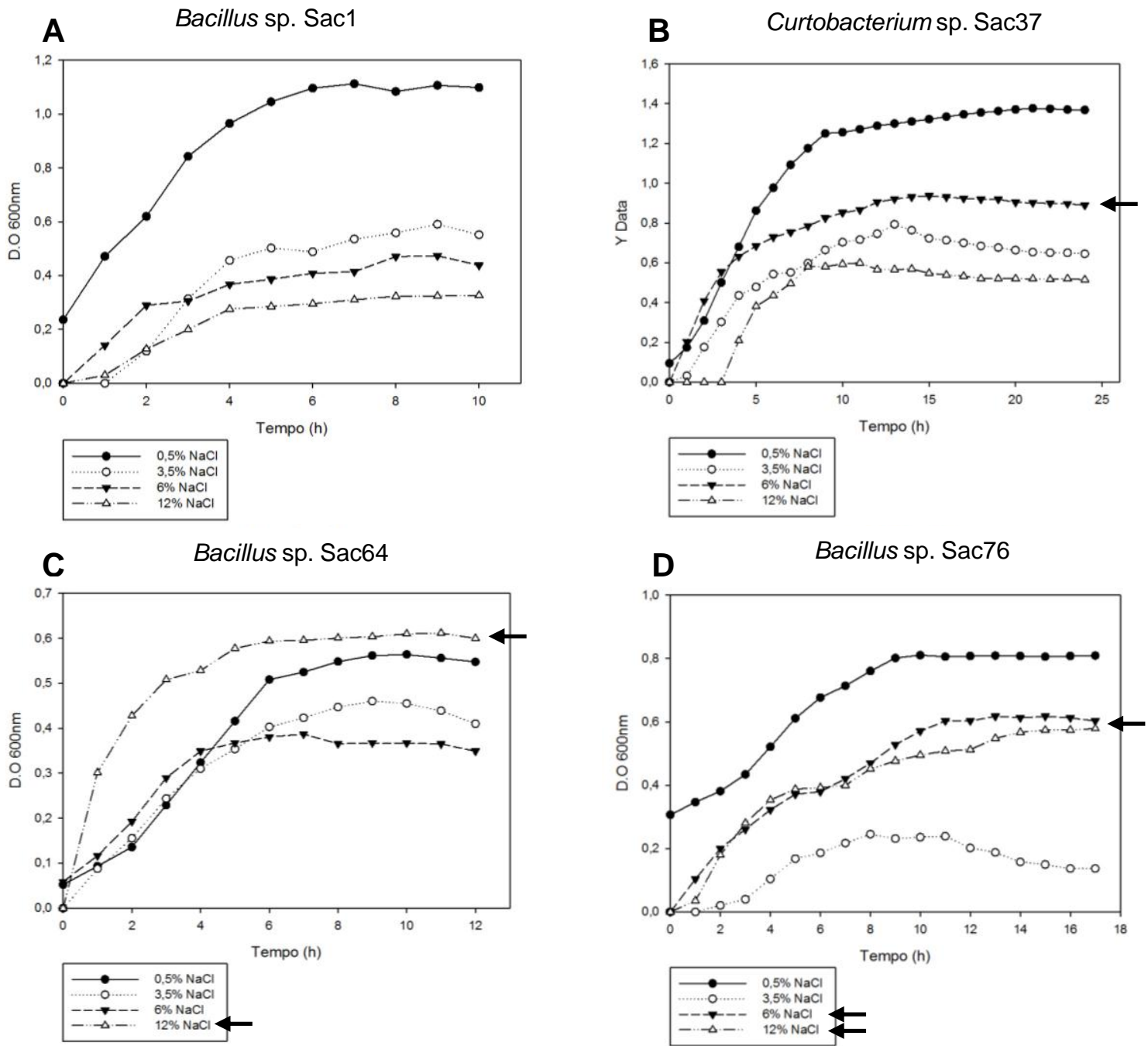

Figura 19 - Curvas de crescimento de quatro isolados halotolerantes da caatinga em meio TSB suplementado com quatro diferentes concentrações de $\mathrm{NaCl}(5,35,60$ e $120 \mathrm{~g} / \mathrm{L})$. A, isolado sac1 (gênero Bacillus), B, isolado sac37 (gênero Curtobacterium), C, isolado sac64 (gênero Bacillus) e D, isolado sac76 (gênero Bacillus). As setas indicam um comportamento não esperado no crescimento das bactérias

Para começar, na figura 18A observa-se o crescimento esperado nas condições avaliadas pelo isolado Bacillus sp. sac1, ou seja, a maior concentração de $\mathrm{NaCl}$ menor D.O. obtida. No entanto, o oposto foi observado na figura $18 \mathrm{C}$, onde o isolado Bacillus 
sp. sac64 mostrou maior D.O. na concentração $120 \mathrm{~g} / \mathrm{L}$ de $\mathrm{NaCl}$, o que poderia indicar que o crescimento óptimo da bactéria encontra-se em concentrações altas de sal. Porém, esse resultado não concorda com a definição de microrganismo halotolerante que relatam Ventosa e Arahal (2011), onde os autores descrevem que o crescimento óptimo desses microrganismos ocorre abaixo de $10 \mathrm{~g} / \mathrm{L}$ de sal (VENTOSA; ARAHAL, 2011).

Por outro lado, no caso dos isolados Curtobacterium sp. sac37 e Bacillus sp. sac76, figura 18B e $D$, nota-se que embora apresentaram maior crescimento na menor concentração de $\mathrm{NaCl}$ avaliada, nas concentrações 60 e $120 \mathrm{~g} / \mathrm{L}$ de $\mathrm{NaCl}$ observou-se maior D.O. em comparação com o crescimento das mesmas em $35 \mathrm{~g} / \mathrm{L}$ de $\mathrm{NaCl}$.

Graças à grande capacidade que possuem os microrganismos halotolerantes de tolerar diferentes concentrações de sal, assim como a produção de diversos compostos de interesse industrial como são, por exemplo, os polihidroxialcanoatos (PHA) e os exopolissacarídeos (EPS), biopolímeros de importância que serão descritos posteriormente neste trabalho, convertem-se em candidatos interessantes para continuar sendo estudados e utilizados em diferentes bioprocessos pois apresentam vantagens como economia\}a de energia (fermentação não precisa de esterilização); baseados em água do mar (preservação da água doce); processamento contínuo aberto (contra processos descontínuos); e uso de substratos de baixo custo, características desejáveis para qualquer processo biotecnológico (AL-MAILEM et al., 2014; DE CARVALHO; FERNANDES, 2010; HAMEDI; MOHAMMADIPANAH; VENTOSA, 2013; OREN, 2008, 2010; VENTOSA et al., 2008; VENTOSA; ARAHAL, 2011; YUE et al., 2014).

\subsection{Ensaios de produção de PHA}

Desde a primeira descoberta de produção de PHA na bactéria Bacillus megaterium, sabe-se que existem mais de 300 microrganismos produtores de PHA e mais de 150 monómeros diferentes relatados (HUANG et al., 2016). A continuação, apresentam-se os resultados obtidos na seleção, produção e determinação de PHA por bactérias halotolerantes da caatinga. 


\subsubsection{Seleção, produção e determinação de PHA}

Os resultados relacionados à seleção e produção de PHA pelos diferentes isolados halotolerantes estão apresentados na tabela 8. Primeiramente, 18 isolados dos 26 cresceram no meio mineral contendo glicose. Porém, apenas cinco isolados, sendo todos pertencentes ao gênero Bacillus, foram positivos na triagem realizada com Sudan Black B (Figura 20). 
Tabela 8 - Triagem e produção de PHA por isolados halotolerantes da caatinga a partir de glicose (10 g/L), após 72 horas

\begin{tabular}{|c|c|c|c|c|}
\hline Isolado & Gênero & $\begin{array}{l}\text { Crescimento } \\
\text { em MMG }\end{array}$ & $\begin{array}{c}\text { Screening } \\
\text { Sudan Black B }\end{array}$ & $\begin{array}{c}\text { Confirmação } \\
\text { Cromatógrafo } \\
\text { gasoso }\end{array}$ \\
\hline sac1 & Bacillus sp. & Sim & Não & - \\
\hline sac7 & Bacillus sp. & Sim & Não & - \\
\hline sac9 & Bacillus sp. & Sim & Não & - \\
\hline sac10 & Bacillus sp. & Não & Não & - \\
\hline sac16 & Bacillus sp. & Não & Não & - \\
\hline sac18 & Bacillus sp. & Não & Não & - \\
\hline sac22 & Bacillus sp. & Não & Não & - \\
\hline sac23 & Bacillus sp. & Sim & Sim & + \\
\hline sac24 & Bacillus sp. & Não & Não & - \\
\hline sac33 & Bacillus sp. & Sim & Sim & + \\
\hline sac34 & Bacillus sp. & Sim & Sim & + \\
\hline sac36 & Exiguobacterium sp. & Não & Não & - \\
\hline sac37 & Curtobacterium sp. & Não & Não & - \\
\hline $\operatorname{sac} 38$ & Staphylococcus sp. & Não & Não & - \\
\hline sac41 & Bacillus sp. & Sim & Não & - \\
\hline sac44 & Bacillus sp. & Sim & Não & - \\
\hline sac45 & Bacillus sp. & Sim & Não & - \\
\hline sac51 & Bacillus sp. & Sim & Não & - \\
\hline sac53 & Curtobacterium sp. & Não & Não & - \\
\hline sac54 & Curtobacterium sp. & Sim & Não & - \\
\hline sac58 & Curtobacterium sp. & Não & Não & - \\
\hline sac59 & Staphylococcus sp. & Não & Não & - \\
\hline sac64 & Bacillus sp. & Sim & Sim & - \\
\hline sac65 & Pseudomonas sp. & Sim & Não & - \\
\hline sac66 & Bacillus sp. & Sim & Sim & + \\
\hline sac76 & Bacillus sp. & Sim & Não & - \\
\hline
\end{tabular}

MMG: Meio mineral glicose; (+) isolado produtor de PHA; (-) isolado não produtor de PHA. 

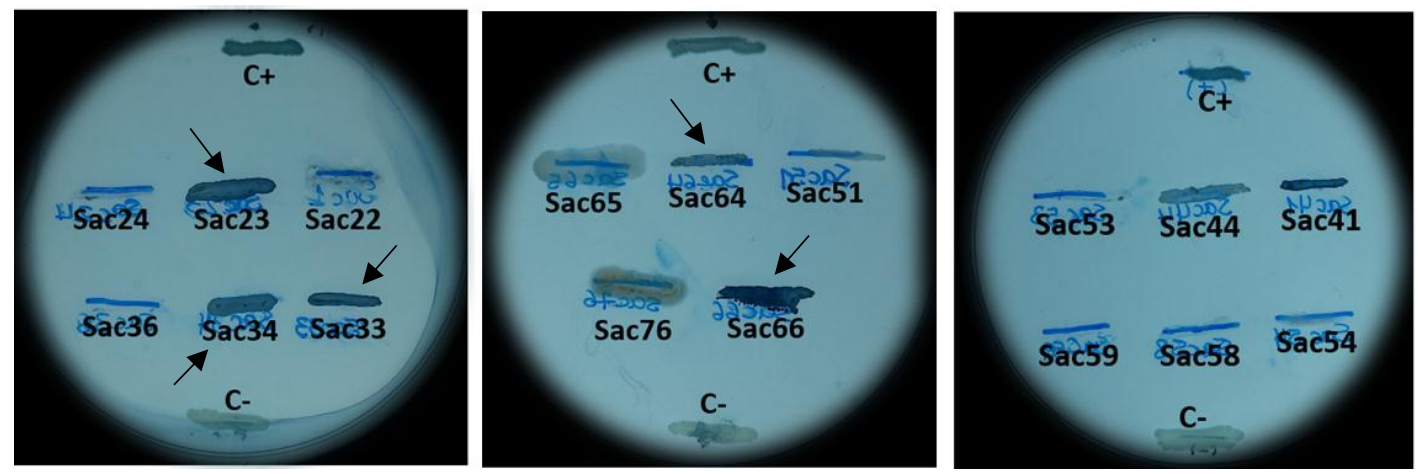

Figura 20 - Triagem qualitativa de produção de PHA com Sudan Black B em placa com meio mineral contendo $10 \mathrm{~g} / \mathrm{L}$ de glicose. Tempo de incubação 72 horas. Controle positivo $\left(\mathrm{C}_{+}\right)$ Pseudomonas sp. LFM 046, controle negativo (C-) Pseudomonas sp. LFM 461. As setas indicam os isolados selecionados como possíveis produtores de $\mathrm{PHA}$

A partir dos isolados selecionados, realizaram-se ensaios de acúmulo de PHA em MMG e caracterização do polímero por cromatografia gasosa. Segundo os cromatogramas obtidos na análise (Figura 21), em quatro dos cinco isolados de Bacillus (Figura 22), foi detectado o monômero 3-hidroxibutirato (3HB), sendo este o único componente do polímero (polihidroxibutirato-PHB). Note-se também que na triagem realizada com Sudan Black $B$ obteve-se um falso positivo (Figura 21E). O resultado anterior pode-se dever ao corante, o qual não cora apenas as colônias acumuladoras de PHA, mas também outros lipídios celulares presentes, como por exemplo os ramnolipídeos (ABDEL-MAWGOUD; LÉPINE; DÉZIEL, 2010). 

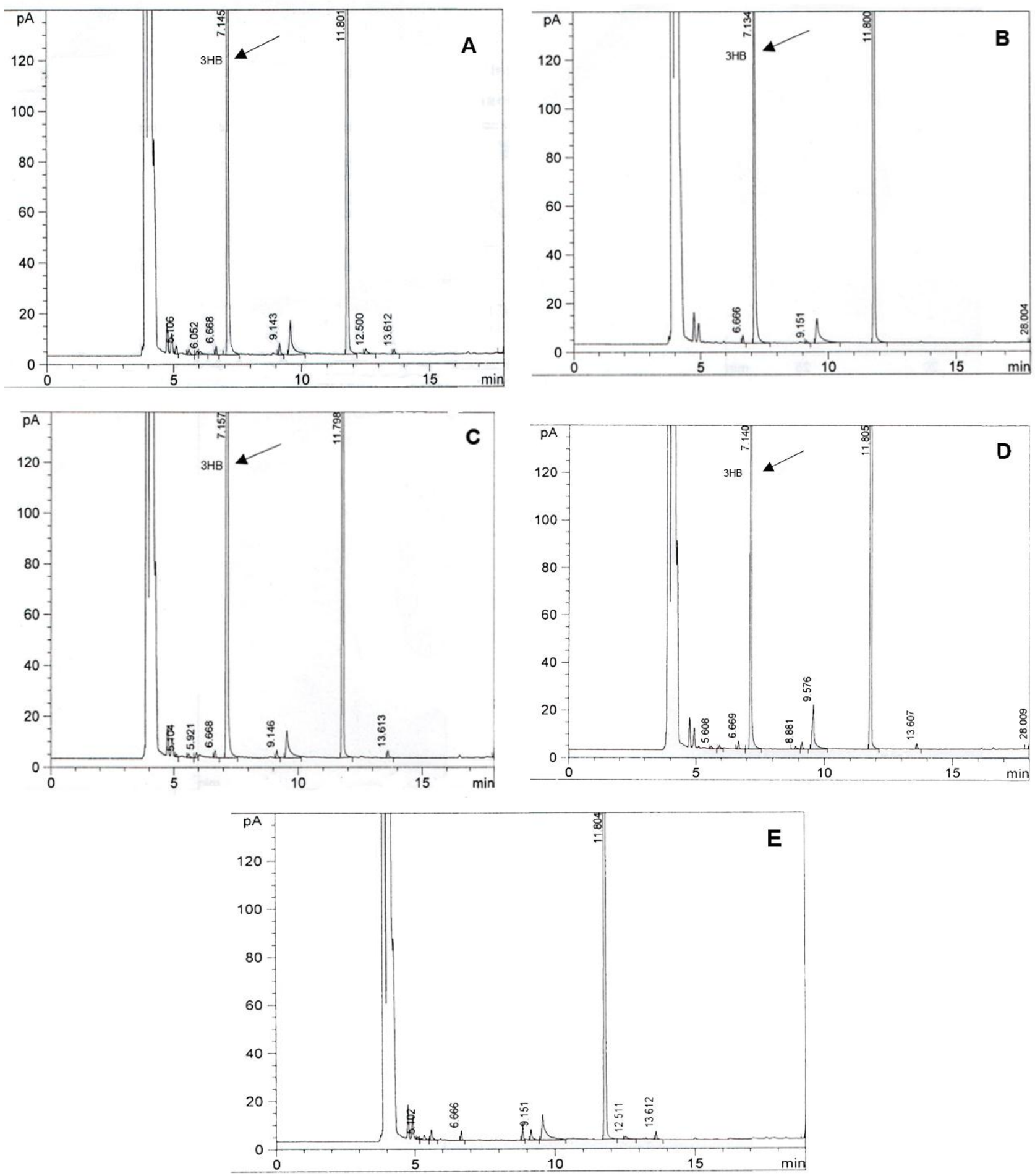

Figura 21 - Espectro de cromatografia gasosa indicando (setas) a presença dos picos (tempo de retenção em minutos) de 3HB. A-D, isolados produtores de 3HB: Bacillus sp. sac23, Bacillus sp. sac33, Bacillus sp. sac34 e Bacillus sp. sac66, respectivamente. E, isolado não produtor de PHA, Bacillus sp. sac64 


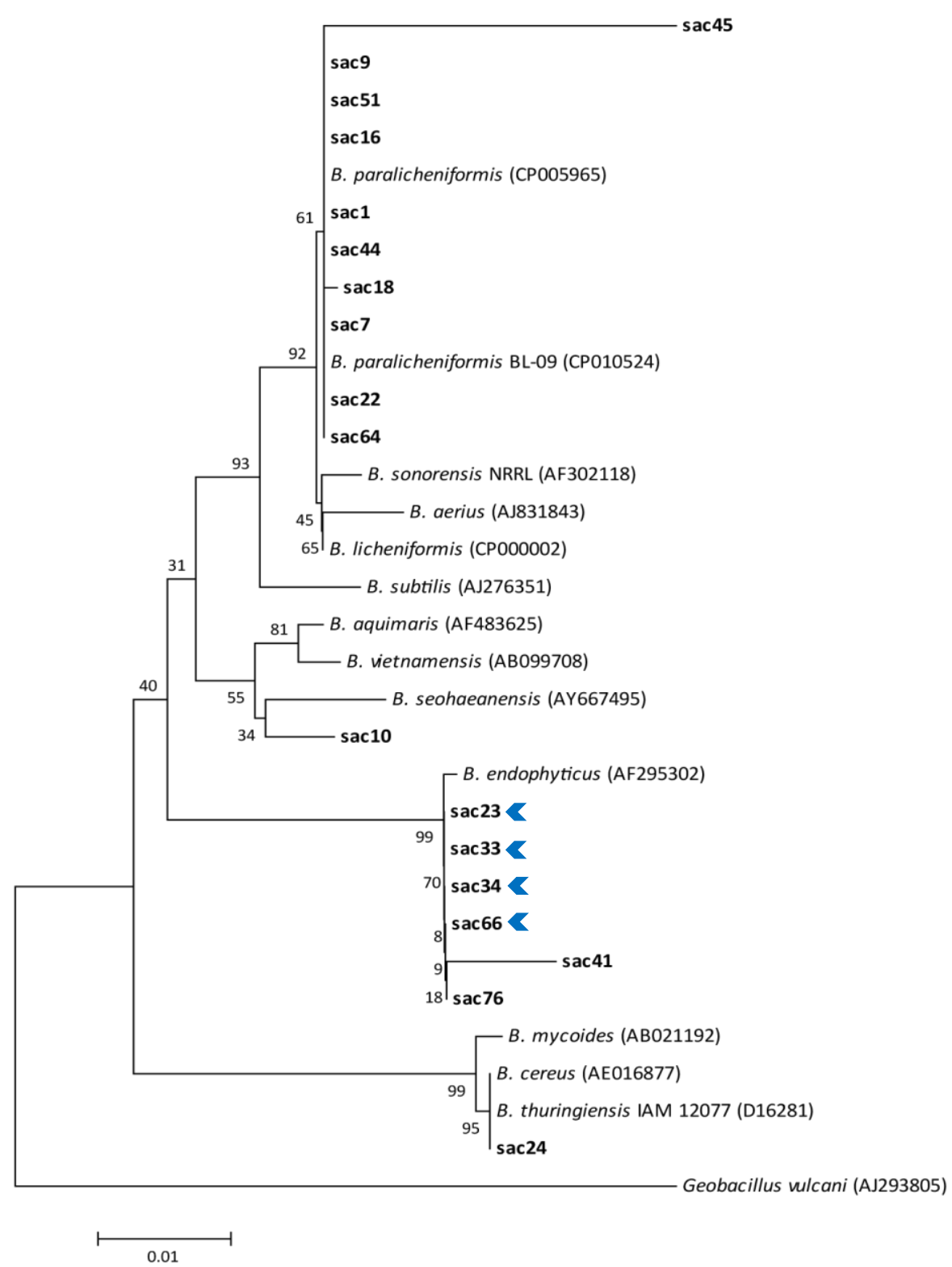

Figura 22 - Árvore filogenética dos isolados do gênero Bacillus produtores de PHA indicados em azul ( $<$ )

Apesar de que um grande número de microrganismos têm sido descritos como produtores de PHA em condições fisiológicas de estresse e na presença de excesso de carbono (KUMAR et al., 2014), em particular o gênero Bacillus destaca-se na pesquisa e produção de PHA. De fato, repare-se que o 3HB, monômero de cadeia curta, foi identificado e isolado a partir de um Bacillus sp., e tem-se indicado que o principal papel do polímero nesse gênero é de servir como uma reserva intracelular de carbono, assim como de fonte de energia para o processo de esporulação (VALAPPIL et al., 2006). 
Também é importante mencionar que o polihidroxibutirato (PHB) foi o primeiro tipo de PHA descoberto e o mais amplamente estudado. Este polímero tem propriedades mecânicas semelhantes aos plásticos convencionais como o polipropileno ou polietileno, contudo os custos de produção deste são mais elevados do que os plásticos petroquímicos (NARANJO et al., 2013b).

Além disso, encontra-se amplamente relatado a utilização de espécies de Bacillus para a produção de PHA pelas muitas vantagens que tem essas bactérias sobre outros gêneros bacterianos, como por exemplo, a ausência da camada de lipopolissacáridos (LPS) o que faz a extração do polímero mais fácil, a capacidade que tem para crescer em matérias-primas baratas, pela elevada taxa de crescimento em comparação com outras bactérias e também porque é geralmente considerado um microrganismo seguro pela Food and Drug Administration (KUMAR et al., 2014; MOHAPATRA et al., 2015; NARANJO et al., 2013a; SINGH et al., 2013b).

Adicionalmente, na literatura descreve-se que algumas cepas de Bacillus spp. são capazes de utilizar uma ampla gama de substratos, tais como, açúcares, ácidos graxos voláteis, álcoois, e matérias primas renováveis para produzir homopolímeros como o PHB. Do mesmo modo, é descrito que os rendimentos de produção de PHB variam entre as diferentes espécies de Bacillus, o que deve-se em grande parte a linhagem usada e à alimentação utilizada no processo (KUMAR et al., 2013).

Contudo, também é importante mencionar que os polímeros de origem microbiana são ainda mais caros que os polímeros petroquímicos convencionais. $\mathrm{O}$ alto impacto da fonte de carbono no custo final deste polímero tem sido um dos principais fatores limitantes para a produção de PHA, sendo responsável por até $50 \%$ dos custos totais de produção, diminuindo para cerca de $30 \%$ quando a produção de PHA é integrada a uma usina de cana de açúcar (SILVA et al., 2014). Portanto, é evidente que a utilização de fontes de carbono mais baratas, localmente disponíveis e renováveis é de interesse económico. Assim, matérias primas como a xilose, glicerol, melaço de cana, soro de queijo, resíduos de biomassa agrícola e florestal são considerados fontes de carbono alternativas para produzir PHA (NARANJO et al., 2013a; SILVA et al., 2014). 
Baseado nesse contexto, comparou-se o acúmulo de PHB em meio mineral contendo glicose e xilose nos quatro isolados Bacillus preliminarmente escolhidos. $\mathrm{Na}$ tabela 9 estão apresentados os resultados dos experimentos.

Tabela 9 - Produção de PHB por isolados halotolerantes do gênero Bacillus a partir de meio mineral glicose $(10 \mathrm{~g} / \mathrm{L})$ e meio mineral xilose $(10 \mathrm{~g} / \mathrm{L})$, após 72 horas

\begin{tabular}{cccc}
\hline \multirow{2}{*}{ Isolados } & \multirow{2}{*}{ Gênero } & MMG & MMX \\
\cline { 3 - 4 } & & 3HB (\% MSC) & 3HB (\% MSC) \\
\hline sac23 & Bacillus sp. & 30,1 & 22,9 \\
sac33 & Bacillus sp. & 40,5 & 31,3 \\
sac34 & Bacillus sp. & 51,1 & 23,0 \\
sac66 & Bacillus sp. & 26,9 & 21,4 \\
\hline MMG: Meio mineral glicose (10 g/L); MMX: Meio mineral xilose (10 g/L); MSC: Masa seca \\
celular; 3HB: 3-hidroxibutirato (4 C).
\end{tabular}

Sabe-se que a glicose e xilose são os açúcares mais abundantes na natureza, e a utilização eficiente destes é essencial para a produção de combustíveis e produtos químicos a partir de biomassa lignocelulósica (HUANG et al., 2016; ZHANG et al., 2014). Por outro lado, encontra-se relatos que mostram que entre os açúcares utilizados para a produção de PHB, a glicose é um dos substratos mais eficientes (KUMAR et al., 2013), porém a xilose custa a metade do preço da glicose, e estudos recentes provaram que a xilose pode ser um substrato potencial e promissor para produção de PHA, gerando uma acumulação máxima até 89\% da biomassa total usando Bacillus sp (HUANG et al., 2016).

No entanto, embora alguns microrganismos nativos sejam capazes de utilizar xilose, a maioria dos organismos não pode consumir xilose como única fonte de carbono (ZHANG et al., 2014). Contudo, quatro isolados da caatinga produtores de PHA, foram capazes de utilizar xilose como única fonte de carbono para produzir o 3-hidroxibutirato (3HB). Embora a porcentagem de acúmulo tenha sido maior em todos os isolados usando o meio mineral glicose, observou-se que o acúmulo em meio mineral xilose foi semelhante, por exemplo, o isolado sac66 acumulou 26,9 \% em MMG e 21,4 \% em MMX (Tabela 9). Porém, deve-se ressaltar que as porcentagens de acúmulo dos isolados produtores da caatinga podem ser melhoradas através de ferramentas de biologia molecular ou mudando os processos fermentativos (condições de fermentação) 
(DHANGDHARIYA et al., 2015; HUANG et al., 2016; KUMAR et al., 2013, 2014; LOPES et al., 2011; SINGH et al., 2011; YUE et al., 2014; ZHANG et al., 2014).

Por outro lado, têm sido descritas três principais vias metabólicas na natureza para utilização microbiana de xilose. A primeira via oxiredutora existe principalmente em fungos. Na segunda via, que é principalmente em procariotos tais como Escherichia coli, a xilose pode ser degradada pela via das Pentoses Fosfato (PPP) por uma isomerase, e por último a xilose pode abastecer o Ciclo dos Ácidos Tricarboxílicos (TCA) através do $\alpha$ cetoglutarato pela via Weimberg, que tem sido descrita para bactéria e arqueia (KÖHLER et al., 2015).

Em particular, Bacillus subtilis, a bactéria gram-positiva mais caracterizada, também possui a segunda via de assimilação de xilose. Tem sido relatado que os genes $x y \mid A$ e $x y \mid B$ de $B$. subtilis codificam xilose isomerase e xilulose quinase, respectivamente. No entanto, a linhagem selvagem de $B$. subtilis não é capaz de utilizar a xilose como única fonte de carbono, devido à ausência do sistema específico de absorção de xilose (ZHANG et al., 2014). Porém, neste trabalho apresentam-se quatro isolados halotolerantes do gênero Bacillus que são capazes de utilizar a xilose como única fonte de carbono para produção de PHA. As vias metabólicas pelas quais essas linhagens halotolerantes da caatinga podem utilizar a xilose ainda têm que ser elucidadas.

De outro lado, cabe ressaltar a importância dos resultados obtidos no presente estudo no contexto econômico brasileiro. A produção de etanol de segunda geração no Brasil, segundo os relatórios da União da Industria de Cana-De-Açúcar (UNICA) é de cerca de 30,232 milhões de metros cúbicos de etanol produzidos na temporada 2015/16, a partir da fração de glicose derivada do hidrolisado de bagaço de cana de açúcar (33,837 milhões de toneladas, dados UNICA). Sabe-se também que esse processo fornece como resíduo agroindustrial grandes quantidades de xilose, valores que estão aproximadamente na ordem de 10,000,000 toneladas disponíveis (SILVA et al., 2014), que podem ser usadas como matéria-prima em processos biotecnológicos de produtos como os PHA (HUANG et al., 2016; LOPES et al., 2009; ZHANG et al., 2014). Em consequência, os quatro Bacillus halotolerantes da caatinga poderiam ser usados em processos para metabolizar essas grandes quantidades de resíduo agroindustrial e assim 
obter o PHB, produto que não somente tem um impacto ecológico, mas também econômico no Brasil.

Adicionalmente, o objetivo dos processos biotecnológicos é a produção de químicos, materiais e biocombustíveis em grande escala usando recursos sustentáveis da agricultura. No entanto, a maioria desses processos baseados em microrganismos não é suficientemente competitiva e tem muitas desvantagens, incluindo a alta demanda de energia devido aos processos de esterilização, o alto consumo de água doce, por serem processos não contínuos e pelo uso de substratos de alimentação humana. Por tudo isto, tornou-se importante desenvolver processos biotecnológicos competitivos que possam economizar energia, que sejam contínuos, que não precisem de água doce e que usem substratos de baixo custo (YUE et al., 2014).

Neste contexto, cabe destacar o papel que podem desenvolver as bactérias halotolerantes da caatinga nos processos biotecnológicos. Conforme descrito anteriormente, estas bactérias são capazes de crescer em $\mathrm{NaCl}$, e a água do mar é rica nesse sal (concentração aproximada de $35 \mathrm{~g} / \mathrm{L}$ ). Mais importante ainda, $97 \%$ da água da Terra é água do mar. Assim, torna-se necessário o uso de bactérias halófilas ou halotolerantes que sejam capazes de crescer rapidamente em água do mar e utilizando substratos de baixo custo, para gerar processos de fermentação contínuos que diminuam o custo de produção (OREN, 2010; YIN et al., 2014; YUE et al., 2014).

Portanto, a partir dos resultados de acúmulo anteriores, e com o intuito de observar o efeito da salinidade e o uso de glicerol, outra fonte de carbono de baixo custo, no acúmulo de PHB, selecionaram-se dois isolados produtores, Bacillus sp. sac33 e Bacillus sp. sac34, por serem os microrganismos que apresentaram maior porcentagem de acúmulo de PHB, tanto em MMG como em MMX (Tabela 9).

Para começar, o glicerol bruto é gerado como um co-produto na produção de biodiesel, e por cada 10 galões de biodiesel produzido, 1 galão de glicerol bruto é gerado (NARANJO et al., 2013a). Estima-se que até 2016, a produção mundial de biodiesel deve chegar aos 37 bilhões de galões, o que implica uma produção aproximada de 4 bilhões de galões de glicerol bruto (DE JESUS ASSIS et al., 2016b). No Brasil, a mistura de 7\% de biodiesel com diesel tornou-se obrigatória em 2014, portanto, a quantidade de biodiesel produzido no Brasil aumentou $241 \%$ nos últimos cinco anos, atingindo 9 milhões 
de galões em 2014 (FABER; FERREIRA-LEITÃO, 2016), sendo este produzido principalmente a partir de soja (ANDRÉ CREMONEZ et al., 2015). Deste modo, a conversão biológica oferece a oportunidade de sintetizar uma grande variedade de produtos a partir desse glicerol residual, como por exemplo a síntese de polihidroxialcanoatos (NARANJO et al., 2013b; RODRÍGUEZ-CONTRERAS et al., 2015).

$\mathrm{Na}$ Tabela 100 e na Figura 233 estão apresentados os resultados dos ensaios de acúmulo realizados. Em geral, observou-se nos dois isolados avaliados que quando concentrações altas de $\mathrm{NaCl}$ foram utilizadas (35, 60 e $120 \mathrm{~g} / \mathrm{L}$ ), foi menor aí não teve teor de PHB acumulado independentemente da fonte de carbono usada. Por outro lado, na ausência de $\mathrm{NaCl}(0 \mathrm{~g} / \mathrm{L})$, maior teor de polímero foi acumulado nas três fontes usadas.

No caso particular do isolado Bacillus sp. sac33, deve-se destacar que quando foram usados $10 \mathrm{~g} / \mathrm{L}$ de xilose em meio sem $\mathrm{NaCl}$ observou-se o maior acúmulo de $\mathrm{PHB}$ correspondente a 36,6 \% da massa seca celular (MSC) (Figura 23A), em comparação com $30,5 \%$ e $21,7 \%$ da MSC quando a fonte de carbono foram glicose e glicerol, respectivamente. Contrariamente, quando foram adicionados $120 \mathrm{~g} / \mathrm{L}$ de $\mathrm{NaCl}$ e $10 \mathrm{~g} / \mathrm{L}$ de glicose observou-se que o acúmulo de PHB diminuiu a 1,5\% da MSC, com respeito ao atingido em meio sem $\mathrm{NaCl}$. Porém é importante reparar que o isolado consegue acumular o polímero numa condição de estresse osmótica alta, e como foi supracitado com ajuda de estratégias de biologia molecular e condições diferentes de fermentação poderia otimizar-se o acúmulo. 
Tabela 10 - Produção de PHB por dois isolados halotolerantes do gênero Bacillus

\begin{tabular}{|c|c|c|c|c|c|}
\hline Isolado & $\begin{array}{l}\text { Fonte de } \\
\text { Carbono }\end{array}$ & $\begin{array}{l}\text { Concentração } \\
\text { de } \mathrm{NaCl}(\mathrm{g} / \mathrm{L})\end{array}$ & $\begin{array}{l}\text { MSC } \\
\text { (g/L) }\end{array}$ & $\begin{array}{c}3 \mathrm{HB} \\
\text { (\%MSC) }\end{array}$ & $\begin{array}{l}\text { PHB } \\
\text { (g/L) }\end{array}$ \\
\hline \multirow{12}{*}{$\begin{array}{l}\text { Bacillus sp. } \\
\text { sac33 }\end{array}$} & \multirow{4}{*}{ Glicose } & 0 & $2,7 \pm 4,4$ & $30,5 \pm 2,2$ & $0,9 \pm 1,4$ \\
\hline & & 35 & $2,4 \pm 3,6$ & $17,6 \pm 0,9$ & $0,4 \pm 0,4$ \\
\hline & & 60 & $3,0 \pm 2,5$ & $15,6 \pm 1,7$ & $0,5 \pm 0,9$ \\
\hline & & 120 & $1,1 \pm 0,0$ & $1,5 \pm 2,6$ & $0,0 \pm 0,0$ \\
\hline & \multirow{4}{*}{ Xilose } & 0 & $1,6 \pm 5,2$ & $36,6 \pm 2,5$ & $0,6 \pm 1,4$ \\
\hline & & 35 & $1,6 \pm 1,3$ & $16,9 \pm 0,6$ & $0,3 \pm 0,2$ \\
\hline & & 60 & $1,4 \pm 1,6$ & $14,1 \pm 3,6$ & $0,2 \pm 0,7$ \\
\hline & & 120 & $1,2 \pm 0,3$ & $0,1 \pm 0,1$ & $0,0 \pm 0,0$ \\
\hline & \multirow{4}{*}{ Glicerol } & 0 & $1,8 \pm 1,8$ & $21,7 \pm 4,6$ & $0,4 \pm 0,4$ \\
\hline & & 35 & $2,3 \pm 2,9$ & $18,5 \pm 2,8$ & $0,4 \pm 0,2$ \\
\hline & & 60 & $2,1 \pm 4,4$ & $17,0 \pm 0,4$ & $0,4 \pm 0,6$ \\
\hline & & 120 & $1,6 \pm 2,3$ & $0,0 \pm 0,0$ & $0,0 \pm 0,0$ \\
\hline \multirow{12}{*}{$\begin{array}{l}\text { Bacillus sp. } \\
\text { sac34 }\end{array}$} & \multirow{4}{*}{ Glicose } & 0 & $3,1 \pm 0,4$ & $27,7 \pm 2,7$ & $0,8 \pm 0,9$ \\
\hline & & 35 & $3,6 \pm 2,1$ & $21,7 \pm 1,2$ & $0,8 \pm 0,3$ \\
\hline & & 60 & $4,2 \pm 1,2$ & $8,7 \pm 1,2$ & $0,4 \pm 0,6$ \\
\hline & & 120 & $2,1 \pm 1,6$ & $0,0 \pm 0,0$ & $0,0 \pm 0,0$ \\
\hline & \multirow{4}{*}{ Xilose } & 0 & $2,0 \pm 1,8$ & $27,0 \pm 2,0$ & $0,5 \pm 0,4$ \\
\hline & & 35 & $2,4 \pm 2,0$ & $21,1 \pm 1,9$ & $0,5 \pm 0,2$ \\
\hline & & 60 & $2,1 \pm 0,1$ & $14,2 \pm 1,4$ & $0,3 \pm 0,3$ \\
\hline & & 120 & $0,7 \pm 2,4$ & $0,0 \pm 0,0$ & $0,0 \pm 0,0$ \\
\hline & \multirow{4}{*}{ Glicerol } & 0 & $1,9 \pm 0,8$ & $20,3 \pm 2,1$ & $0,4 \pm 0,4$ \\
\hline & & 35 & $2,1 \pm 2,9$ & $14,8 \pm 1,4$ & $0,3 \pm 0,8$ \\
\hline & & 60 & $1,6 \pm 4,2$ & $10,9 \pm 2,7$ & $0,2 \pm 0,0$ \\
\hline & & 120 & $1,6 \pm 2,5$ & $0,0 \pm 0,0$ & $0,0 \pm 0,0$ \\
\hline
\end{tabular}

Produção a partir de meio mineral glicose $(10 \mathrm{~g} / \mathrm{L})$, meio mineral xilose $(10 \mathrm{~g} / \mathrm{L})$ e meio mineral glicerol $(10$ $\mathrm{g} / \mathrm{L})$, contendo quatro concentrações de $\mathrm{NaCl}$, após 72 horas. Os dados correspondem à média dos experimentos em triplicata e seu respectivo desvio padrão. MSC: Masa seca celular; 3HB: 3-hidroxibutirato (4 C).

Do mesmo modo, os ensaios de acúmulo realizados com o isolado Bacillus sp. sac34 evidenciaram que o aumento da salinidade no meio diminui o teor de PHB produzido pela bactéria (Figura 23B), ou levando a porcentagem de acúmulo até 0,0\% quando $120 \mathrm{~g} / \mathrm{L}$ de $\mathrm{NaCl}$ é adicionado no meio. O maior teor de PHB acumulado pelo isolado foi observado quando se utilizou glicose em meio sem sal (27,7 \% da MSC), porém, o acúmulo da bactéria foi semelhante em meio com xilose, sendo este de 27,0 \%. Note-se também que o acúmulo deste isolado quando $35 \mathrm{~g} / \mathrm{L}$ de $\mathrm{NaCl}$ (salinidade aproximada à água do mar) são adicionados em meios com glicose e xilose, sendo estes 
de $21,7 \%$ e $21,1 \%$ respectivamente, foram maiores que os apresentados pelo isolado Bacillus sp. sac33 nas mesmas fontes (17,6 \% em glicose e $14,1 \%$ em xilose).
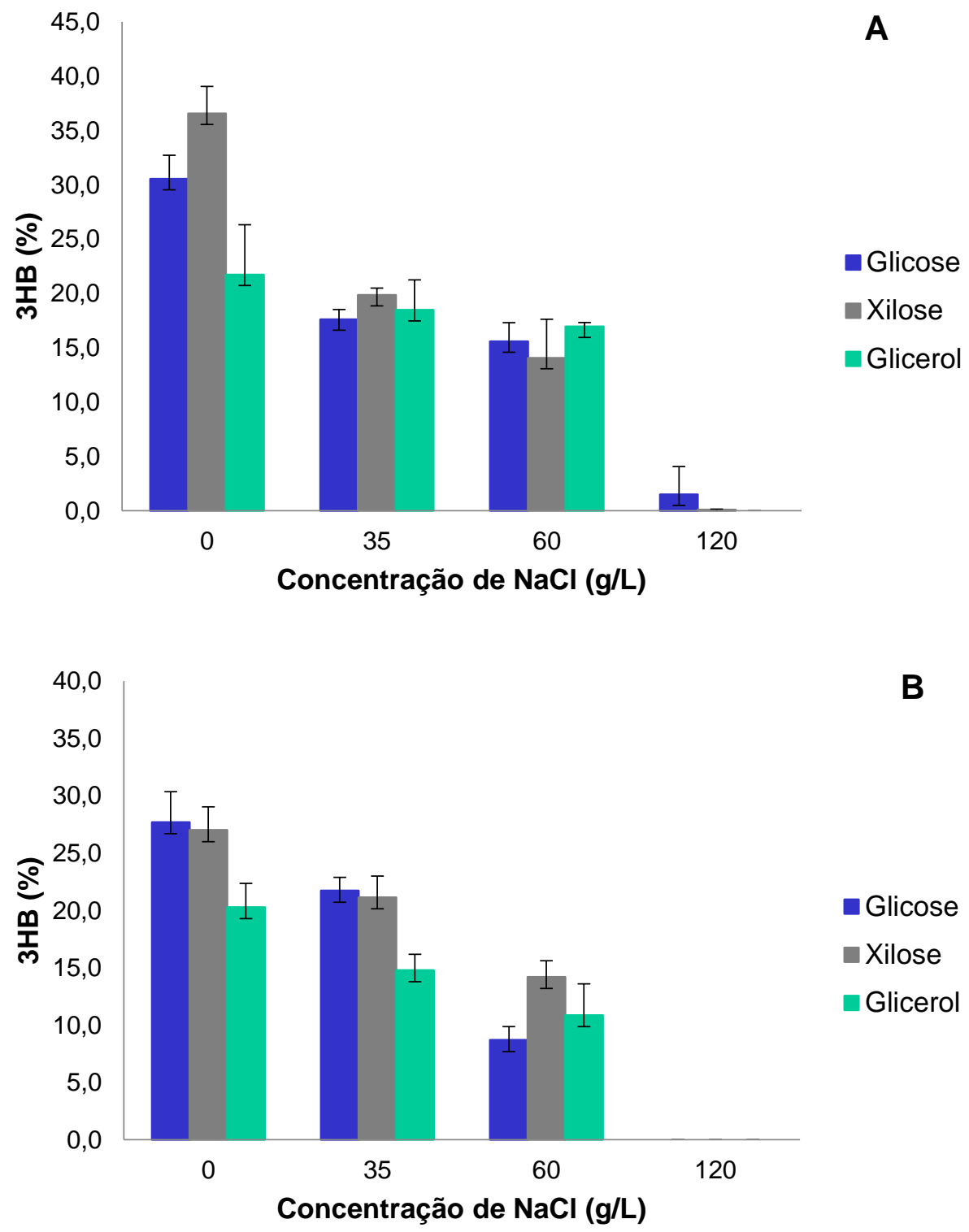

Figura 23 - Gráficos do perfil de acúmulo do monômero 3HB por dois isolados do gênero Bacillus a partir de glicose, xilose e glicerol em meio mineral contendo quatro diferentes concentrações de $\mathrm{NaCl}$. A, isolado Bacillus sp. sac33. B, isolado Bacillus sp. sac34 
Além disso, observou-se também que em geral a fonte de carbono que menor teor de PHB permitiu acumular nos dois isolados avaliados foi o glicerol, apresentando as culturas um acúmulo total de polímero entre 10,9 e 21,7 \% da massa celular. No entanto, deve-se destacar de novo a importância que tem em nível industrial e ambiental o isolamento de bactérias que possam usar naturalmente esse tipo de fontes de carbono de baixo custo, neste caso o glicerol, para produção de PHB, e como foram apresentados os dois isolados da caatinga avaliados no estudo conseguem fazê-lo.

Estes resultados sugerem o potencial uso destas bactérias pertencentes ao gênero Bacillus na produção de PHB em processos ambientalmente amigáveis, onde fontes de carbono de baixo custo e a água do mar podem ser usadas (OREN, 2010; YIN et al., 2014), e tendo em consideração que a pesar de ter obtido teores de PHB menores aos relatados por alguns pesquisadores para bactérias do gênero Bacillus (Tabela 11), este ensaio foi a primeira triagem realizada com os isolados halotolerantes da caatinga e a porcentagem de acúmulo de PHB ainda pode ser melhorada usando diferentes abordagens biotecnológicas.

Tabela 11 - Dados de produção de PHA por bactérias do gênero Bacillus relatados na literatura

\begin{tabular}{|c|c|c|c|c|}
\hline Linhagem & Fonte de carbono & PHA & $\begin{array}{c}\text { PHA } \\
\text { (\% MSC) }\end{array}$ & Referência \\
\hline Bacillus sp. MA3.3 & Glicose & P3HB & 62,2 & \multirow{2}{*}{$\begin{array}{l}\text { (LOPES et al., } \\
\text { 2009) }\end{array}$} \\
\hline Bacillus sp. MA3.3 & Xilose & P3HB & 64,4 & \\
\hline Bacillus sp. & Glicose & P3HB & 40,0 & \multirow{2}{*}{$\begin{array}{l}\text { (SINGH et al., } \\
\text { 2011) }\end{array}$} \\
\hline Bacillus sp. & Xilose & P3HB & 37,4 & \\
\hline Bacillus megaterium & Glicerol & P3HB & 60,0 & $\begin{array}{l}\text { (NARANJO et al., } \\
\text { 2013b) }\end{array}$ \\
\hline Bacillus subtilis NG05 & $\begin{array}{l}\text { Água residual, } \\
\text { indústria de açúcar }\end{array}$ & P3HB & 50,1 & $\begin{array}{l}\text { (SINGH et al., } \\
\text { 2013a) }\end{array}$ \\
\hline Bacillus spp. & Glicose & $\mathrm{P}(\mathrm{HB}-\mathrm{co}-3 \mathrm{HV})$ & 60,5 & $\begin{array}{l}\text { (KUMAR et al., } \\
\text { 2014) }\end{array}$ \\
\hline $\begin{array}{c}\text { Bacillus megaterium } \\
\text { JK4h }\end{array}$ & Glicose & P3HB & 56,7 & $\begin{array}{l}\text { (DHANGDHARIYA } \\
\text { et al., 2015) } \\
\text { (MAYELI; }\end{array}$ \\
\hline $\begin{array}{c}\text { Bacillus axaraqunsis } \\
\text { BIPC01 }\end{array}$ & $\begin{array}{c}\text { Água residual, } \\
\text { indústria petroquímica }\end{array}$ & P3HB & 66,0 & $\begin{array}{c}\text { MOTAMEDI; } \\
\text { HEIDARIZADEH, } \\
\text { 2015) } \\
\end{array}$ \\
\hline
\end{tabular}




\subsection{Ensaios de produção de EPS}

Nos últimos anos, o aumento da demanda por polímeros naturais para alimentos, indústria farmacêutica, indústria de cosméticos e outras aplicações industriais incentivou o interesse de isolar e identificar novos polissacarídeos produzidos por microrganismos, que sendo isolados de ambientes extremos podem ter aplicações inovadoras ou características diferentes às tradicionais (POLI; ANZELMO; NICOLAUS, 2010). Em especial, destaca-se o recente uso dos EPS nas aplicações médicas devido às suas atividades biológicas específicas, tais como atividade antioxidante, efeitos imunoestimulantes, efeitos antitumorais e atividade antiviral (YE et al., 2012).

Por outro lado, os microrganismos halófilos e halotolerantes além de serem de especial interesse para os cientistas graças a que desempenham um papel importante nos ambientes salinos e hipersalinos, têm a capacidade de produzir exopolissacarídeos como estratégia para o crescimento, a adesão a substratos sólidos e a sobrevivência em condições adversas (SPANÒ; ARENA, 2016; UPADHYAY et al., 2016). A continuação apresenta-se os resultados obtidos na seleção, produção e extração de EPS por bactérias halotolerantes da caatinga, como também se expõem resultados interessantes referentes aos ensaios de ativação de macrófagos realizados com extratos brutos de EPS bacterianos.

\subsubsection{Seleção de isolados produtores de EPS}

Os resultados relacionados à seleção dos isolados halotolerantes produtores de EPS estão apresentados na tabela 12. Para começar, $46 \%$ dos isolados halotolerantes (doze bactérias) foram capazes de produzir EPS, resultado observado como a formação de um halo mucoide e viscoso no meio sólido (Figura 24). 
Tabela 12 - Isolados halotolerantes produtores de EPS, após 48 horas

\begin{tabular}{|c|c|c|c|}
\hline Isolado & Gênero & Produção EPS & Halo (mm) \\
\hline sac1 & Bacillus sp. & + & 35 \\
\hline sac7 & Bacillus sp. & + & 33 \\
\hline sac9 & Bacillus sp. & + & 30 \\
\hline sac10 & Bacillus sp. & + & 22 \\
\hline sac16 & Bacillus sp. & + & 28 \\
\hline sac18 & Bacillus sp. & + & 24 \\
\hline sac22 & Bacillus sp. & + & 36 \\
\hline sac23 & Bacillus sp. & - & - \\
\hline sac24 & Bacillus sp. & - & - \\
\hline sac33 & Bacillus sp. & - & - \\
\hline sac34 & Bacillus sp. & - & - \\
\hline sac36 & Exiguobacterium sp. & - & - \\
\hline sac37 & Curtobacterium sp. & - & - \\
\hline sac38 & Staphylococcus sp. & - & - \\
\hline sac41 & Bacillus sp. & - & - \\
\hline sac44 & Bacillus sp. & - & - \\
\hline sac45 & Bacillus sp. & + & 17 \\
\hline sac51 & Bacillus sp. & + & 18 \\
\hline sac53 & Curtobacterium sp. & - & - \\
\hline sac54 & Curtobacterium sp. & + & 30 \\
\hline sac58 & Curtobacterium sp. & - & - \\
\hline sac59 & Staphylococcus sp. & - & - \\
\hline sac64 & Bacillus sp. & + & 17 \\
\hline sac65 & Pseudomonas sp. & + & 12 \\
\hline sac66 & Bacillus sp. & - & - \\
\hline sac76 & Bacillus sp. & - & - \\
\hline
\end{tabular}

(+) isolado produtor de EPS; (-) isolado não produtor de EPS. 

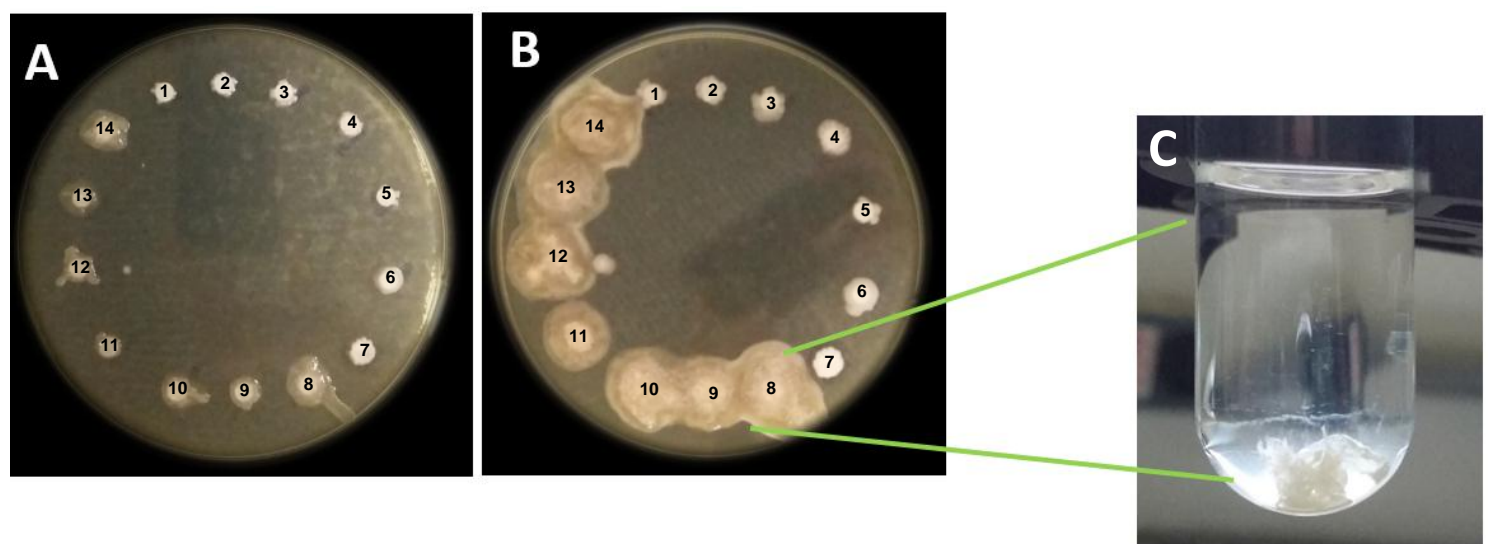

Figura 24 - Teste qualitativo de produção de EPS por isolados halotolerantes. A, produção após de 24 horas de incubação, B, produção após de 48 horas, e C, confirmação da produção de EPS pela formação de um precipitado. 1: Staphylococcus sp. sac38, 2: Curtobacterium sp. sac37, 3: Exiguobacterium sp. sac36, 4: Bacillus sp. sac34, 5: Bacillus sp. sac33, 6: Bacillus sp. sac24, 7: Bacillus sp. sac23, 8: Bacillus sp. sac22, 9: Bacillus sp. sac18, 10: Bacillus sp. sac16, 11: Bacillus sp. sac10, 12: Bacillus sp. sac9, 13: Bacillus sp. sac7 e 14: Bacillus sp. sac1

Especificamente, os isolados produtores foram um isolado do gênero Pseudomonas (Figura 25), um isolado do gênero Curtobacterium (Figura 26), e dez Bacillus (Figura 27) produzindo halos de $17-36 \mathrm{~mm}$, sendo o isolado sac22 aquele que produziu o maior halo (36 mm).

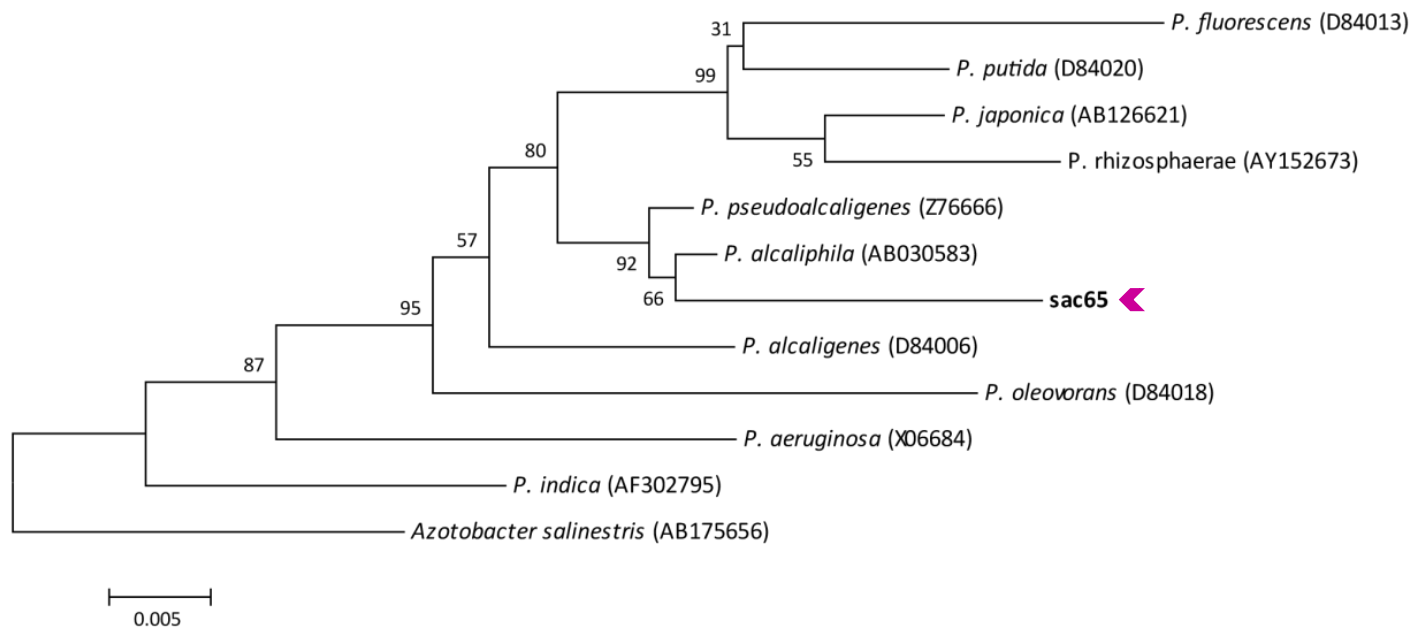

Figura 25 - Árvore filogenética do isolado do gênero Pseudomonas produtor de EPS indicado em roxo (C) 
O gênero Pseudomonas é uma fonte rica de exopolissacarídeos. Na literatura encontra-se amplamente relatado a produção de EPS por uma grande variedade de espécies do gênero Pseudomonas (CELIK; ASLIM; BEYATLI, 2008; KAVAMURA et al., 2013b; SHARMA et al., 2013), sendo os mais estudados os produzidos pela espécie $P$. aeruginosa que incluem o alginato, Psl e Pel (XIE et al., 2014). Mas também, encontramse outros EPS com aplicações diferentes as tradicionais como descreveram YE et al. (2012), que isolaram e purificaram um polímero com atividade antioxidante a partir da cepa marinha de Pseudomonas PF-6, e depois em 2016, relataram a biossíntese de um EPS rico em selênio (Se-EPS), também com atividade antioxidante, produzido a partir da cepa de Pseudomonas PT-8 (YE et al., 2016). Do mesmo modo, Sirajunnisa et al. (2016) relataram a produção de um EPS com atividade antioxidante, obtido a partir da cepa $P$. fluorescens CrN6.

Por outro lado, não se encontram relatos que descrevam o gênero Curtobacterium como microrganismo produtor de exopolissacarídeos, provavelmente pelos poucos estudos que são realizados com esse gênero bacteriano. Contudo, no presente estudo descreva-se pela primeira vez o isolado sac54 como microrganismo produtor de EPS, sendo uma das bactérias que apresentou maior halo de produção no teste $(30 \mathrm{~mm})$.

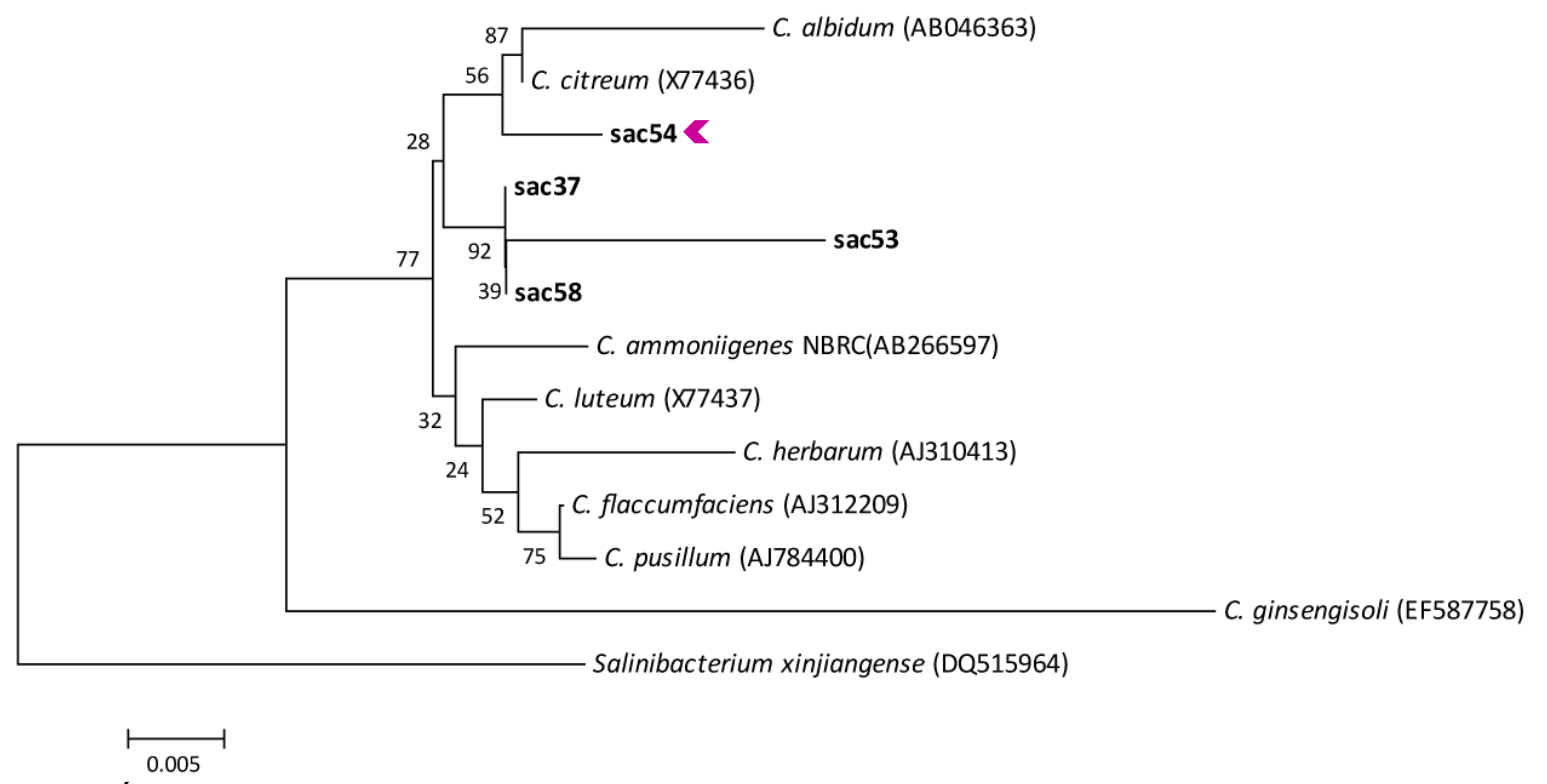

Figura 26 - Árvore filogenética do isolado do gênero Curtobacterium produtor de EPS indicado em roxo (C) 
Contrariamente ao gênero Curtobacterium, a produção de EPS pelo gênero Bacillus encontra-se relatada na literatura, assim como também as diferentes aplicações nas indústrias. Contudo, chama atenção o uso recente destes polímeros como agentes antivirais, antioxidantes, imunoestimuladores e antibiofilme. Yang et al. (2015) publicaram o isolamento de um EPS (EPS-1) produzido por um B. amyloliquefaciens composto por glicose, manose, galactose e arabinose, que exibiu uma forte atividade antioxidante em células HepG2.

Igualmente, Gugliandolo et al. (2014) e Spanò et al. (2016) descreveram um EPS novo produzido pela linhagem $B$. licheniformis T14, denominado EPS1-T14, solúvel em água, não citotóxico, que apresenta duas atividades importantes; 1) tem a capacidade de estimular a resposta imune mediada por células Th1, que poderia ser utilizado como defesa imunológica contra vírus como o Herpes simples tipo 2 (HSV-2), e 2) pode prevenir a formação de biofilme de bactérias de importância clínica como Escherichia coli, Klebsiella pneumoniae, Pseudomonas aeruginosa e Staphylococcus aureus.

Mais tarde em 2016, o mesmo grupo de pesquisa analisou o papel do EPS-B315 , produzido por $B$. licheniformis cepa B3-15, na produção de citocinas do tipo Th2 por células mononucleares do sangue periférico (PBMC, do inglês Peripheral Blood Mononuclear Cell) infectadas e não infectadas com HSV-2, demonstrando a capacidade do EPS de induzir uma rede particular de citocinas, com consequentes efeitos sobre as células do sistema imunológico durante uma infecção de HSV-2 (SPANÒ; ARENA, 2016). 


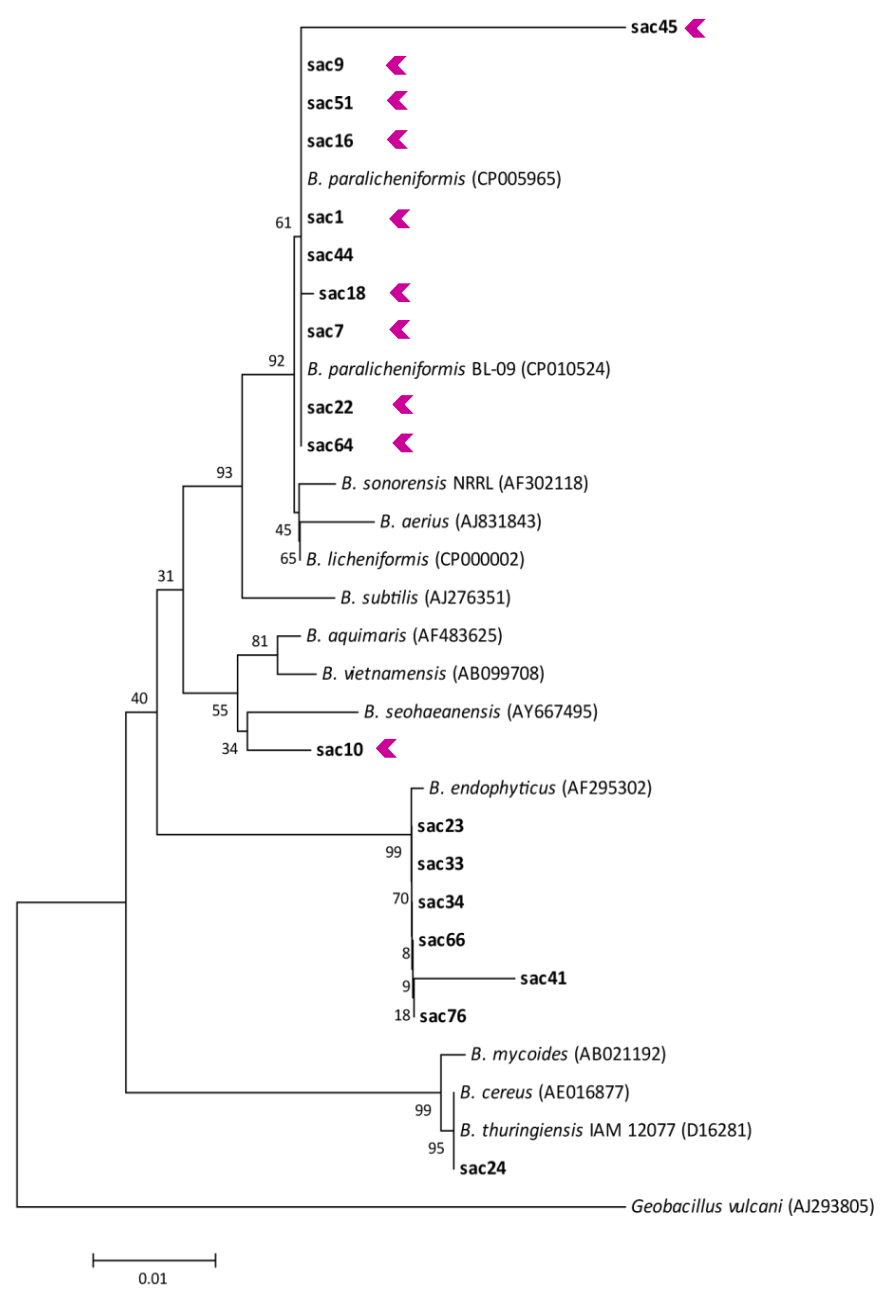

Figura 27 - Árvore filogenética dos isolados do gênero Bacillus produtores de EPS indicados em roxơ( )

Baseados nesses estudos, e tendo em consideração a importância de desenvolver novas terapias e medicamentos que ajam contra microrganismos resistentes como os vírus e bactérias, decidiu-se avaliar a possível atividade imunoestimuladora dos EPS bacterianos produzidos no estudo. Os resultados obtidos são descritos a seguir.

\subsubsection{Produção, extração de EPS e ensaios de ativação de macrófagos}

Os macrófagos ocupam uma posição única no sistema imune, exercendo um papel vital como interface entre a imunidade inata e adaptativa. Eles podem neutralizar substâncias estranhas, microrganismos patógenos e células cancerosas diretamente através de fagocitose e indiretamente através da secreção de citocinas e de moléculas 
citotóxicas, incluindo o fator de necrose tumoral (TNF) -, interleucina (IL) -1 e óxido nítrico (NO). Assim, os macrófagos são células alvo de alguns agentes imunomoduladores e antitumorais que podem ser ativados por diferentes substâncias biologicamente ativas, como os polissacarídeos. Estes produtos que podem ser de origem microbiano, têm demonstrado possuir atividade imunoestimulante potente sobre as respostas celulares e humorais contra antígenos, estimulando as células assassinas naturais, células- $T$, células B, macrófagos e respostas do sistema imune (WANG et al., 2016).

A ativação de macrófagos pelos EPS bacterianos obtidos no estudo, foi medida através do teste do Griess conforme descrito no item 4.6.6.1 de Material e Métodos, e realizado por colaboradores do Laboratório de Bioprospecção e Biotecnologia Marinha da Universidade Federal do Ceará. O ensaio do Griess é um teste analítico que mensura indiretamente a produção de óxido nítrico (NO), pela detecção da presença de nitrito em solução. O NO é uma importante molécula envolvida na resposta imune além de outros sistemas (TRIPATHI, 2007).

Através da Reação de Griess, o nitrito presente na amostra reage em meio ácido com uma amina aromática, produzindo um sal de diazônio. Este sal reagirá com a 3hidroxi-1,2,3,4-tetraidrobenzilquinolina, uma molécula orgânica, e produzirá a coloração rosa. A coloração resultante tem intensidade de cor em proporção direta com a concentração de nitrito na amostra (GREEN et al., 1982; GREEN; TANNENBAUM; GOLDMAN, 1981).

Assim, este ensaio avaliou as respostas farmacológicas produzidas por macrófagos murinos (RAW 264.7) tratadas com EPS de bactérias. A figura 28 mostra a resposta dos EPS bacterianos utilizados no experimento. 

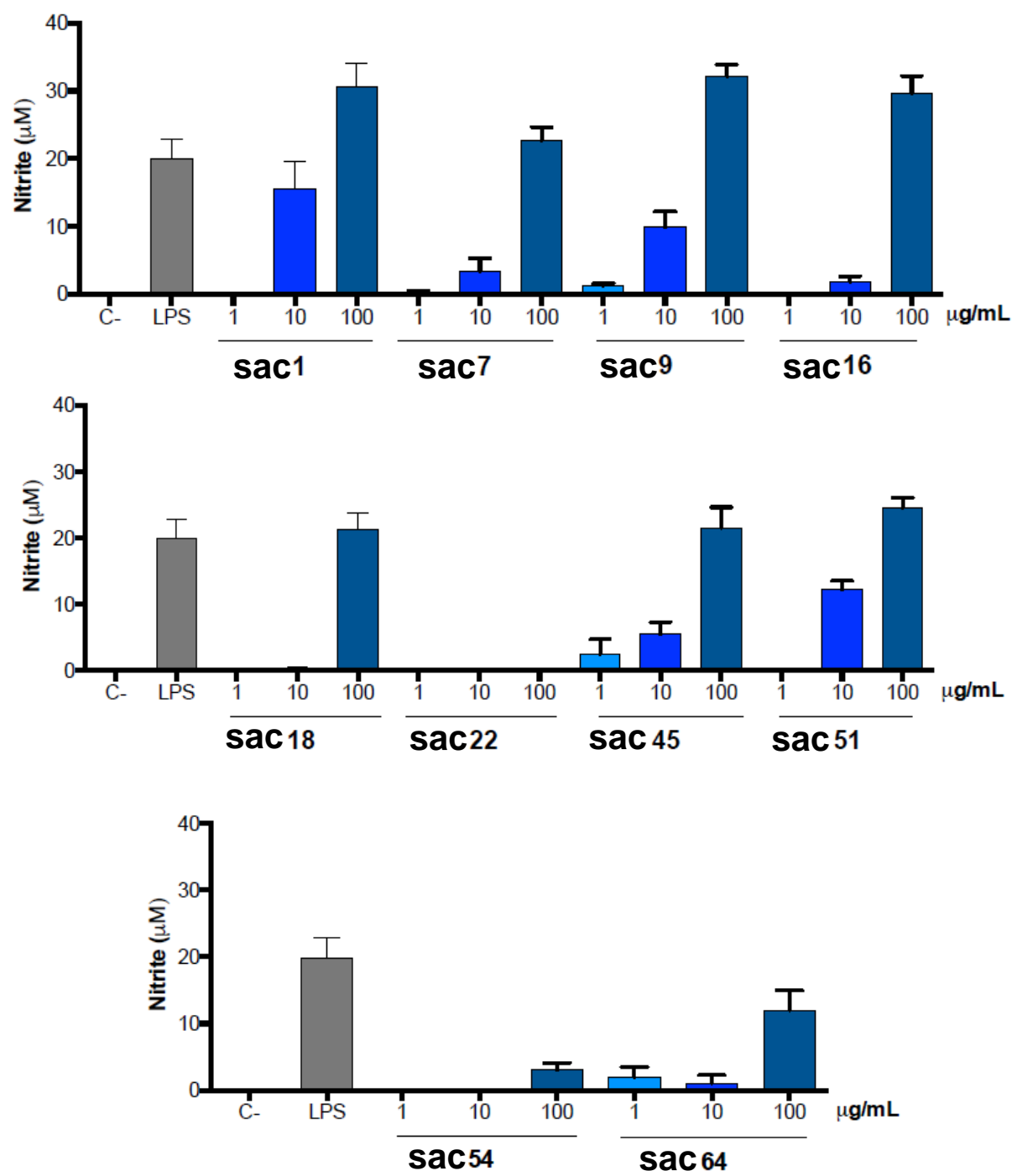

Figura 28 - Detecção de nitrito no sobrenadante de macrófagos murinos (RAW 264.7) estimulados in vitro com meio (C-), LPS (C+) ou 1, 10 e $100 \mu \mathrm{g} / \mathrm{ml}$ dos exopolissacarídeos bacterianos (EPS) após 48 horas de incubação

Como se observa na figura 28 , a maior parte dos EPS bacterianos na concentração de $100 \mathrm{\mu g} / \mathrm{ml}$ aumentaram as concentrações de nitrito ( $\mathrm{NO}^{-2}$ ) no sobrenadante dos macrófagos, sendo alguns maiores que o causado pelo controle positivo (LPS). Outros EPS que aumentaram as concentrações de $\mathrm{NO}^{-2}$ foram os produzidos pelos isolados Curtobacterium sp. sac54 e Bacillus sp. sac64, porém o aumento foi menor em comparação com o aumento produzido pelo LPS e pelos outros EPS avaliados. Por outro lado, o único EPS que não gerou nenhum aumento nas concentrações de $\mathrm{NO}^{-2}$ foi o produzido pelo isolado Bacillus sp. sac22. 
Estes resultados são uma primeira aproximação ao potencial imunoestimulatório dos EPS avaliados, porém, ainda tem que ser realizados outros ensaios confirmatórios da atividade observada, assim como a caracterização química dos exopolissacarídeos bacterianos.

\subsubsection{Ensaios de morte celular}

Finalmente, os ensaios de morte celular também foram realizados por colaboradores do Laboratório de Bioprospecção e Biotecnologia Marinha da Universidade Federal do Ceará. Este ensaio baseia-se na medida do dano induzido pela amostra (EPS bacteriano) em estudo no metabolismo celular de glicídios usualmente através da avaliação da atividade de desidrogenases mitocondriais. A viabilidade mitocondrial é quantificada pela redução do MTT (sal de coloração amarela) a formazan (sal de coloração arroxeada) pela atividade daquelas enzimas. Dessa forma, a redução do MTT a formazan, será diretamente proporcional à atividade mitocondrial e a viabilidade celular.

As linhagens celulares utilizadas nesse ensaio foram: HCT-116 (câncer de cólon), B16-F10 (melanoma murino) e RAW 264.7 (macrófagos murinos). As células foram tratadas após 24 horas de plaqueamento e a viabilidade mensurada após 48 horas de tratamento (Figura 29). 

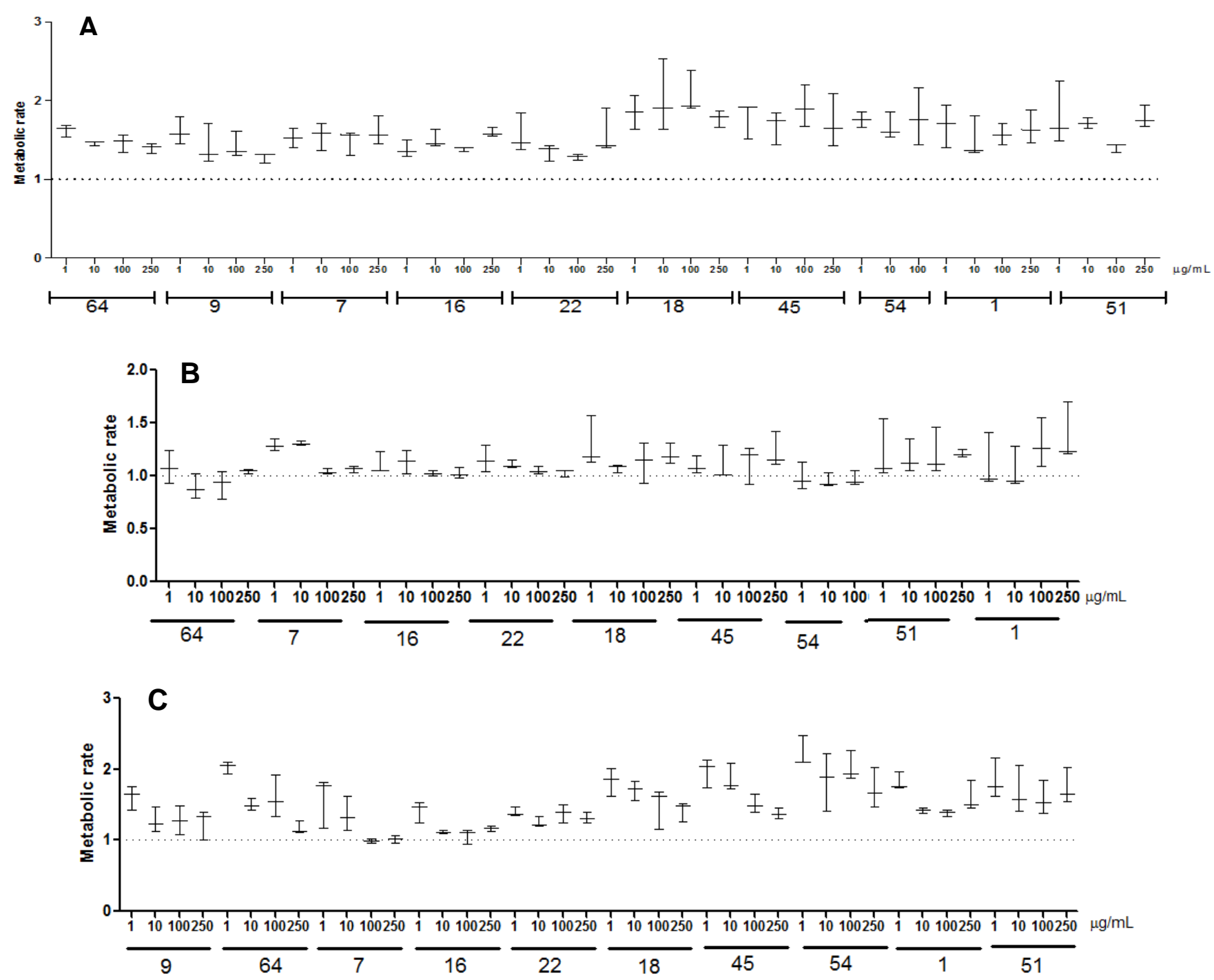

Figura 29 - Morte celular quantificada pela redução do MTT após 48 horas. A, B16-F10 (melanoma murino), B, HCT-116 (câncer de cólon), e C, RAW 264.7 (macrófagos murinos). 1: Bacillus sp. sac1; 7: Bacillus sp sac7; 9: Bacillus sp sac9; 16: Bacillus sp sac16; 18: Bacillus sp sac18; 22: Bacillus sp sac22; 45: Bacillus sp sac45; 51: Bacillus sp sac51; 54: Curtobacterium sp. sac54; e 64: Bacillus sp sac64

As amostras não apresentaram porcentagem de inibição de crescimento significante, quer dizer, não apresentaram citotoxidade para as células avaliadas, sendo mostrado na figura a taxa metabólica das linhagens com as respectivas amostras testadas. Nas linhagens B16-F10 e RAW 264.7 (Figura 29 A e C), todas apresentaram valores maiores que a taxa metabólica do controle negativo (tracejado), podendo indicar aumento da proliferação. No caso da linhagem HCT-116 (Figura 29B), alguns 
tratamentos exibiram taxa metabólica menor que o controle negativo, porém a maioria apresentou uma taxa maior que o controle. Mais testes deverão ser feitos para avaliar esses resultados.

\subsection{Ensaios de produção de Ácido Hialurônico}

$\mathrm{O}$ ácido hialurônico $(\mathrm{AH})$ é um biopolímero natural de elevado peso molecular que, graças as suas propriedades estruturais, reológicas, fisiológicas e biológicas, desempenha funções estruturais, de reconhecimento e de sinalização nos tecidos do corpo de humanos e animais (SHENG; LING; WANG, 2014; WIDNER et al., 2005; YU et al., 2008). Pela mesma razão, essa macromolécula tem sido usada em medicamentos, cosméticos, sistemas de entrega de drogas, vacinas contra Aids e alimentos. Na indústria é produzido utilizando a bactéria Gram-positiva Streptococcus zooepidemicus, porém, esse microrganismo não é a fonte mais ideal de $\mathrm{AH}$ devido ao seu potencial para produzir exotoxinas, a dificuldade no controle da fermentação e do alto custo do meio de cultivo necessário para o crescimento. Em consequência, a procura de outros microrganismos alternativos para produção de AH é de interesse e desejável para a indústria (SHENG; LING; WANG, 2014).

Deste modo, conhecendo o potencial biotecnológico de novas linhagens produtoras de $\mathrm{AH}$, avaliou-se a capacidade de produção de ácido hialurônico dos isolados halotolerantes da caatinga realizando culturas em meio liquido de produção e quantificação pelo método de Alcian Blue. Os resultados obtidos são apresentados a continuação na tabela 14 e na figura 30 . Os dados da curva padrão de $\mathrm{AH}$ encontra-se no apêndice $B$.

Para começar, o Alcian blue é um corante de ftalocianina de cobre $\left(\mathrm{C}_{56} \mathrm{H}_{68} \mathrm{C}_{14} \mathrm{CuN}_{16} \mathrm{~S}_{4}\right)$ e solúvel em água, que pode ser utilizado para coloração de ácidos mucopolissacarídeos sulfatados e carboxilados. Sabe-se que o corante age formando ligações de sal com os grupos ácidos de mucopolissacarídeos devido à presença de cobre na molécula, o que causa uma diminuição da cor azul (YU et al., 2008). Dado que o AH é um mucopolissacarídeo, o método descrito por YU et al. (2008) é usado para quantificação desse biopolímero. 
Assim, o método consiste na medição fotométrica de uma solução de Alcian blue que precipita com $\mathrm{AH}$, o que cria uma relação inversa entre a concentração de $\mathrm{AH}$ e a absorbância do corante, que finalmente é ajustada num polinômio de segunda ordem permitindo a quantificação do $\mathrm{AH}$ nas amostras.

Tabela 13 -Screening de produção e quantificação de AH usando o Alcian blue. Linhagem controle Streptococcus equi subsp. Zooepidemicus ATCC 39920. Os dados correspondem à média dos experimentos em triplicata e seu respectivo desvio padrão

\begin{tabular}{|c|c|c|}
\hline $\begin{array}{l}\text { Isolado } \\
\end{array}$ & D. $0_{540 \mathrm{~nm}}$ & $\mathrm{AH}(\mathrm{mg} / \mathrm{L})$ \\
\hline \multirow{2}{*}{$\begin{array}{c}\text { Streptococcus equi } \\
\text { subsp. Zooepidemicus ATCC } 39920 \\
\text { sac1 }\end{array}$} & $0,171 \pm 0,0$ & 640,6 \\
\hline & $0,214 \pm 0,0$ & 561,6 \\
\hline sac7 & $0,300 \pm 0,0$ & 420,0 \\
\hline sac9 & $0,171 \pm 0,0$ & 640,6 \\
\hline sac10 & $0,187 \pm 0,0$ & 610,6 \\
\hline sac16 & $0,783 \pm 0,0$ & 34,2 \\
\hline sac18 & $0,295 \pm 0,0$ & 426,4 \\
\hline sac22 & $0,301 \pm 0,0$ & 418,5 \\
\hline sac23 & $0,163 \pm 0,0$ & 655,6 \\
\hline sac24 & $0,266 \pm 0,0$ & 472,6 \\
\hline sac33 & $0,159 \pm 0,0$ & 663,6 \\
\hline sac34 & $0,177 \pm 0,0$ & 628,9 \\
\hline sac36 & $0,190 \pm 0,0$ & 603,5 \\
\hline sac37 & $0,155 \pm 0,0$ & 671,4 \\
\hline sac38 & $0,191 \pm 0,0$ & 601,6 \\
\hline sac41 & $0,161 \pm 0,0$ & 658,2 \\
\hline sac44 & $0,233 \pm 0,0$ & 527,0 \\
\hline sac45 & $0,799 \pm 0,0$ & 33,3 \\
\hline sac51 & $0,805 \pm 0,1$ & 33,1 \\
\hline sac53 & $0,168 \pm 0,0$ & 645,4 \\
\hline sac54 & $0,131 \pm 0,0$ & 719,0 \\
\hline sac58 & $0,163 \pm 0,0$ & 655,9 \\
\hline sac59 & $0,152 \pm 0,0$ & 676,3 \\
\hline sac64 & $0,173 \pm 0,0$ & 636,8 \\
\hline sac65 & $0,206 \pm 0,0$ & 575,9 \\
\hline sac66 & $0,173 \pm 0,0$ & 636,8 \\
\hline
\end{tabular}




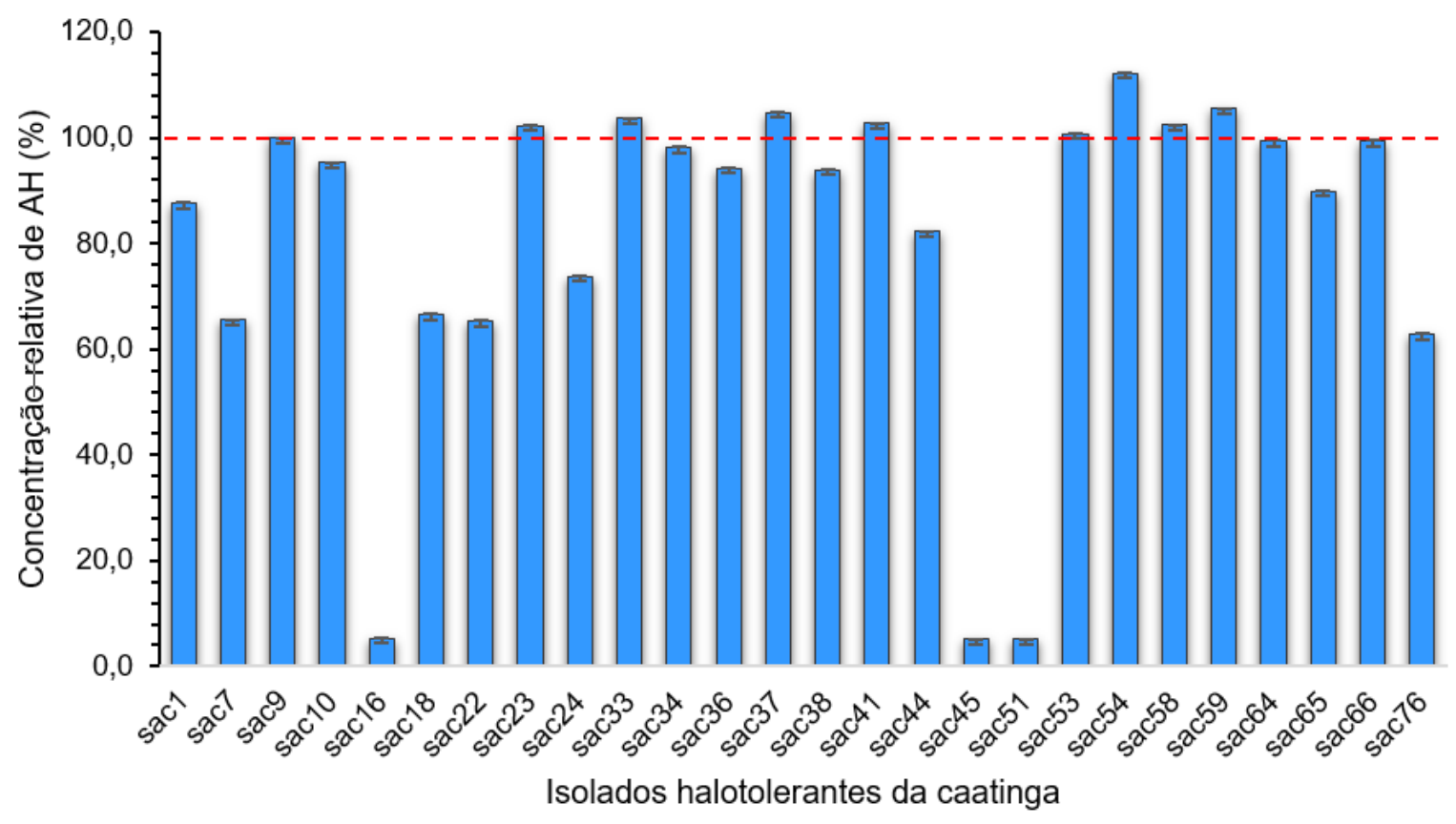

Figura 30 - Gráfico da concentração relativa de AH obtida a partir de isolados halotolerantes da caatinga. Linhagem controle (linha tracejada em vermelho-100\%), Streptococcus equi subsp. Zooepidemicus ATCC 39920

Como se observa na figura 30, o isolado Curtobacterium sp. sac54 mostrou a maior concentração relativa de $\mathrm{AH}(112 \%)$ em relação ao controle (linha $100 \%)$. Vejase também que os isolados Bacillus sp. sac23 (102\%), Bacillus sp. sac33 (104\%), Curtobacterium sp. sac37 (105\%), Bacillus sp. sac41 (103\%), Curtobacterium sp. sac58 (102\%) e Staphylococcus sp. sac59 (106\%) apresentaram uma produção de AH maior ao controle. Por outro lado, de 15 isolados que apresentaram concentrações entre $90 \%$ ou maiores ao controle, 53 \% pertencem ao gênero Bacillus, 27 \% a Curtobacterium, 13 $\%$ a Staphylococcus e 7\% a Exiguobacterium.

No caso dos isolados Bacillus sp. sac16, Bacillus sp. sac45 e Bacillus sp. sac51, observou-se uma concentração relativa inferior ao $10 \%$. Contudo, destaca-se que em geral mais da metade dos isolados halotolerantes, segundo sugere o método de Alcian blue, foram capazes de produzir $\mathrm{AH}$ e também de acumular o biopolímero em concentrações maiores ou semelhantes ao controle, fato que demostra o potencial promissor destas linhagens como fonte alternativa na produção industrial de $\mathrm{AH}$. Porém, os resultados ainda têm que ser avaliados por métodos analíticos devido a que o corante 
pode medir também outro tipo de mucopolissacarídeos como foi mencionado anteriormente. 


\section{CONCLUSÕES}

O presente trabalho buscou contribuir no estudo do potencial biotecnológico de microrganismos isolados no bioma caatinga, destacando sua biodiversidade e a relevância de continuar explorando ambientes extremos pouco estudados. Os resultados descritos ao longo do texto evidenciam que os isolados halotolerantes são uma fonte rica em compostos com atividades interessantes para as diferentes industrias. Consequentemente, os ensaios preliminares realizados indicaram que a maioria dos isolados são bactérias Gram-positivas, pertencentes a gêneros descritos frequentemente em ambientes extremos, que graças à capacidade que possuem de sintetizar diferentes compostos conseguem proliferar nessas condições adversas e até proteger outro tipo de organismos como espécies vegetais. Todos os isolados avaliados são microrganismos halotolerantes, que apresentam a capacidade de crescer em $120 \mathrm{~g} / \mathrm{L} \mathrm{de} \mathrm{NaCl}$, característica relevante para a aplicação destas bactérias em nível industrial em processos ambientalmente amigáveis onde a água do mar pode ser usada.

Este trabalho permitiu confirmar que quatro isolados do gênero Bacillus são capazes de acumular 3-hidroxibutirato (3HB) a partir de glicose, xilose e glicerol, adicionalmente, observou-se acúmulo de $3 \mathrm{HB}$ em experimentos se fornecendo altas concentrações de $\mathrm{NaCl}$, o que levou a uma diminuição no acúmulo. Porém, os resultados sugerem o potencial uso destas bactérias pertencentes ao gênero Bacillus na produção de $\mathrm{PHB}$, em processos onde fontes de carbono de baixo custo e meios com elevada concentração de sal podem ser usadas.

Alguns isolados halotolerantes foram capazes de produzir EPS, os quais não são citotóxicos e têm efeitos imunoestimulantes em macrófagos murinos, resultados que mostram a relevância desses compostos bacterianos no desenvolvimento de novas drogas e medicamentos para o tratamento de diferentes doenças como as geradas por virus e células cancerígenas. Os ensaios de produção de biopolímeros permitiram evidenciar dois grupos, membros do mesmo gênero Bacillus, diferenciados pelo composto sintetizado e posição filogenética: produção de $\mathrm{PHB}$ (isolados próximos à espécie $B$. endophyticus), e produção de EPS (isolados próximos à espécie $B$. paralicheniformis). 
Todos os isolados halotolerantes foram capazes de produzir $\mathrm{AH}$ e $58 \%$ deles acumularam o biopolímero em concentrações maiores ou semelhantes ao controle. A produção deste biopolimero a partir das bactérias halotolerantes isoladas do bioma caatinga, apresentam uma vantagem sob as linhagens usadas atualmente nas industrias pois não são microrganismos patogênicos. 


\section{REFERÊNCIAS*}

ABDEL-MAWGOUD, A. M.; LÉPINE, F.; DÉZIEL, E. Rhamnolipids: Diversity of structures, microbial origins and roles. Applied Microbiology and Biotechnology, v. 86, n. 5, p. 1323-1336, 2010.

ALBARRACÍN, V. H.; GÄRTNER, W.; FARIAS, M. E. Forged under the Sun: Life and Art of Extremophiles from Andean Lakes. Photochemistry and Photobiology, v. 92, n. 1, p. 14-28, 2016.

AL-MAILEM, D. et al. Culture-Dependent and Culture-Independent Analysis of Hydrocarbonoclastic Microorganisms Indigenous to Hypersaline Environments in Kuwait. Microbial Ecology, v. 67, p. 857-865, 2014.

ANDRÉ CREMONEZ, P. et al. Biodiesel production in Brazil: Current scenario and perspectives. Renewable and Sustainable Energy Reviews, v. 42, p. 415-428, 2015.

BHARTI, N. et al. Exiguobacterium oxidotolerans, a halotolerant plant growth promoting rhizobacteria, improves yield and content of secondary metabolites in Bacopa monnieri (L.) Pennell under primary and secondary salt stress. World Journal of Microbiology and Biotechnology, v. 29, n. 2, p. 379-387, 2013.

BHATNAGAR, A; BHATNAGAR, M. Microbial diversity in desert ecosystems. Current Science, v. 89, n. 1, p. 91-100, 2005.

CABRIA, G. L. B. et al. Draft Genome Sequence of Haloalkaliphilic Exiguobacterium sp. Strain AB2 from Manleluag Ophiolitic Spring, Philippines. Genome Announcements, v. 2, n. 4, p. 2-3, 2014.

CARDINALE, M. et al. Paradox of plant growth promotion potential of rhizobacteria and their actual promotion effect on growth of barley (Hordeum vulgare L.) under salt stress. Microbiological Research, v. 181, p. 22-32, 2015.

*De acordo com:

ASSOCIAÇÃO BRASILEIRA DE NORMAS TÉCNICAS. NBR 6023: Informação e documentação: referências: elaboração. Rio de Janeiro, 2002. 
CELIK, G. Y.; ASLIM, B.; BEYATLI, Y. Characterization and production of the exopolysaccharide (EPS) from Pseudomonas aeruginosa G1 and Pseudomonas putida G12 strains. Carbohydrate Polymers, v. 73, n. 1, p. 178-182, 2008.

CHAUHAN, $\mathrm{H}$. et al. Novel plant growth promoting rhizobacteria-Prospects and potential. Applied Soil Ecology, v. 95, p. 38-53, 2015.

CHIMETTO, L. A. et al. Vibrios dominate as culturable nitrogen-fixing bacteria of the Brazilian coral Mussismilia hispida. Systematic and Applied Microbiology, v. 31, n. 4, p. 312-319, 2008.

CHONG, B. F. et al. Microbial hyaluronic acid production. Applied Microbiology and Biotechnology, v. 66, n. 4, p. 341-351, 2005.

CHROMASPRO. Version 2.1.2. Technelysium ${ }^{\odot}$, 1998. Software. Disponível em: http://technelysium.com.au/wp/chromaspro. Acesso em: 12 nov. 2014.

DALY, M. J. Extremophiles Handbook. Extremophiles, p. 1118-1130, 2010.

DAOUD, L. et al. Purification and biochemical characterization of a halotolerant Staphylococcus sp. extracellular lipase. International Journal of Biological Macromolecules, v. 57, p. 232-237, 2013.

DE ALBUQUERQUE, U. P. et al. Medicinal plants of the caatinga (semi-arid) vegetation of NE Brazil: A quantitative approach. Journal of Ethnopharmacology, v. 114, n. 3, p. 325-354, 2007.

DE CARVALHO, C. C. C. R.; FERNANDES, P. Production of metabolites as bacterial responses to the marine environment. Marine Drugs, v. 8, n. 3, p. 705-727, 2010.

DE JESUS ASSIS, D. et al. Simultaneous Biosynthesis of Polyhydroxyalkanoates and Extracellular Polymeric Substance (EPS) from Crude Glycerol from Biodiesel Production by Different Bacterial Strains. Applied Biochemistry and Biotechnology, 2016a.

DE JESUS ASSIS, D. et al. Simultaneous Biosynthesis of Polyhydroxyalkanoates and Extracellular Polymeric Substance (EPS) from Crude Glycerol from Biodiesel Production by Different Bacterial Strains. Applied Biochemistry and Biotechnology, 29 jun. 2016b. 
DE LOS SANTOS, M. C. et al. Identification and characterization of the part of the bacterial community associated with field-grown tall fescue (Festuca arundinacea) cv. SFRO Don Tomás in Uruguay. Annals of Microbiology, v. 66, n. 1, p. 1-14, 2015.

DHAKAR, K.; PANDEY, A. Wide $\mathrm{pH}$ range tolerance in extremophiles: towards understanding an important phenomenon for future biotechnology. Applied Microbiology and Biotechnology, v. 100, n. 6, p. 1-12, 2016.

DHANGDHARIYA, J. H. et al. Polyhydroxyalkanoate from marine Bacillus megaterium using CSMCRI's Dry Sea Mix as a novel growth medium. International Journal of Biological Macromolecules, v. 76, p. 254-261, maio 2015.

DIAS, A. C. F. et al. Diversity and biotechnological potential of culturable bacteria from Brazilian mangrove sediment. World Journal of Microbiology and Biotechnology, v. 25, n. 7, p. 1305-1311, 2009.

DIKEN, E. et al. Genomic analysis reveals the biotechnological and industrial potential of levan producing halophilic extremophile, Halomonas smyrnensis AAD6T. SpringerPlus, v. 4 , p. $393,2015$.

DRANCOURT, M.; RAOULT, D. rpoB Gene Sequence-Based Identification of Staphylococcus Species. Journal of Clinical Microbiology, v. 40, n. 4, p. 1333-1338, 2002.

EDDOUAOUDA, K. et al. Characterization of a novel biosurfactant produced by Staphylococcus sp. strain 1E with potential application on hydrocarbon bioremediation. Journal of Basic Microbiology, v. 52, n. 4, p. 408-418, 2012.

EL-DEEB, B.; FAYEZ, K.; GHERBAWY, Y. medicinal plant in Saudi Arabia desert and their antimicrobial activities. Journal of Plant Interactions, v. 9145, n. June 2015, p. 19, 2012.

ELLEUCHE, S. et al. Exploration of extremophiles for high temperature biotechnological processes. Current Opinion in Microbiology, v. 25, p. 113-119, 2015.

EMPRESA BRASILEIRA DE PESQUISA AGROPECUÁRIA. Laboratório de Microbiologia Ambiental. 2014. 1 fotografia. 
FABER, M. DE O.; FERREIRA-LEITÃO, V. S. Optimization of biohydrogen yield produced by bacterial consortia using residual glycerin from biodiesel production. Bioresource Technology, v. 219, p. 365-370, 2016.

FERREIRA, C. Dinâmica do microbioma da rizosfera de mandacaru na Caatinga. 2014. 88 f. Dissertação (Mestrado em Ciências) - Universidade de São Paulo Escola Superior de Agricultura "Luiz de Queiroz", Piracicaba, 2014.

GENBANK. National center for Biotechnology Information. Disponível em: (www.ncbi.nlm.nih.gov). Acesso em: 4 out. 2015.

GIAMMARINARO, P. et al. Development of a new oligonucleotide array to identify staphylococcal strains at species level. Journal of Clinical Microbiology, v. 43, n. 8, p. 3673-3680, 2005.

GONÇALVES, V. N. et al. Antibacterial, antifungal and antiprotozoal activities of fungal communities present in different substrates from Antarctica. Polar Biology, p. 11431152, 2015.

GOOGLE. Google imagens. Mapa bioma caatinga. 2016. Disponível em: https://www.google.com.br. Acesso em: 15 jun. 2014.

GOOGLE. Google Earth. 2016. Areia Branca. Disponível em: https://www.google.com.br/intl/pt-BR/earth/download/thanks.html\#os=win\#updater=yes. Acesso em: 18 maio 2016.

GOUDARZI, G. et al. Particulate matter and bacteria characteristics of the Middle East Dust (MED) storms over Ahvaz, Iran. Aerobiologia, v. 30, n. 4, p. 345-356, 2014.

GREEN, L. C. et al. Analysis of nitrate, nitrite, and [15N]nitrate in biological fluids. Analytical Biochemistry, v. 126, n. 1, p. 131-138, 1982.

GREEN, L. C.; TANNENBAUM, S. R.; GOLDMAN, P. Nitrate synthesis in the germfree and conventional rat. Science (New York, N.Y.), v. 212, n. 4490, p. 56-8, 3 abr. 1981.

GUGLIANDOLO, C. et al. Antiviral and immunomodulatory effects of a novel bacterial exopolysaccharide of shallow marine vent origin. Journal of Applied Microbiology, $v$. 116, n. 4, p. 1028-1034, 2014. 
HAMEDI, J.; MOHAMMADIPANAH, F.; VENTOSA, A. Systematic and biotechnological aspects of halophilic and halotolerant actinomycetes. Extremophiles, v. 17, n. 1, p. 113, 2013.

HEYMANN, D. et al. Anti-metastatic properties of a marine bacterial exopolysaccharidebased derivative designed to mimic glycosaminoglycans. Molecules, v. 21, n. 3, 2016.

HOLBEN, W. E. et al. GC Fractionation Enhances Microbial Community Diversity Assessment and Detection of Minority Populations of Bacteria by Denaturing Gradient Gel Electrophoresis GC Fractionation Enhances Microbial Community Diversity Assessment and Detection of Minority Po. Applied and Environmantal Microbiology, v. 70, n. 4, p. 2263-2270, 2004.

HUANG, L. et al. The composition analysis and preliminary cultivation optimization of a PHA-producing microbial consortium with xylose as a sole carbon source. Waste Management, v. 52, p. 77-85, jun. 2016.

ISNANSETYO, A.; KAMEI, Y. Bioactive substances produced by marine isolates of Pseudomonas. Journal of Industrial Microbiology \& Biotechnology, v. 36, n. 10, p. 1239-1248, 2009.

JAIN, R.; NAGAL, S.; JAIN, P. C. Halophiles - Taxonomy, Diversity, Physiology and Applications. Microorganisms in Environmental Management, 745-766, 2012.

JOGHEE, N. N.; JAYARAMAN, G. Biochemical Changes Induced by Salt Stress in Halotolerant Bacterial Isolates is Media Dependent as Well as Species Specific. Preparative Biochemistry and Biotechnology, n. March 2015, p. 37-41, 2014.

JUIBARI, M. M. et al. Investigation of a Hot-Spring Extremophilic Ureibacillus thermosphaericus Strain Thermo-BF for Extracellular Biosynthesis of Functionalized Gold Nanoparticles. BioNanoScience, v. 5, n. 4, p. 233-241, 2015.

KAPLAN, D. et al. A survey of the microbial community in the rhizosphere of two dominant shrubs of the Negev Desert highlands, Zygophyllum dumosum (Zygophyllaceae) and Atriplex halimus (Amaranthaceae), using cultivation-dependent and cultivationindependent methods. American Journal of Botany, v. 100, n. 9, p. 1713-1725, 2013.

KAVAMURA, V. N. et al. Screening of Brazilian cacti rhizobacteria for plant growth promotion under drought. Microbiological Research, v. 168, n. 4, p. 183-191, 2013a. 
KAVAMURA, V. N. et al. Screening of Brazilian cacti rhizobacteria for plant growth promotion under drought. Microbiological Research, v. 168, n. 4, p. 183-91, 6 maio 2013b.

KIM, M. K. et al. Curtobacterium ginsengisoli sp. nov., isolated from soil of a ginseng field. International Journal of Systematic and Evolutionary Microbiology, v. 58, n. 10, p. 2393-2397, 2008a.

KIM, S. K. et al. Prospective of the cosmeceuticals derived from marine organisms. Biotechnology and Bioprocess Engineering, v. 13, n. 5, p. 511-523, 2008b.

KIMURA, M. A simple method for estimating evolutionary rates of base substitutions through comparative studies of nucleotide sequences. Journal of Molecular Evolution, v. 16, n. 2, p. 111-20, dez. 1980.

KÖHLER, K. A. K. et al. D-Xylose assimilation via the Weimberg pathway by solventtolerant Pseudomonas taiwanensis. Environmental Microbiology, v. 17, p. 156-170, 2015.

KREYENSCHULTE, D.; KRULL, R.; MARGARITIS, A. Recent Advances in Microbial Biopolymer Production and Purification. Critical Reviews in Biotechnology, v. 34, n. 1, p. 1-15, 29 mar. 2014.

KUHLMAN, K. R. et al. Enumeration, isolation, and characterization of ultraviolet (UV-C) resistant bacteria from rock varnish in the Whipple Mountains, California. Icarus, v. 174, n. 2, p. 585-595, 1 abr. 2005.

KULKARNI, S. O. et al. International Journal of Biological Macromolecules Production of copolymer, poly ( hydroxybutyrate-co-hydroxyvalerate ) by Halomonas campisalis MCM B-1027 using agro-wastes. International Journal of Biological Macromolecules, v. 72 , p. $784-789,2015$.

KUMAR, P. et al. Extending the limits of Bacillus for novel biotechnological applications. Biotechnology Advances, v. 31, n. 8, p. 1543-1561, dez. 2013.

KUMAR, P. et al. Ecobiotechnological Approach for Exploiting the Abilities of Bacillus to Produce Co-polymer of Polyhydroxyalkanoate. Indian Journal of Microbiology, v. 54, n. 2, p. 151-7, 2014. 
LIANG, T. W.; WANG, S. L. Recent advances in exopolysaccharides from Paenibacillus spp.: Production, isolation, structure, and bioactivities. Marine Drugs, v. 13, n. 4, p. 18471863, 2015.

LINDGREN, A. R. et al. Life on the Edge-the Biology of Organisms Inhabiting Extreme Environments: An Introduction to the Symposium. Integrative and Comparative Biology, p. 1-7, 2016.

LIU, L. et al. Microbial production of hyaluronic acid: current state, challenges, and perspectives. Microbial Cell Factories, v. 10, n. 1, p. 99, 2011.

LIU, R. et al. Pseudomonas duriflava sp. nov., isolated from a desert soil. International Journal of Systematic and Evolutionary Microbiology, v. 58, n. 2008, p. 1404-1408, 2008.

LOPES, M. S. G. et al. Screening of bacteria to produce polyhydroxyalkanoates from xylose. World Journal of Microbiology and Biotechnology, v. 25, n. 10, p. 1751-1756, 2009.

LOPES, M. S. L. et al. Role of CcpA in polyhydroxybutyrate biosynthesis in a newly isolated Bacillus sp. MA3.3. Journal of Molecular Microbiology and Biotechnology, v. 20, n. 2, p. 63-69, 2011.

MANDIC-MULEC, I.; STEFANIC, P.; ELSAS, J. A. N. D. V. A. N. Ecology of Bacillaceae. American Society for Microbiology, p. 1-25, 2015.

MARRONI, I. V. Screening of bacteria of the genus Bacillus for the control of the plantpathogenic fungus Macrophomina phaseolina. Biocontrol Science and Technology, v. 25, n. 3, p. 302-315, 2014.

MÁTHÉ, I. et al. Vertical physico-chemical gradients with distinct microbial communities in the hypersaline and heliothermal Lake Ursu (Sovata, Romania). Extremophiles, v. 18, n. 3, p. 501-514, 2014.

MAYELI, N.; MOTAMEDI, H.; HEIDARIZADEH, F. Production of Polyhydroxybutyrate by Bacillus axaraqunsis BIPC01 using Petrochemical Wastewater as Carbon Source. Brazilian Archives of Biology and Technology, v. 58, n. 4, p. 643-650, 2015. 
MOHAPATRA, S. et al. Production of Polyhydroxyalkanoates (PHAs) by Bacillus Strain Isolated from Waste Water and Its Biochemical Characterization. Proceedings of the National Academy of Sciences, India Section B: Biological Sciences, v 4, n. 16, p. 1 8, 2015.

MOKHTARZADEH, A. et al. Bacterial-derived biopolymers: Advanced natural nanomaterials for drug delivery and tissue engineering. TrAC - Trends in Analytical Chemistry, v. 82, p. 367-384, 2016.

MOORKOTH, D.; NAMPOOTHIRI, K. M. Bioresource Technology Production and characterization of poly ( 3-hydroxy butyrate-co-3 hydroxyvalerate) ( PHBV ) by a novel halotolerant mangrove isolate. Bioresource Technology, v. 201, p. 253-260, 2016.

MOTA, M. J. et al. Microorganisms under high pressure - Adaptation, growth and biotechnological potential. Biotechnology Advances, v. 31, n. 8, p. 1426-1434, 2013.

MUANGWONG, A. et al. Medium chain length polyhydroxyalkanoates consisting primarily of unsaturated 3 - hydroxy - 5 - cis - dodecanoate synthesized by newly isolated bacteria using crude glycerol. Microbial Cell Factories, v.15, n. 55, p. 1-17, 2016.

NARANJO, J. M. et al. Valorization of glycerol through the production of biopolymers: The PHB case using Bacillus megaterium. Bioresource Technology, v. 133, p. 38-44, $2013 a$.

NARANJO, J. M. et al. Valorization of glycerol through the production of biopolymers: The PHB case using Bacillus megaterium. Bioresource Technology, v. 133, p. 38-44, abr. 2013b.

NEIFAR, M. et al. Extremophiles as source of novel bioactive compounds with industrial potential. In: Gupta, V. K.; TUOHY, M. G. Biotechnology of bioactive compounds: sources and applications. West Sussex: John Wiley \& Son, 2015. p. 736.

NESSNER KAVAMURA, V. et al. Water Regime Influences Bulk Soil and Rhizosphere of Cereus jamacaru Bacterial Communities in the Brazilian Caatinga Biome. PLoS ONE, v. 8, n. 9, p. e73606, 2013.

NICOLAUS, B. et al. Polysaccharides from extremophilic microorganisms. Origins of Life and Evolution of the Biosphere, v. 34, n. 1-2, p. 159-169, 2004. 
ORDOÑEZ, O. F. et al. Extremophile culture collection from Andean lakes: Extreme pristine environments that host a wide diversity of microorganisms with tolerance to UV radiation. Microbial Ecology, v. 58, n. 3, p. 461-473, 2009.

OREN, A. Microbial life at high salt concentrations: phylogenetic and metabolic diversity. Saline Systems, v. 4, p. 2, jan. 2008.

OREN, A. Industrial and environmental applications of halophilic microorganisms. Environmental Technology, v. 31, n. 8-9, p. 825-834, 2010.

PAULO, E. M. et al. An alternative method for screening lactic acid bacteria for the production of exopolysaccharides with rapid confirmation. Food Science and Technology, v. 32, n. 4, p. 710-714, dez. 2012.

PEIX, A.; RAMÍREZ-BAHENA, M. H.; VELÁZQUEZ, E. Historical evolution and current status of the taxonomy of genus Pseudomonas. Infection, Genetics and Evolution, $v$. 9, n. 6, p. 1132-1147, 2009.

PODAR, M.; REYSENBACH, A.-L. New opportunities revealed by biotechnological explorations of extremophiles. Current Opinion in Biotechnology, v. 17, n. 3, p. 250 255, 2006.

POLI, A.; ANZELMO, G.; NICOLAUS, B. Bacterial Exopolysaccharides from Extreme Marine Habitats: Production, Characterization and Biological Activities. Marine Drugs, $v$. 8, n. 6, p. 1779-1802, 2010.

POWELL, J. T. et al. Desert crust microorganisms, their environment, and human health. Journal of Arid Environments, v. 112, p. 127-133, jan. 2015.

PRADOS, E.; MAICAS, S. Bacterial Production of Hydroxyalkanoates (PHA). Universal Journal of Microbiology Research, v. 4, n. 1, p. 23-30, 2016.

RADDADI, N. et al. Biotechnological applications of extremophiles, extremozymes and extremolytes. Applied Microbiology and Biotechnology, v. 99, n. 19, p. 7907-7913, 2015.

RAMSAY, B. A. et al. Production of poly-(beta-hydroxybutyric-co-beta-hydroxyvaleric) acids. Applied and Environmental Microbiology, v. 56, n. 7, p. 2093-8, 1990. 
RAVEENDRAN, S. et al. Extremophilic polysaccharide nanoparticles for cancer nanotherapy and evaluation of antioxidant properties. International Journal of Biological Macromolecules, v. 76, p. 310-319, 2015.

REHM, B. H. A. Bacterial polymers: biosynthesis, modifications and applications. Nature reviews. Microbiology, v. 8, n. 8, p. 578-592, 2010.

RIBOSOMAL DATABASE PROJECT II. Version 11. Michigan State University, 2014. Software. Disponível em: http://rdp.cme.msu.edu. Acesso em: 4 out. 2015.

RIIS, V.; MAI, W. Gas chromatographic determination of poly- $\beta$-hydroxybutyric acid in microbial biomass after hydrochloric acid propanolysis. Journal of Chromatography A, v. 445 , p. 285-289, jan. 1988.

RIVERA-TERCEROS, P. et al. Production of poly(3-hydroxybutyrate) by Halomonas boliviensis in an air-lift reactor. Journal of Biological Research-Thessaloniki, v. 22, n. 8, p. 1-9, 2015.

RODRÍGUEZ-CONTRERAS, A. et al. Influence of glycerol on poly ( 3-hydroxybutyrate ) production by Cupriavidus necator and Burkholderia sacchari. Biochemical Engineering Journal, v. 94, p. 50-57, 2015.

$\mathrm{ROOHI}$, A. et al. Isolation and phylogenetic identification of halotolerant/halophilic bacteria from the salt mines of Karak, Pakistan. International Journal of Agriculture and Biology, v. 16, n. 3, p. 564-570, 2014.

SAMBROOK, J.; FRITSCH, E.F.; Maniatis, T. Molecular cloning - A Laboratory Manual. E5. New York: Cold Spring Harbor, 1989. v. 3.

SANGER, F.; NICKLEN, S.; COULSON, A. DNA sequencing with chain-terminating inhibitors. Proceedings of the National Academy of Sciences of the United States of America. v. 74, n. 12, p. 5463-7, 1977.

SANGKHARAK, K.; PRASERTSAN, P. Screening and identifi cation of polyhydroxyalkanoates producing bacteria and biochemical characterization of their possible application. The Journal of General and Applied Microbiology, v. 58, 2012.

SARMIENTO, F.; PERALTA, R.; BLAMEY, J. M. Cold and Hot Extremozymes: Industrial 
Relevance and Current Trends. Frontiers in Bioengineering and Biotechnology, v. 3, p. 148, 2015.

SCHLEGEL, H. G.; LAFFERTY, R.; KRAUSS, I. The isolation of mutants not accumulating poly-beta-hydroxybutyric acid. Archiv für Mikrobiologie, v. 71, n. 3, p. 283-94, 1970.

SCHMID, J.; SIEBER, V.; REHM, B. Bacterial exopolysaccharides: Biosynthesis pathways and engineering strategies. Frontiers in Microbiology, v. 6, n. MAY, p. 1-24, 2015.

SHARMA, G. et al. Biologicals Pseudomonas aeruginosa biofilm: Potential therapeutic targets. Biologicals, v. 42, p. 1-7, 2013.

SHENG, J.; LING, P.; WANG, F. Constructing a recombinant hyaluronic acid biosynthesis operon and producing food-grade hyaluronic acid in Lactococcus lactis. Journal of Industrial Microbiology and Biotechnology, v. 42, n. 2, p. 197-206, 2014.

SHI, W. et al. Anditalea andensis ANESC-S ${ }^{\top}$ - An alkaliphilic halotolerant bacterium capable of electricity generation under alkaline-saline conditions. PLoS ONE, v. 10, n. 7, p. 1-12, 2015.

SHIN, J.-S. et al. Exopolysaccharide fraction from Pediococcus pentosaceus KFT18 induces immunostimulatory activity in macrophages and immunosuppressed mice. Journal of Applied Microbiology, p. n/a-n/a, 2016.

SILVA, L. F. et al. Perspectives on the production of polyhydroxyalkanoates in biorefineries associated with the production of sugar and ethanol. International Journal of Biological Macromolecules, v. 71, p. 2-7, 2014.

SILVI, S. et al. Physiologic and metabolic characterization of a new marine isolate (BM39) of Pantoea sp. producing high levels of exopolysaccharide. Microbial Cell Factories, v. 12, n. 1, p. 10, 2013.

SINDHU, R. et al. Pentose-rich hydrolysate from acid pretreated rice straw as a carbon source for the production of poly-3-hydroxybutyrate. Biochemical Engineering Journal, v. 78, p. 67-72, set. 2013.

SINGH, G. et al. Optimization of Poly-B-Hydroxybutyrate Production from Bacillus 
species. European Journal of Biological Sciences, v. 3, n. 4, p. 112-116, 2011.

SINGH, G. et al. Cost Effective Production of Poly- $\beta$-Hydroxybutyrate by Bacillus subtilis NG05 Using Sugar Industry Waste Water. Journal of Polymers and the Environment, v. 21, n. 2, p. 441-449, 25 jun. $2013 a$.

SINGH, M. et al. Production of Polyhydroxyalkanoate Co-polymer by Bacillus thuringiensis. Indian Journal of Microbiology, v. 53, n. 1, p. 77-83, 2013b.

SIRAJUNNISA, A. R. et al. Optimization, kinetics and antioxidant activity of exopolysaccharide produced from rhizosphere isolate, Pseudomonas fluorescens CrN6. Carbohydrate Polymers, v. 135, p. 35-43, 2016.

SOARES, F. L. et al. Cellulolytic bacteria from soils in harsh environments. World Journal of Microbiology and Biotechnology, v. 28, n. 5, p. 2195-2203, 2012.

SPANÒ, A. et al. In Vitro Antibiofilm Activity of an Exopolysaccharide from the Marine Thermophilic Bacillus licheniformis T14. Current Microbiology, v. 72, n. 5, p. 518-528, 2016.

SPANÒ, A.; ARENA, A. Bacterial Exopolysaccharide of Shallow Marine Vent Origin as Agent in Counteracting Immune Disorders Induced by Herpes Virus. Journal of Immunoassay and Immunochemistry, v. 37, n. 3, p. 251-260, 2016.

STOTT, M. B.; TAYLOR, M. W. Microbial ecology research in New Zealand. New Zealand Journal of Ecology, v. 40, n. 1, p. 12-28, 2016.

SUKAN, A.; ROY, I.; KESHAVARZ, T. Dual production of biopolymers from bacteria. Carbohydrate Polymers, v. 126, p. 47-51, 2015.

SURIYAMONGKOL, P. et al. Biotechnological approaches for the production of polyhydroxyalkanoates in microorganisms and plants - A review. Biotechnology Advances, v. 25, n. 2, p. 148-175, 2007.

TAMURA, K. et al. MEGA6: Molecular Evolutionary Genetics Analysis version 6.0. Molecular Biology and Evolution, v. 30, n. 12, p. 2725-9, 1 dez. 2013.

TRIPATHI, P. Nitric oxide and the immune response. Indian Journal of Biochemistry 
Biophysics, v. 44, p. 310-319, 2007.

UNIÃO DA INDUSTRIA DE CANA-DE-AÇÚCAR. Acompanhamento de safra. Disponível em: http://www.unica.com.br/. Acesso em: 10 set. 2016.

UNITED NATIONS ENVIRONMENT PROGRAMME. Global environment outlook: environment for development (GEO - 4). Section B State and - Trends of the Environment: 1987-2007. Malta: Valletta, 2007. 540 p.

UPADHYAY, K. H. et al. Diversity assessment and EPS Production Potential of Cultivable Bacteria from the Samples of Coastal site of Alang. Journal of Microbiology and Food Sciences, p. 661-666, 2016.

VALAPPIL, S. P. et al. Polyhydroxyalkanoates in Gram-positive bacteria: insights from the genera Bacillus and Streptomyces. Antonie van Leeuwenhoek, v. 91, n. 1, p. 1-17, 2006.

VARSHNEY, P. et al. Extremophilic micro-algae and their potential contribution in biotechnology. Bioresource Technology, v. 184, p. 363-372, 2015.

VATSA, A. M.; ZAKARI, Y. I.; IGWE, J. C.; ISEGHOHI, F.; AKPA, A. U.; JIBRIN, A. Y.; ABUBAKAR, A. K.; ADAMU, R. Review of anticancer and antioxidant activities of radioresistant extremophiles at molecular level: an itinerary to the discovery of cancer drugs in Nigerian extreme radiation environments. Nigerian Journal of Biotechnology, v. 27, p. $40-47,2014$.

VENTOSA, A. et al. Halophile and Halotolerant Micro-Organisms from Soils. Microbiology of Extreme Soils, p. 87-115, 2008.

VENTOSA, A. et al. Microbial diversity of hypersaline environments: A metagenomic approach. Current Opinion in Microbiology, v. 25, n. JUNE, p. 80-87, 2015.

VENTOSA, A.; ARAHAL, D. R. Halophily (Halophilism and Halophilic Microorganisms). Extremophiles, v. 2, 2011.

VISHNIVETSKAYA, T. A.; KATHARIOU, S.; TIEDJE, J. M. The Exiguobacterium genus: Biodiversity and biogeography. Extremophiles, v. 13, p. 541-555, 2009. 
WANG, G. et al. Exopolysaccharide from Trichoderma pseudokoningii induces macrophage activation. Carbohydrate Polymers, v. 149, p. 112-120, 2016.

WEISBURG, W. G. et al. 16S ribosomal DNA amplification for phylogenetic study. Journal of Bacteriology, v. 173, n. 2, p. 697-703, 1991.

WIDNER, B. et al. Hyaluronic Acid Production in Bacillus subtilis. Applied and Environmental Microbiology, v. 71, n. 7, p. 3747-3752, 2005.

XIE, F. et al. Pseudomonas kunmingensis sp. nov., an exopolysaccharide-producing bacterium isolated from a phosphate mine. International Journal of Systematic and Evolutionary Microbiology, v. 64, n. PART 2, p. 559-564, 2014.

YAMADA, K.; KOMAGATA, K. Taxonomic Studies on corynneform bacteria. The Journal of General and Applied Microbiology, v. 431, n. 18, p. 417-431, 1972.

YANG, H. et al. Two Novel Exopolysaccharides from Bacillus amyloliquefaciens C-1: Antioxidation and Effect on Oxidative Stress. Current Microbiology, v. 70, n. 2, p. 298306, 2015.

YÁÑEZ, J. et al. Biodegradation of tributyltin (TBT) by extremophile bacteria from atacama desert and speciation of tin by-products. Bulletin of Environmental Contamination and Toxicology, v. 95, n. 1, p. 126-130, 2015.

YE, S. et al. Antioxidant activities of an exopolysaccharide isolated and purified from marine Pseudomonas PF-6. Carbohydrate Polymers, v. 87, n. 1, p. 764-770, 2012.

YE, S. et al. Biosynthesis of selenium rich exopolysaccharide (Se-EPS) by Pseudomonas PT-8 and characterization of its antioxidant activities. Carbohydrate Polymers, v. 142, p. 230-239, 2016.

YILDIZ, S. Y. et al. Genomic analysis of Brevibacillus thermoruber 423 reveals its biotechnological and industrial potential. Applied Microbiology and Biotechnology, v. 99, n. 5, p. 2277-2289, 2015.

YIN, J. et al. Halophiles, coming stars for industrial biotechnology. Biotechnology Advances, 2014. 
$\mathrm{YU}, \mathrm{H}$. et al. A high-throughput screen for hyaluronic acid accumulation in recombinant Escherichia coli transformed by libraries of engineered sigma factors. Biotechnology and Bioengineering, v. 101, n. 4, p. 788-796, 2008.

YUE, H. et al. A seawater-based open and continuous process for polyhydroxyalkanoates production by recombinant Halomonas campaniensis LS21 grown in mixed substrates. Biotechnology for Biofuels, v. 7, n. 1, p. 108, 2014.

YUMOTO, I. et al. Exiguobacterium oxidotolerans sp. nov., a novel alkaliphile exhibiting high catalase activity. International Journal of Systematic and Evolutionary Microbiology, v. 54, n. 2004, p. 2013-2017, 2004.

ZHANG, B. et al. Inverse metabolic engineering of Bacillus subtilis for xylose utilization based on adaptive evolution and whole-genome sequencing. Applied Microbiology and Biotechnology, v. 99, n. 2, p. 885-896, 2014.

ZHANG, L. et al. Exploring novel bioactive compounds from marine microbes. Current Opinion in Microbiology, v. 8, n. 3, p. 276-281, 2005.

ZHAO, Y. et al. Antagonistic Action of Bacillus subtilis Strain SG6 on Fusarium graminearum. Plos One, v. 9, n. 3, p. e92486, 20 mar. 2014.

ZHENG, J. et al. Antimicrobial ergosteroids and pyrrole derivatives from halotolerant Aspergillus flocculosus PT05-1 cultured in a hypersaline medium. Extremophiles, v. 17, n. 6, p. 963-971, 2013.

ZHU, D. et al. Bacillus ectoiniformans sp. nov., a halotolerant bacterium isolated from deep-sea sediments. International Journal of Systematic and Evolutionary Microbiology, v. 66, p. 616-622, 2016. 


\section{APÊNDICES}

APÊNDICE A - Curvas de crescimento dos isolados da caatinga em meio TSB suplementado com quatro diferentes concentrações de $\mathrm{NaCl}$

Isolado Sac 1

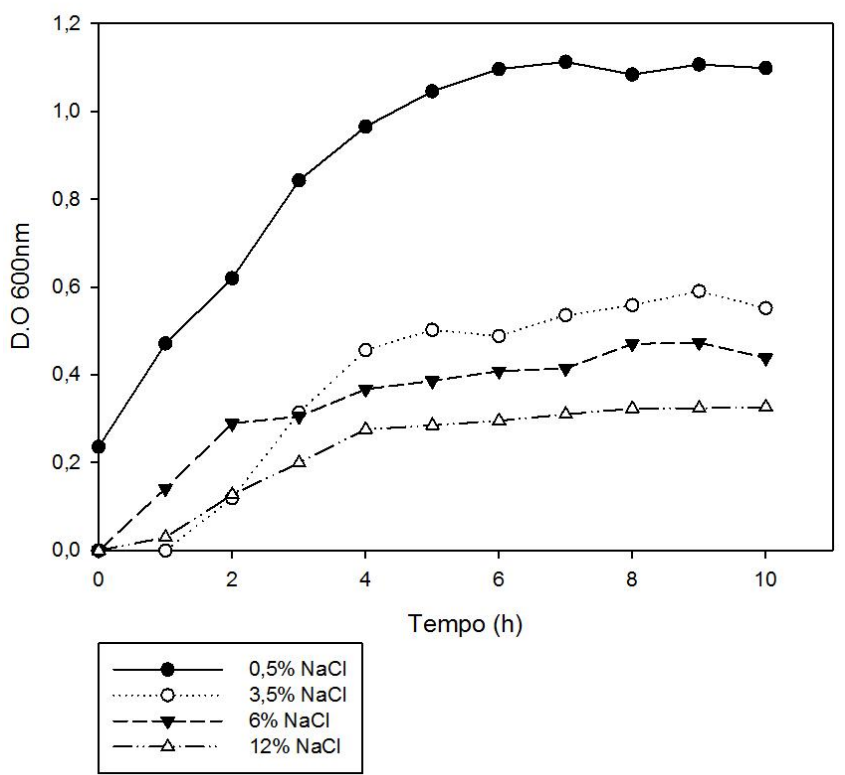

Isolado Sac 9

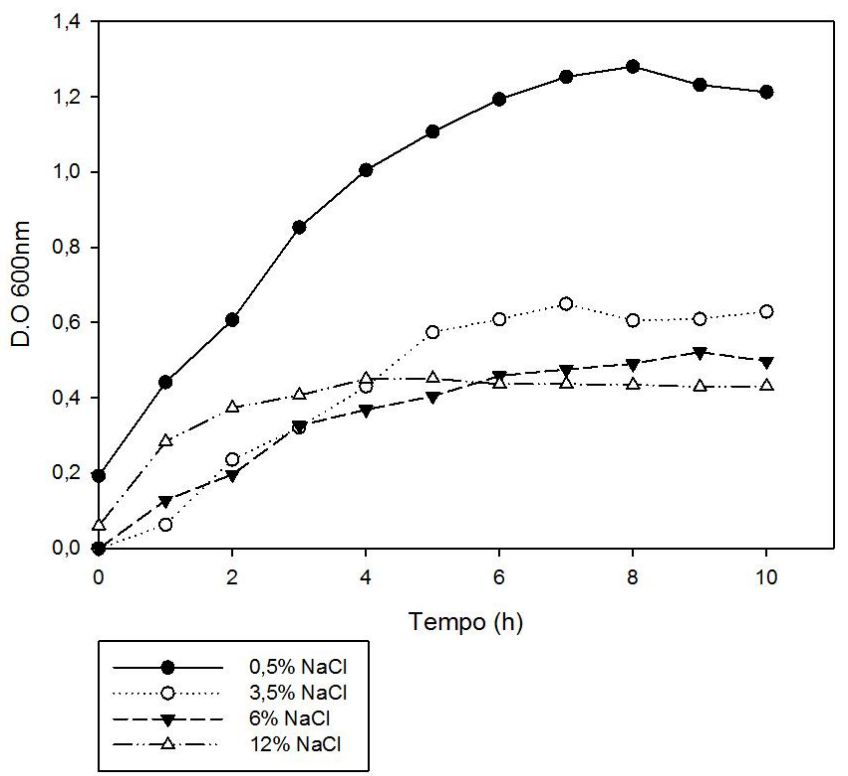

Isolado Sac 7

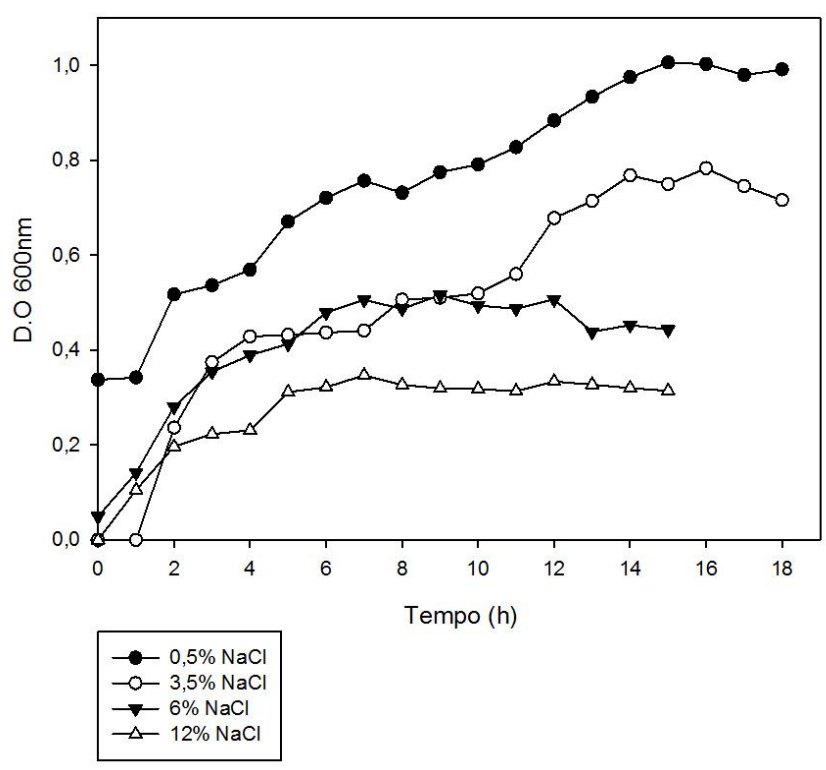

Isolado Sac 10

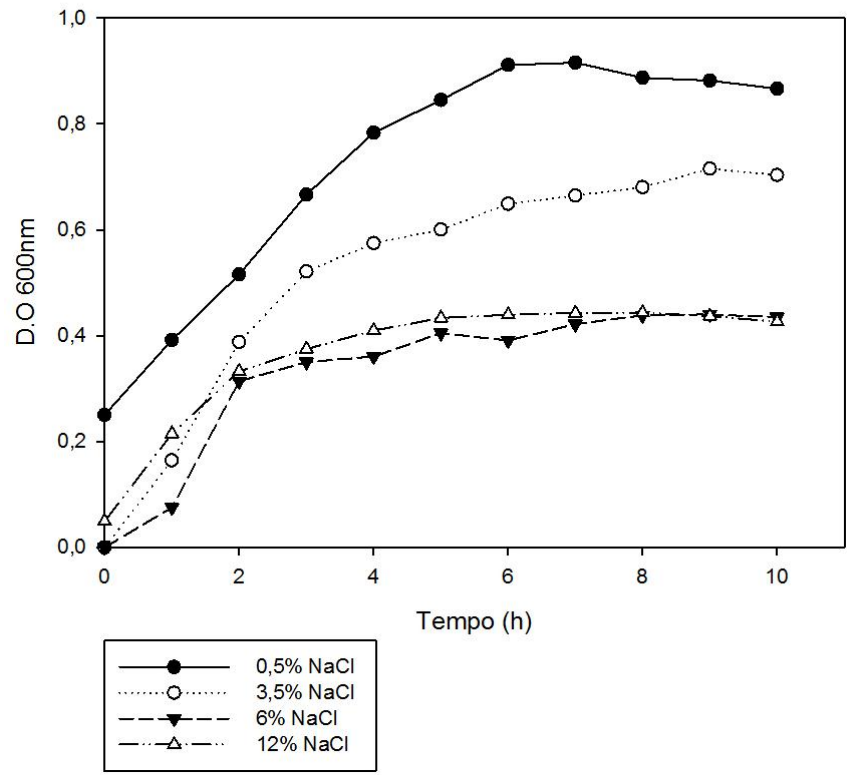


Isolado Sac 16

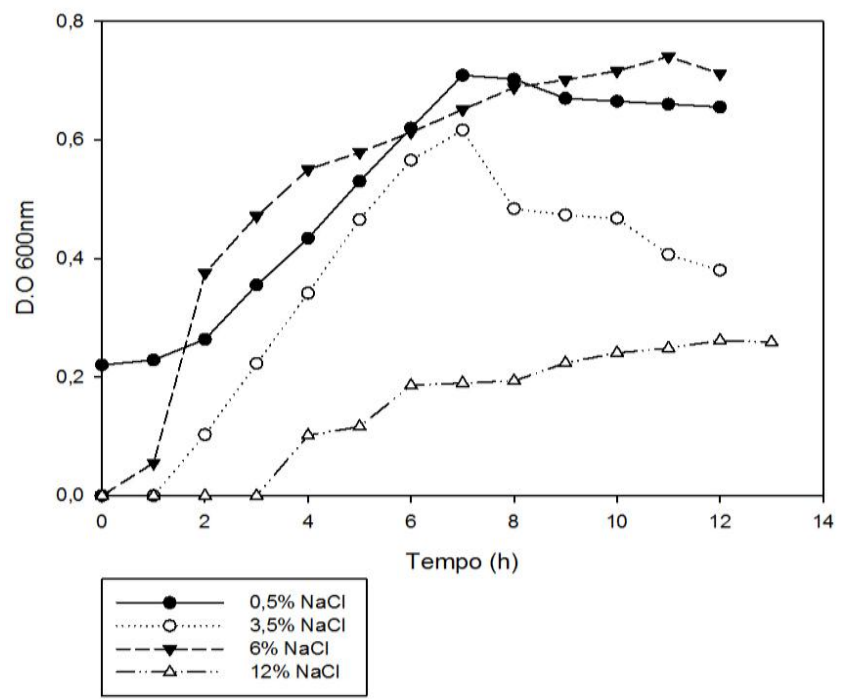

Isolado Sac 22

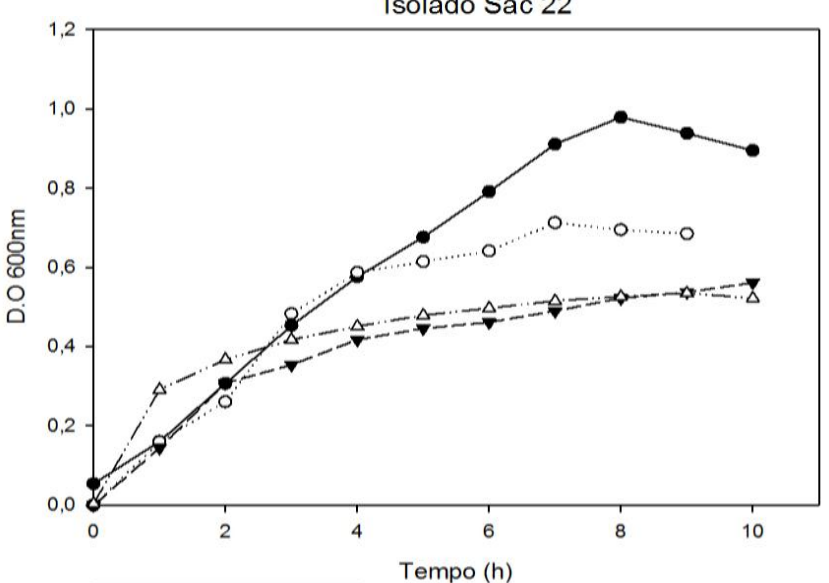

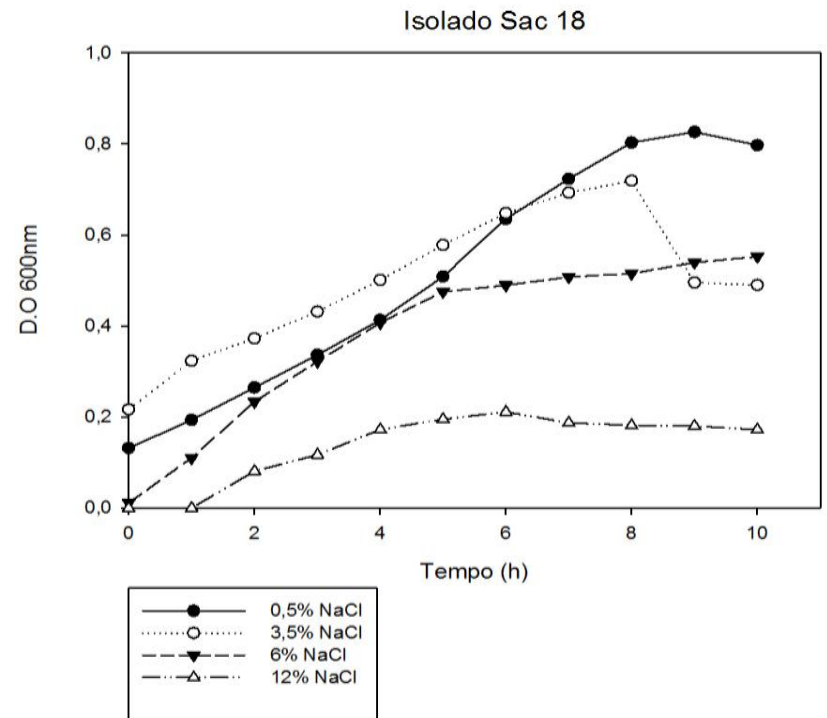

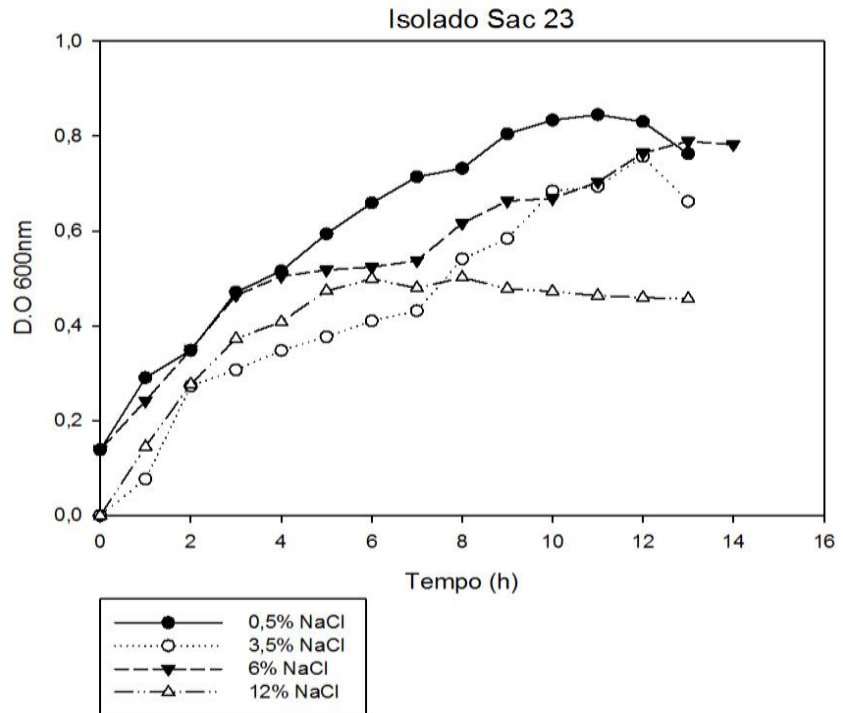

Isolado Sac 24
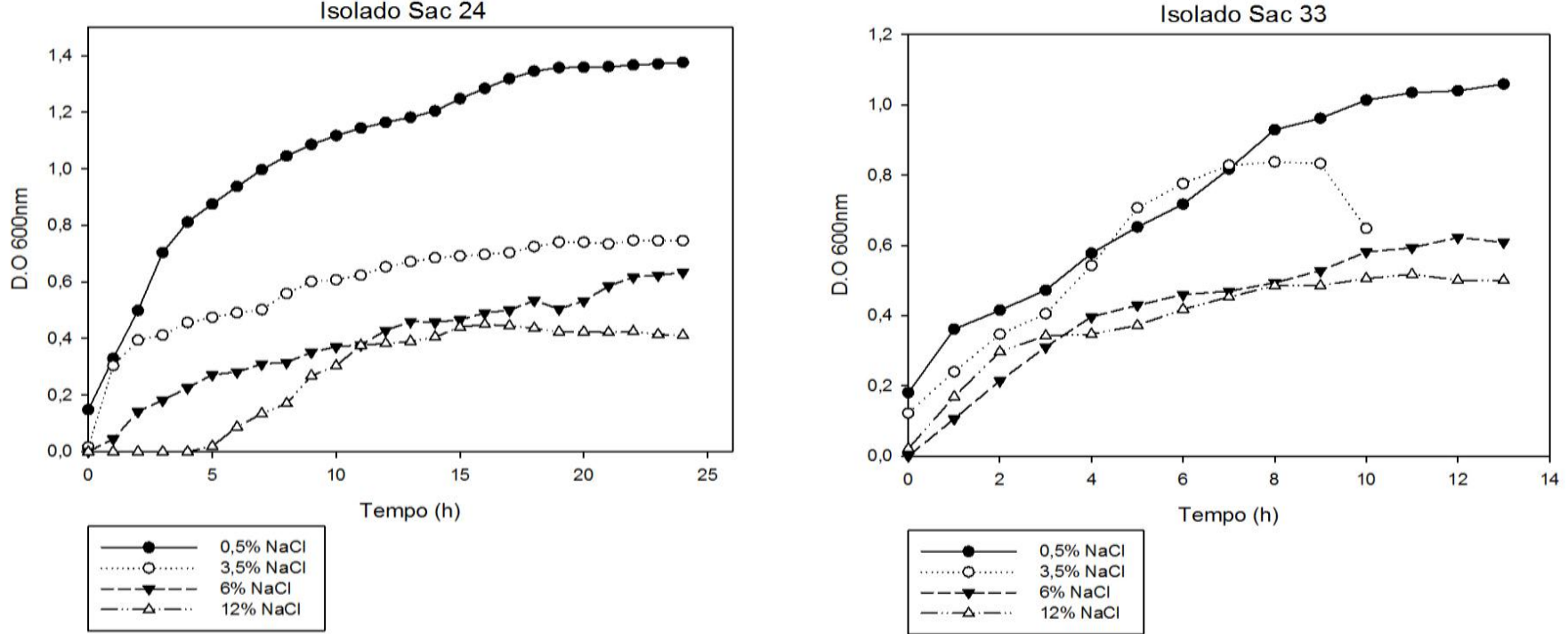

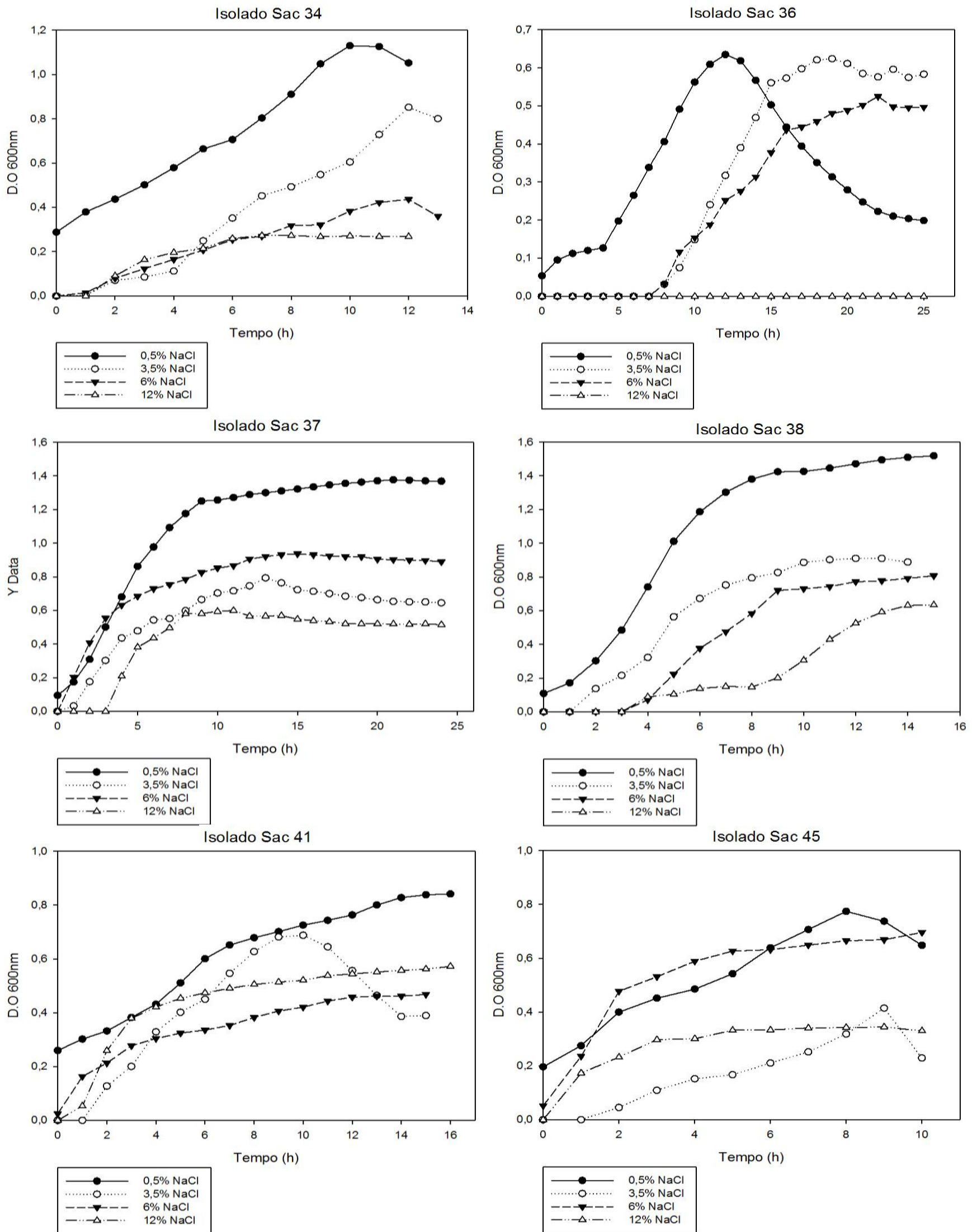

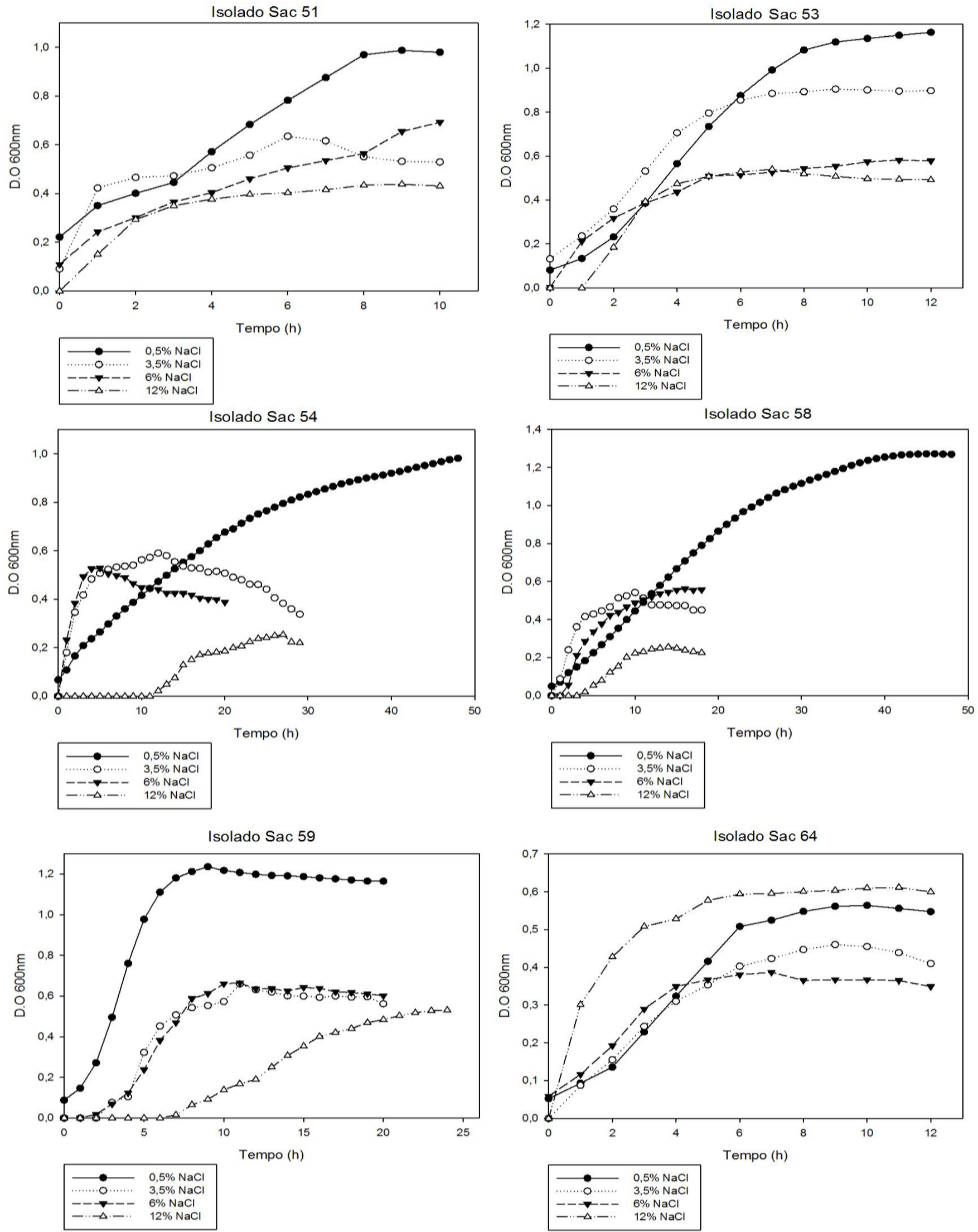

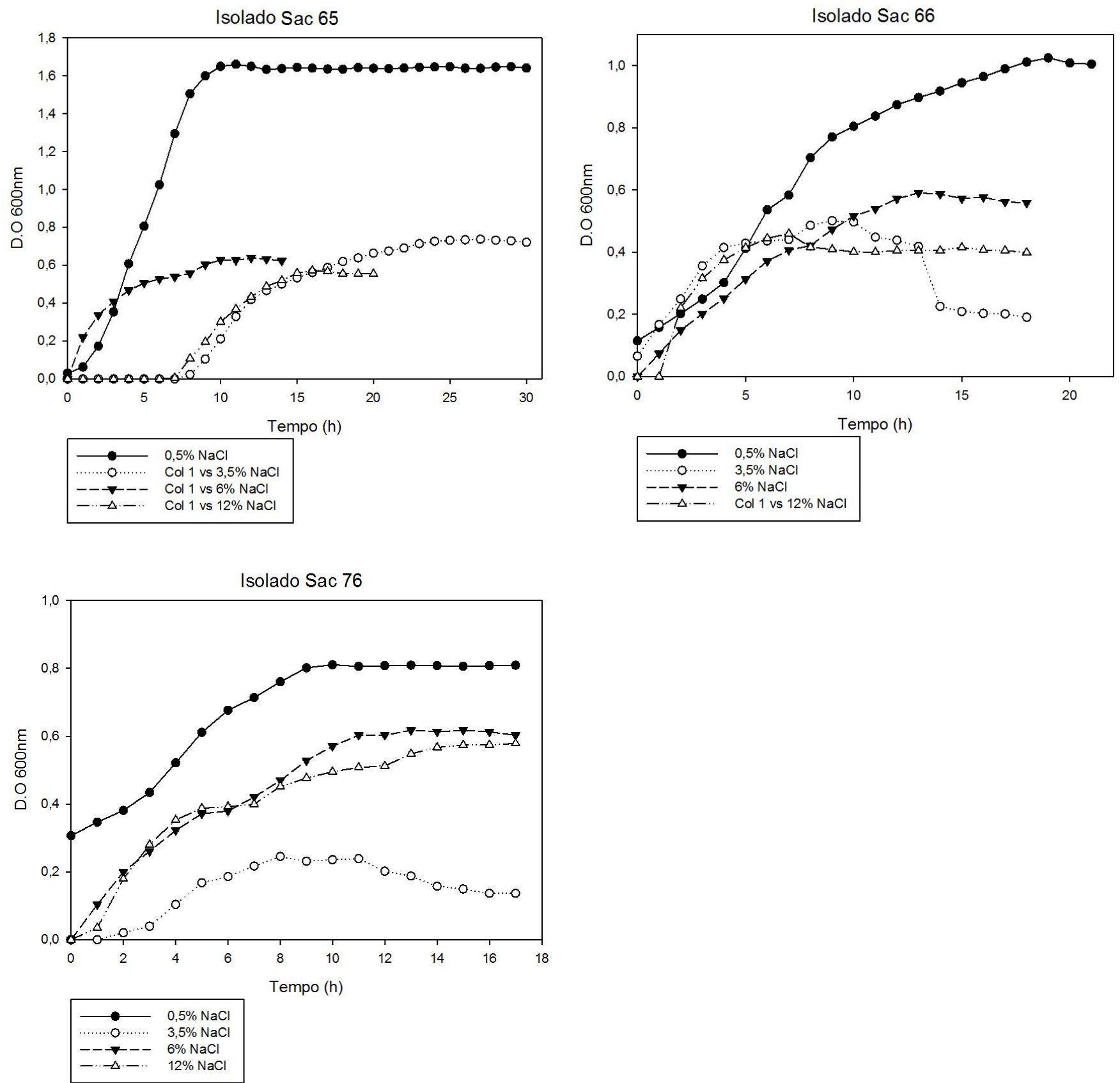
APÊNDICE B - Curva padrão de ácido hialurônico

\begin{tabular}{cc}
\hline $\begin{array}{c}\text { Concentração } \\
\mathrm{AH}(\mathrm{mg} / \mathrm{L})\end{array}$ & D.O540nm \\
\hline $\mathbf{0}$ & $0,804 \pm 0,0$ \\
$\mathbf{5 0}$ & $0,758 \pm 0,1$ \\
$\mathbf{1 0 0}$ & $0,681 \pm 0,0$ \\
$\mathbf{2 0 0}$ & $0,464 \pm 0,0$ \\
$\mathbf{3 0 0}$ & $0,348 \pm 0,0$ \\
$\mathbf{5 0 0}$ & $0,273 \pm 0,0$ \\
\hline
\end{tabular}

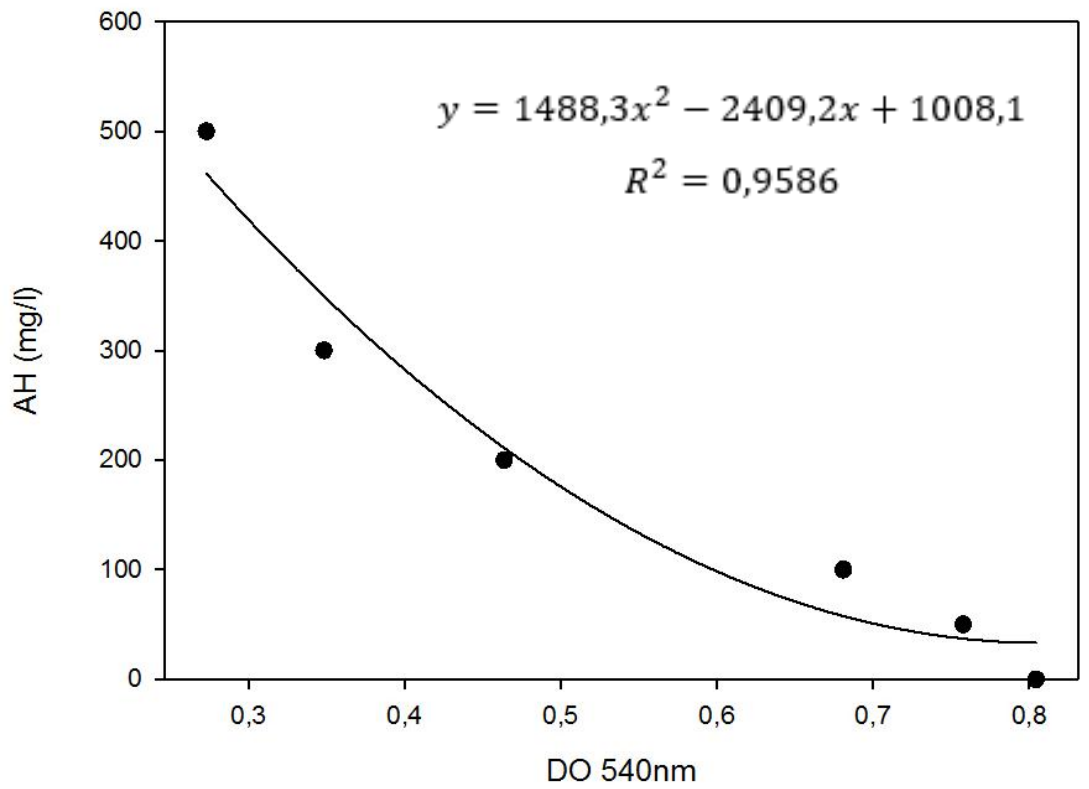

